\title{
WestVirginiaUniversity
}

THE RESEARCH REPOSITORY @ WVU

Graduate Theses, Dissertations, and Problem Reports

2006

\section{Mechanisms of environmental carcinogenesis and metal -induced cellular signaling}

Jacquelyn Jo Bower

West Virginia University

Follow this and additional works at: https://researchrepository.wvu.edu/etd

\section{Recommended Citation}

Bower, Jacquelyn Jo, "Mechanisms of environmental carcinogenesis and metal -induced cellular signaling" (2006). Graduate Theses, Dissertations, and Problem Reports. 2395.

https://researchrepository.wvu.edu/etd/2395

This Dissertation is protected by copyright and/or related rights. It has been brought to you by the The Research Repository @ WVU with permission from the rights-holder(s). You are free to use this Dissertation in any way that is permitted by the copyright and related rights legislation that applies to your use. For other uses you must obtain permission from the rights-holder(s) directly, unless additional rights are indicated by a Creative Commons license in the record and/ or on the work itself. This Dissertation has been accepted for inclusion in WVU Graduate Theses, Dissertations, and Problem Reports collection by an authorized administrator of The Research Repository @ WVU.

For more information, please contact researchrepository@mail.wvu.edu. 


\title{
Mechanisms of environmental carcinogenesis and metal- induced cellular signaling.
}

\author{
Jacquelyn Jo Bower \\ Dissertation submitted to the \\ School of Pharmacy \\ At West Virginia University \\ In partial fulfillment of the requirements \\ for the degree of \\ Doctor of Philosophy \\ In \\ Pharmacuetical Sciences \\ Xianglin Shi, Ph.D., Chair \\ Patrick Callery, Ph.D. \\ Vincent Castranova, Ph.D. \\ Fei Chen, Ph.D. \\ Yongyut Rojanasakul, Ph.D.
}

Department of Basic Pharmaceutical Sciences

Morgantown, West Virginia

2006

Keywords: human genome, gene-environment interactions, siRNA, Microarrays, SNPs, environmental biosecurity, antioxidants, carcinogenesis, DNA damage, metals, reactive oxygen species, GADD45 $\alpha$, arsenite, As(III), arsenic, BEAS-2B 


\begin{abstract}
Mechanisms of environmental carcinogenesis and metal-induced cellular signaling.
\end{abstract}

\title{
Jacquelyn Jo Bower
}

Low dose chronic exposure to environmental carcinogens is a major cause of human cancers. More than 375 known or suspected environmental carcinogens have been identified, many of which are transition metals or metal containing compounds (IARC, updated to 2004, http://www-cie.iarc.fr/monoeval/crthall.html). Although much research has focused on the ability of these metals to induce reactive oxygen species formation (ROS), DNA damage, and apoptosis, less effort has been put forth to examine the cellular signaling mechanisms responsible for these effects. Our experimental research has focused on the signaling pathways induced in response to arsenic exposure. Arsenic is a highly interesting transition metal due to its widespread exposure and paradoxic ability to induce carcinogenesis as well as apoptosis. Here, we highlight the importance of the human genome project in advancing the knowledge of the molecular mechanisms of metal-induced toxicology/carcinogenesis. In addition, we review the latest research in the field of metal-induced carcinogenesis. Finally, we describe a mechanism for the induction of the growth-arrest and DNA damage inducible protein 45 alpha (GADD45 $\alpha$ ) involving arsenic-induced ROS formation in the non-tumorigenic human lung airway epithelial cell line, BEAS-2B. 


\section{Dedicated to}

\section{My Family,}

Dennis and JoAnn Bower,

\section{Elizabeth Hooks, Kathryn Bower,}

Matthew Hirsch, and Neo the Wonderdog. 


\section{ACKNOWLEDGEMENTS}

First and foremost I would like to thank my advisor, Dr. Xianglin Shi, and the members of the Shi lab, particulary Fei Chen, Steve Leonard, and Yong Qian. Without their help and support I would not have made it through the last four years.

I would also like to thank my committee members Dr. Patrick Callery, Dr. Vincent

Castranova, Dr. Fei Chen, and Dr. Yongyut Rojanasakul for their helpful comments and guidance throughout my graduate career.

In addition I would like to thank my parents, Dennis and JoAnn Bower for their love and support. They have been wonderful parents and I would not be here today if it weren't for them.

To my sisters, Elizabeth Hooks and Kathryn Bower: you are the best sisters anyone could ever hope to have in their corner. Thank you for being there to listen to me and yell at me, whatever was necessary at the time.

And finally, to Dr. Matthew Hirsch and Neo the Wonderdog, you have made my experience in Morgantown wonderful and delightful. You have been my sounding board for the past three years and I could have never accomplished what I have without you. 


\section{TABLE OF CONTENTS}

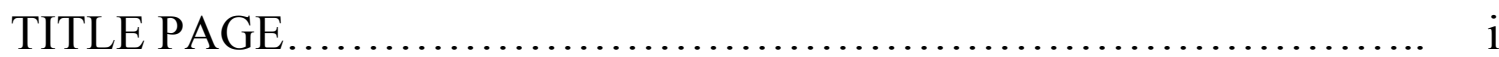

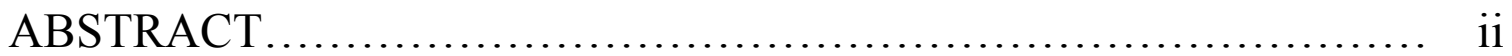

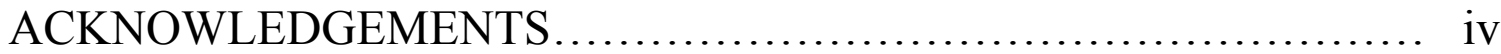

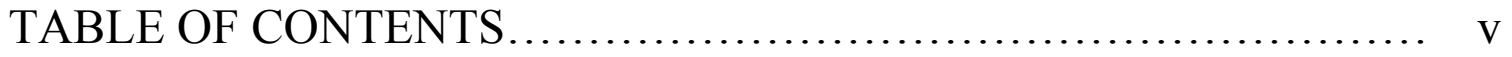

LIST OF FIGURES ..................................................

SECTION I: Overview............................................ 1

Arsenic........................................................... 2

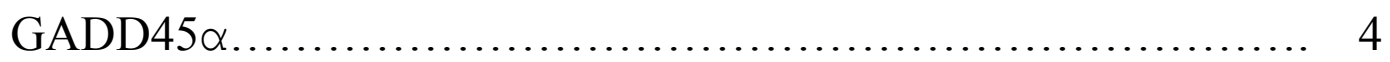

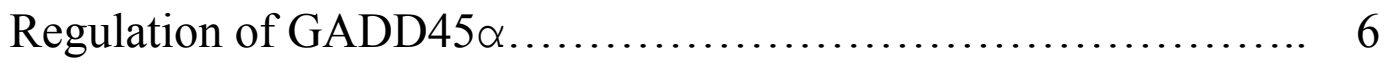

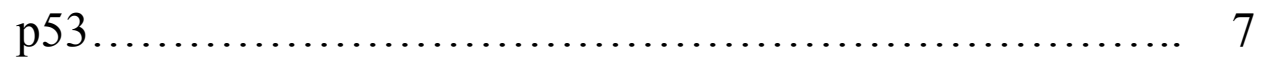

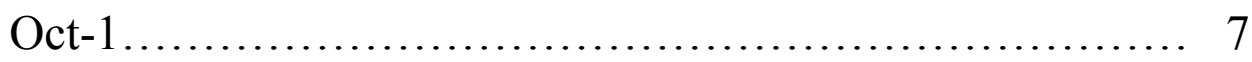

ZBRK1................................................. 8

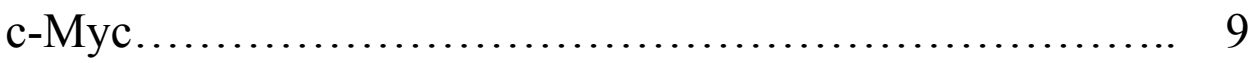

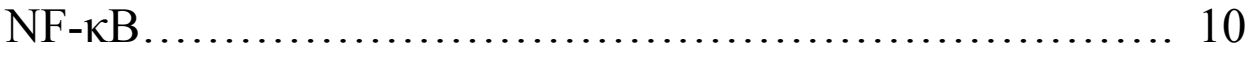

FOXO3a ............................................. 10

Post-transcriptional Regulation............................ 11

References.................................................. 12 
SECTION II: Environmental Health Research in the Post-Genome Era:

New Fields, New Challenges, and New Opportunities............ 22

Abstract........................................................ 23

Introduction................................................... 24

Environmental Exposure and Genetic Susceptibility.............. 25

Single Nucleotide Polymorphisms (SNPs).................... 27

Environmental Genome Project............................... 30

Bioinformatics and the -omics Explosion...................... 31

Bioinformatics....................................... 32

Proteomics............................................. 32

Structural Genomics..................................... 33

Using Bioinformatics to Fuel New Directions in Environmental Health Research............................................... 34

Metabolomics......................................... 35

Pharmacogenomics..................................... 36

Toxicogenomics..................................... 37

Comparative Genomics............................... 38

Comparative Genomics: Sequencing of the Mouse Genome. 39

Systems Biology..................................... 40

Current Technology - Global Transcriptional Analysis............. 41

Global Transcriptional Analysis - DNA Microarrays........ 41 
Global Transcriptional Analysis - MPSS and SAGE....... 46

Current Technology - siRNA.............................. 47

Emerging Technology - Peptide/Protein Microarrays.............. 49

Biosecurity and Bioterrorism................................. 53

Preparedness in the Case of a CB Attack.................. 54

Preparedness in the Case of a CB Terrorist Attack - Mass

Vaccination.......................................... 55

Early Detection of CB Agents in the Environment........... 57

Environmental Health Research, the Human Genome Project, and Biosecurity..................................... 59

Novel Treatments in a CB Attack........................ 60

Future Directions............................................. 61

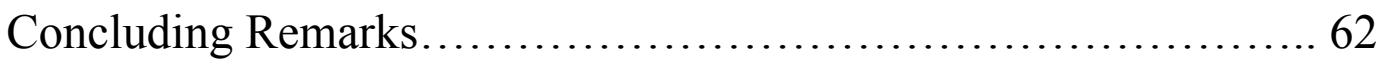

Acknowledgements.......................................... 63

Figures and Tables.......................................... 64

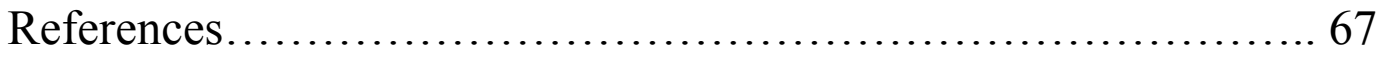

SECTION III: Molecular Mechanisms of Metal Toxicity and

Carcinogenesis................................................... 89

Abstract................................................... 90

Introduction.............................................. 91

Epidemiological implications of metal exposure and the search for reliable biomarkers......................................... 91 
Balancing act: The role of reactive oxygen species (ROS) and antioxidants

DNA damage/lesions and mitotic effects....................... 101

Metal-induced cellular signaling............................. 104

Arsenic signaling..................................... 105

Chromium signaling................................... 108

Cadmium signaling................................... 109

Cobalt and copper signaling........................... 111

Nickel signaling..................................... 112

Animal Studies............................................. 114

Summary................................................. 117

References.................................................... 119

SECTION IV: As(III) transcriptionally activates the gadd45a gene via the

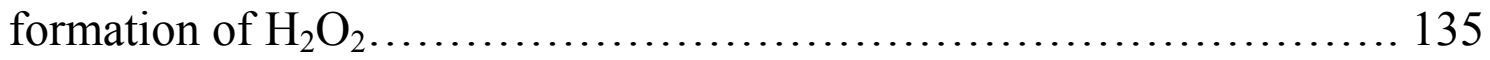

Abstract................................................. 136

Introduction ........................................... 137

Materials and Methods....................................... 139

Results................................................. 145

Discussion................................................. 149

List of Abbreviations......................................... 153

Figures and Figure Legends..................................156 
References................................................ 168

OVERALL CONCLUSIONS....................................... 177

CURRICULUM VITAE........................................... 178 


\section{LIST OF FIGURES}

SECTION II: Environmental Health Research in the Post-Genome Era:

New Fields, New Challenges, and New Opportunities

Figure 1: Webguide to bioinformatics sites and useful database links..... 64

Table 1: CDC's list of potential biological warfare agents............. 66

SECTION IV: As(III) transcriptionally activates the gadd45a gene via the

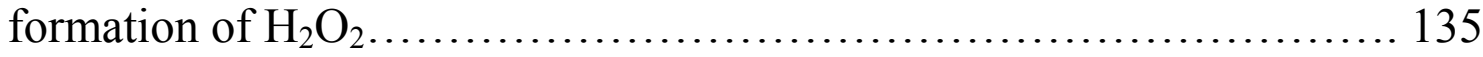

Figure 1: $25 \mu \mathrm{M}$ As(III) induces maximal GADD45 $\alpha$ expression at 12 hours......................................................... 156

Figure 2A: As(III) exposure increases $\mathrm{O}_{2}$ consumption in BEAS-2B cells....

Figure 2B: As(III) induces the formation of ${ }^{\circ} \mathrm{OH}$ in BEAS-2B cells...... 158

Figure 2C: Graphical representation of ESR peak heights............. 159

Figure 3: Overexpression of the $\mathrm{H}_{2} \mathrm{O}_{2}$ scavenger enzyme GPx1 reduces GADD $45 \alpha$ protein expression..................................... 160

Figure 4: As(III) exposure increases GADD45 $\propto$ transcript abundance... 161

Figure 5: As(III) activates both the GADD $45 \alpha$ promoter region and the intron 3 region................................................. 162

Figure 6: Overexpression of GPx1 reduces GADD $45 \propto$ promoter activation but not intron 3 activation........................................... 163

Figure 7A: Schematic diagram of GADD $45 \alpha$ promoter-luciferase deletion constructs...................................................... 164 
Figure 7B: GADD $45 \alpha$ promoter activation occurs between the -234 and -81 region............................................................ 165

Figure 7C: Activation of the full length, $-1326,-817$, and -234 constructs was reduced by $50 \%$ in GPx1-overexpressing cell lysates.............. 166

Figure 8: Proposed ROS pathway involving arsenic................. 167 


\section{SECTION I: OVERVIEW}




\section{$\underline{\text { Arsenic }}$}

Arsenic is a ubiquitous environmental contaminant found in food, water, cigarette smoke, soil, pesticides, and wood preservatives; thus, exposure can occur through dermal contact, inhalation, ingestion, and occupational routes (1-8). A multitude of adverse health effects, including hyperkeratosis, hyperpigmentation, diabetes mellitus, cardiovascular disease, reproductive defects, and cancers of the liver, bladder, skin, lung, kidney, and prostate, have been associated with arsenic exposure (9-17). The most common route of exposure is the ingestion of arsenic contaminated drinking water, which has been documented in Latin America, South Asia, Taiwan, the United States, and Japan at concentrations as high as 1.5-3.4 $\mathrm{mg} / \mathrm{L}(18-25)$. These figures exceed the World Health Organization's maximum contaminant level of $10 \mathrm{ug} / \mathrm{L}$ by ten-fold or more. In the U.S. alone, an estimated 56 million Americans are exposed to concentrations of arsenic known to cause cancer $(18,19,23-25)$.

Arsenic was first suggested to act as a human carcinogen by Hutchinson in the year 1887 when he noticed an abnormal number of skin cancers occurring in patients who were being treated with arsenicals (19). Since then, epidemiological studies have shown that arsenic exposure is associated with cancers of the skin, lung, liver, bladder, and prostate (9-12). In 1980, Rossman et al showed that inorganic arsenic was poorly mutagenic and genotoxic in both E. coli and CHO cells (26). Although arsenic induces DNA adduct formation, DNA-protein crosslinks, and ROS formation in vitro, attempts to examine the in vivo carcinogenic effects of arsenic in rodent models have largely failed in the absence of another carcinogenic agent (27-29). 
Because of arsenic's poor mutagenicity, the current theory is that its carcinogenic effects are mediated by epigenetic mechanisms. This hypothesis is supported by the studies of Chen et al, in which overexpression of the oncogene c-myc and DNA hypomethylation of the promoter region of the estrogen receptor alpha gene have been observed in liver tumors of adult rats exposed to arsenic in utero (30,31). Additional supporting evidence includes the identification of the Erk MAPK as an essential component of the signal transduction pathways responsible for arsenic-induced transformation of JB6 murine fibroblast cells in vitro (32). Other studies have suggested that arsenic may prevent signaling events leading to cellular differentiation. For example, inorganic arsenic has also been shown to suppress involucrin expression, a marker of keratinocyte differentiation (33).

Although the previously described studies strongly suggest that gene expression and protein signaling events activated and suppressed during arsenic exposure play a central role in arsenic-induced tumorigenesis in vitro, knowledge of the signaling mechanisms responsible for transformation in a human model system remain virtually non-existent. Several colleagues have examined the transcriptional profiles of cell lines and tissues that have been exposed to arsenic. Examples include Liu's group (34), who showed that hepatocellular carcinoma induced by arsenic exposure in utero upregulated the expression of 56 genes and downregulated the expression of 26 genes when compared to non-tumor liver samples from $\mathrm{CH} 3$ mice. Moreover, gene expression changes in a BEAS-2B cell line differed between low $(5 \mu \mathrm{M})$ and high $(50 \mu \mathrm{M})$ doses of arsenic. In the high dose samples, general stress response genes were induced, whereas more subtle changes were observed at a lower dose of arsenic (35). 
To date, only three groups have examined the effects of arsenic in mammalian models on a proteomic scale (36-38). Yet, both Lau's and He's groups used a rat lung epithelial cell line in which arsenic-induced transformation was not observed (37). In addition, He's group used the known carcinogen benzo-a-pyrene in conjunction with arsenic treatment (36). Furthermore, Wang's group chose to study only the nuclear matrix fraction of the K562 chronic myelogenous leukemic cell line in which arsenic is known to induce apoptosis, not transformation (38). In spite of the valuable information provided by these studies, an understanding of the signaling pathways responsible for arsenic-induced carcinogenesis is still in its infancy.

\section{$\underline{G A D D 45 \alpha}$}

One epigenetic mechanism by which arsenic may induce carcinogenesis is through the dysregulation of the cell cycle. Previous research from our laboratory has suggested that arsenic can increase the number of BEAS-2B cells found in the $\mathrm{G}_{2} / \mathrm{M}$ phase fraction in a dose-dependent manner (39). The GADD45 $\alpha$ protein is a major player in the $\mathrm{G}_{2} / \mathrm{M}$ phase checkpoint, and a transcriptional profile analysis of the BEAS2B cells showed that the gadd45a gene is upregulated in response to both low and high dose exposure to arsenic (35). We therefore hypothesized that GADD45 $\alpha$ may be involved in arsenic's ability to induce $\mathrm{G}_{2} / \mathrm{M}$ phase arrest.

The involvement of GADD45 $\alpha$ in the $\mathrm{G}_{2} / \mathrm{M}$ phase checkpoint is thought to occur through its interaction with the cyclin dependent kinase cdc2 (also known as cdk1). GADD45 $\alpha$ is thought to bind to cdc2 and sequester it in the cytoplasm preventing cdc2 from associating with its cyclin counterpart, cyclin B1 (40). Recombinant GADD45 $\alpha$ 
$(\operatorname{rGADD} 45 \alpha)$ protein expression has been shown to prevent cdc2 from immunoprecipitating with cyclin B1, thus specifically inhibiting cyclin B1/cdc2dependent phosphorylation of its target protein histone $\mathrm{H} 1$ in vitro (40).

Additional functions of GADD45 $\alpha$ have also been proposed. For example, Smith et al have shown that GADD45 $\alpha$ and the proliferating cell nuclear antigen (PCNA) coimmunoprecipitate in ML-1 human myeloid leukemia cells containing a functional p53 gene upon exposure to ionizing radiation (IR) (41). PCNA is a sliding clamp ring protein that functions in DNA synthesis and recruits DNA repair proteins to the site of DNA damage (42). Furthermore, rGADD45 $\alpha$ addition has also been shown to stimulate nucleotide excision repair (NER) in both ML-1 and RKO cells (41). Taken together, these results suggest that PCNA may recruit GADD45 $\alpha$ to the site of DNA damage during cellular proliferation, implying a role for GADD45 $\alpha$ as a link between the DNA damage sensing machinery and DNA damage repair.

GADD $45 \propto$ has also been shown to play a role in $\mathrm{G}_{1} / \mathrm{S}$ phase arrest. Exposure of mouse embryo fibroblasts to IR can induce a p53-dependent $\mathrm{G}_{1} / \mathrm{S}$ phase arrest (43). GADD45 $\alpha$ mRNA was increased after IR in the wild-type p53 ML-1, RKO, WI38, 344, U2-OS cell lines, but not in p53-deficient cell lines (43). Furthermore, p53 deficiency prevented GADD45 $\alpha$ mRNA induction and led to a loss of $G_{1}$ arrest after IR (43). An alternative mechanism of GADD $45 \alpha$ action at the $\mathrm{G}_{1} / \mathrm{S}$ phase checkpoint suggests that it can prevent DNA synthesis from occurring, since a Balb/c-3T3 fibroblast GADD45 $\alpha$ IPTG-inducible cell line can inhibit entry into S phase when IPTG is present (44).

Another function of the GADD45 $\alpha$ protein is to allow for topoisomerase I relaxing and cleavage activity (45). Addition of GADD45 $\alpha$ and core histones can relax 
supercoiled DNA (45). GADD45 $\alpha$ can directly bind histones H1, H2A, H2B, H3, and H4, and subsequently interfere with their ability to interact with DNA (45). Furthermore, DNAse I sensitivity increased when GADD45 $\alpha$ was added in the presence of hyperacetylated nucleosomes (45). GADD45 $\alpha$ can bind only hyperacetylated nucleosomes (not underacetylated) and can also bind UV-damaged DNA mononucleosomes and free DNA damaged by UV (45). The region of the protein responsible for these interactions is contained in amino acids 71-124 (45). Interestingly, this is the same region of the GADD45 $\alpha$ protein responsible for preventing cdc2/cyclin B1 kinase activity and phosphorylation of histone $\mathrm{H} 1$.

\section{Regulation of GADD45}

gadd45a is an inducible gene that was isolated as a novel mRNA increased after DNA damage (46). It is induced by many different types of cellular stress including methylmethane sulfonate (MMS) treatment, medium starvation, ionizing radiation (IR), ultraviolet radiation (UV), and sodium arsenite (47). Depending on which type of stressor is present in the system, the mechanisms of gadd45a induction differ. The most studied mechanism is the p53-dependent mechanism; however, a p53-independent mechanism also exists.

In some cases, the first step required for the transcription of inducible genes is the remodeling of nucleosomes. This allows the transcription factor to bind to the inducible gene and increase gene expression. In other cases, the nucleosomes have already been arranged around the transcription factor binding sites, allowing for quick binding of the selected transcription factor at any time. The gadd $45 a$ gene is thought to be one of these 
so-called preset genes, in which the nucleosomes are arranged such that the promoter

region and the $3^{\text {rd }}$ intron are poised for easy access to transcription factors, since these regions are hypersensitive to DNase cleavage (48). Therefore, most studies of gadd45a transcriptional regulation have focused on the promoter and $3^{\text {rd }}$ intron regions.

$\underline{p 53}$

The p53-dependent mechanism of gadd45a induction is usually seen in response to IR exposure. Graunke et al, have shown that IR treatment causes a 15 -fold induction of gadd45a mRNA as measured by northern blotting in the absence of de novo protein synthesis (48). In addition, Zhan et al have shown that the p53-dependent induction of gadd45a occurs via p53 binding to its consensus sequence in the $3^{\text {rd }}$ intron of the gadd45a gene and subsequently interacting with the WT1 transcription factor (49). However, this response seems to be strictly employed only with exposure to IR.

\section{$\underline{\text { Oct-1 }}$}

Oct-1 is a ubiquitously expressed cis-regulatory transcription factor of the POU (pit-oct-unc) family. It has been shown to regulate the transcription of many genes, including histone $\mathrm{H} 2 \mathrm{~B}$, the small nuclear RNA gene, immunoglobulin genes in B cells, the von Willebrand factor, TIF2, GnRH, and the vascular cell adhesion molecule (VCAM) gene $(50,51)$. The Oct-1 transcription factor has also been shown to bind the promoter region of the gadd45a gene between -101 to -82 bp relative to the transcriptional start site (TSS) in a p53-independent manner following MMS treatment and UV irradiation (50-53). 
Takahashi and colleagues have suggested that a cofactor is needed in order for Oct-1 to induce gadd45a transcription in response to UV treatment (50). Jin et al have suggested that this cofactor may be the ubiquitous NF-YA transcription factor which binds to a CAAT-box motif located in the same region of the gadd 45 a promoter as the Oct-1 binding motif. Both Jin and Zhao found that Oct-1 is induced in response to MMS treatment, which contradicts Takahashi's results suggesting that Oct-1 abundance was not increased in response to UV stimulus (50-52). Jin also suggests that Oct-1 protein induction is mediated through a post-transcriptional mechanism (PTM), whereas Takahashi claims that the Oct-1 protein is not modified $(50,51)$. These differences could be due to differences in the cell lines examined or the stimulus used for the induction of gadd45a. Both Takahashi's and Jin's work is supported by that of Graunke et al, in which LMPCR was used to identify potential protein binding interactions, one of which was the Oct-1 transcription factor (48).

\section{$\underline{Z B R K 1}$}

ZBRK1 is a zinc finger protein that is thought to repress gadd45a transcription by binding to the $3^{\text {rd }}$ intron in a BRCA1-dependent manner (54). BRCA1 itself cannot bind directly to a regulatory DNA sequence; it must associate with a transcription factor that is capable of binding to a specific DNA sequence. There may be additional ZBRK1 binding sites in the gadd45a promoter region (54). Many other genes besides gadd45a contain putative ZBRK1 binding sequences, including GADD153, Ki-67, Bax, p21, EGR1, amphiregulin, prothymosin, TIMP-1, TIMP-2, and Topo IIa, suggesting that ZBRK1 may be involved in the cellular response to DNA damage (55). Yun et al have 
recently shown that upon UV and MMS exposure, ZBRK1 is rapidly degraded (within 30 minutes) by the ubiquitin proteasome pathway, which subsequently results in an increase in GADD45 $\alpha$ protein expression (54). One possibility is that stress activation of BRCA1 could promote the degradation of ZBRK1 through its E3 ubiquitin ligase activity, relieving gadd45a gene repression.

$\underline{c-M y c}$

c-Myc is a well-known oncogene that increases its expression in response to mitogens. Its de-regulation prevents cells from exiting the cell cycle and from responding to growth-arrest signals. c-Myc has been shown to regulate many cell cycle control genes including Cdc25a, eIF-4E, $\mathrm{C} / \mathrm{EBP} \alpha$, cyclin D1, GADD153, and most recently GADD45 $\alpha$ (56). Marhin et al, report that c-Myc activation represses gadd45a transcription and that this process requires de novo protein synthesis (56). Interestingly, amino acids 106-143 of c-Myc are required for suppression of gadd45a transcription, the same region required for cell cycle progression and c-Myc-induced cellular transformation (56). Despite the absence of a canonical c-Myc binding site in the gadd45a gene, c-Myc represses its transcription possibly by inhibiting CAAT-binding transcription factors such as the $\mathrm{CTF} / \mathrm{NF} 1$ or $\mathrm{C} / \mathrm{EBP}$ family of transcription factors (52, 56). Graunke's LMPCR results in ML-1 cells support Marhin's results, suggesting that $\mathrm{C} / \mathrm{EBP}$ binds to the gadd45a promoter region (48). 
$\underline{N F-\kappa B}$

UV treatment has also been shown to activate NF- $\kappa B$, a known inhibitor of JNK expression. NF- $\kappa \mathrm{B}$ is thought to cause an inflammatory response and has been shown to be overexpressed in many cancer cell systems. Zerbini et al have recently reported that $\mathrm{NF}-\kappa \mathrm{B}$ can repress gadd45a transcription in an indirect manner by activating c-Myc (57). After inhibiting NF- $\kappa$ B activation, an increase of approximately 3-fold in GADD $45 \alpha$ and $\gamma$ mRNA was observed (57). The inhibition of NF- $\mathrm{kB}$ is thought to prevent cell proliferation and increase apoptosis, both of which have been suggested to be functional roles for the GADD45 family of proteins.

\section{$\underline{F O X O 3 a}$}

FOXO3a is a member of the forkhead transcription factor family, and its sequence is similar to that of the DAF-16 gene in C. elegans, which is required for SOD and catalase transcriptional upregulation. DAF-16 has been shown to be involved in stress resistance and an increased life span, whereas FOXO3a overexpression has been shown to result in $\mathrm{G}_{1}$ arrest (58). FOXO3a is a downstream target of the PI3K and PKB/Akt pathway, which promotes cell survival. PKB/Akt phosphorylates and inhibits FOXO transcription factors, sequestering the transcription factor in the cytoplasm. Tran et al, have shown that inducible expression of an Estrogen Receptor-FOXO3a fusion protein with 4-hydroxytamoxifin can induce gadd45a promoter luciferase activity in a Rat-1 cell line (58). Tran and colleagues identified the positions of the forkhead response elements (FHREs) in the gadd45a promoter region at $-505,-377$, and -803 , relative to the TSS. 
In cells passing through the $\mathrm{G}_{2}$ phase, FOXO3a was localized to the nucleus. In addition, constitutive expression of FOXO3a led to a $\mathrm{G}_{2} / \mathrm{M}$ phase delay as did treatment with a PI3K inhibitor, LY294002. Furthermore, overexpression of FOXO3a managed to repair a UV damaged CMV-luciferase construct in RKO and MEF cells. Tran et al also showed that FOXO3a could bind directly to the FHRE2 and FHRE3 elements in the gadd45a promoter region (58). All of the FOXO3a effects on $\mathrm{G}_{2}$ arrest and the UV damaged CMV luciferase construct were diminished in a GADD45 $\alpha$-/- fibroblast cell line, suggesting that the effects of GADD $45 \alpha$ are at least in part mediated through a transcriptional increase of GADD $45 \alpha$ protein by FOXO3a (58).

\section{Post-Transcriptional Regulation}

In addition to transcriptional upregulation, GADD45 $\alpha$ has also been shown to be post-transcriptionally regulated. Rishi et al observed a four-fold increase in the amount of GADD $45 \alpha$ mRNA stability in a human breast carcinoma cell line after treatment with the synthetic retinoid CD437 which has been shown to cause $G_{0} / G_{1}$ arrest and apoptosis (59). Rishi's group further established that GADD45 $\alpha$ mRNA stability is dependent upon 45 base pairs of the 5' untranslated region (UTR) of the GADD45 $\alpha$ mRNA (59). Rishi's report is the only published report of post-transcriptional regulation of the GADD $45 \alpha$ protein.

\section{Working Hypothesis}

Because GADD $45 \alpha$ is a stress-inducible protein that is responsive to a multitude of DNA damaging agents each with their own mechanism of action, it is reasonable to 
suggest that its induction may be related to the production of ROS. UV-irradiation, IR, and sodium arsenite have all been shown to produce ROS in cellular systems and also induce GADD45 $\alpha$ expression (60). We have therefore hypothesized that ROS can act as second messengers to induce the GADD $45 \alpha$ protein and possibly mediate the effects of ROS on the cell cycle, apoptosis, and DNA damage repair. The experimental research presented in this manuscript suggests that arsenite can transcriptionally induce GADD45 $\alpha$ expression via the formation of $\mathrm{H}_{2} \mathrm{O}_{2}$ through a Fenton-like reaction mechanism.

\section{$\underline{\text { References }}$}

1. Balasoiu CF, Zagury GJ, Deschenes L. Partitioning and speciation of chromium, copper, and arsenic in CCA-contaminated soils: influence of soil composition. Sci Total Environ 280:239-255 (2001).

2. Stephanopoulos DE, Willman DA, Shevlin D, Pinter L, Gummin DD. Treatment and toxicokinetics of acute pediatric arsenic ingestion: danger of arsenic insecticides in children. Pediatr Crit Care Med 3:74-80 (2002).

3. Bailey, E.J., Kennaway, E.L., Urquhart, M.E. Arsenic content of cigarettes. Br J Cancer 11:49-53 (1957).

4. Das HK, Mitra AK, Sengupta PK, Hossain A, Islam F, Rabbani GH. Arsenic concentrations in rice, vegetables, and fish in Bangladesh: a preliminary study. Environ Int 30:383-387 (2004). 
5. Haque R, Mazumder DN, Samanta S, Ghosh N, Kalman D, Smith MM, Mitra S, Santra A, Lahiri S, Das S, De BK, Smith AH. Arsenic in drinking water and skin lesions: dose-response data from West Bengal, India. Epidemiology 14:174-182 (2003).

6. Roychowdhury T, Uchino T, Tokunaga H, Ando M. Arsenic and other heavy metals in soils from an arsenic-affected area of West Bengal, India. Chemosphere 49:605-618 (2002).

7. Axelson O, Dahlgren E, Jansson CD, Rehnlund SO. Arsenic exposure and mortality: a case-referent study from a Swedish copper smelter. Br J Ind Med 35:8-15 (1978).

8. Smith AH, Lingas EO, Rahman M. Contamination of drinking-water by arsenic in Bangladesh: a public health emergency. Bull World Health Organ 78:1093-1103 (2000).

9. Centeno, J.A., Mullick, F.G., Martinez, L., Page, N.P., Gibb, H., Longfellow, D., Thompson, C., and Ladich, E.R. (2002) Pathology related to chronic arsenic exposure. Envrion Health Perspect 110 Supp 5; 883-886.

10. Chen, C.J., Chuang, Y.C., Lin, T.M., and Wu, H.Y. (1985) Malignant neoplasms among residents of a blackfoot disease-endemic area in Taiwan: high-arsenic artesian well water and cancers. Cancer Res 45: 5895-5899.

11. Chen, C.J., Hsueh, Y.M., Lai, M.S., Shyu, M.P., Chen, S.Y., Wu, M.M., Kuo, T.L., and Tai, T.Y. (1995) Hypertension 25; 53-60. 
12. IARC (1980). Carcinogenesis of arsenic compounds. IARC Monograph on Evaluation of Carcinogenic Risks, Vol. 23, pp. 37-141. IARC, Lyon.

13. Leonard, A. and Lauwerys, R.R. (1980) Carcinogenicity, teratogenicity and mutagenicity of arsenic. Mutat Res 75; 49-62.

14. Mabuchi, K., Lilienfeld, A.M., and Snell, L.M. (1979) Lung cancer among pesticide workers exposed to inorganic arsenicals. Arch Environ Health 34;312-20. 15. Pinto, S.S. and Nelson, K.W. (1976) Arsenic toxicology and industrial exposure. Annu Rev Pharmacol Toxicol 16; 95-100.

15. Pinto, S.S. and Nelson, K.W. (1976) Arsenic toxicology and industrial exposure. Annu Rev Pharmacol Toxicol 16; 95-100.

16. Pinto, S.S., Enterline, P.E., Henderson, V., Varner, M.O. (1977) Mortality experience in relation to a measured arsenic trioxide exposure. Environ Health Perspect 19;127-30.

17. Steinmaus, C., Moore, L., Hopenhayn-Rich, C., Biffs, M.L., and Smith, A.H. (2000) Arsenic in drinking water and bladder cancer. Cancer Invest $18 ; 174-82$.

18. World health Organization (1999). Arsenic in Drinking Water, Fact Sheet No. 210, pp.1-6, WHO Press, Geneva.

19. National Research Council (1999). Arsenic in Drinking Water, National Academy Press, Washington, D.C. 
20. Klaassen, C.D., Amdur, M.O., and Doull, J (1996) Cassarett and Doull's Toxicoligy: The Basic Sciences of Poisons, pp. 691-736, McGraw-Hill, New York

22. Bagla, P. and Kaiser, J. (1996) India's spreading health crisis draws global arsenic experts. Science 29; 174-175.

23. Natural Resources Defense Council (2001) Arsenic and Old Laws: A scientific and public health analysis of arsenic occurrence in drinking water, its health effects, and EPA's outdated arsenic tap water standard. http://www.nrdc.org/water/drinking/arsenic/chapl.asp

24. Lewis, D.R., Southwick, J.W., Ouellet-Hellstrom, R., Rench, J., and Calderon, R.L. (1999) Drinking water arsenic in Utah: A cohort mortality study. Environ Health Perspect 107;359-65.

25. Nordstrom, D.K. (2002) Public health. Worldwide occurrences of arsenic in ground water. Science 296; 2143-2145.

26. Rossman, T.G., Stone, D., Molina, M., and Troll, W. (1980) Absence of arsenite mutagenicity in E. coli and Chinese hamster cells. Environ Mutagen 2; 371-379.

27. Germolec, D.R., Spalding, J., Boorman, G.A., Wilmer, J.L., Yoshida, T., Simeonova, P.P., Bruccoleri, A., Kayama, F., Gaido, K., Tennant, R., Burleson, F., Dong, W., Lang, R.W., and Luster, M.I. (1997). Arsenic can mediate skin neoplasia by chronic stimulation of keratinocyte-derived growth factors. Mutat Res 386; 20918. 
28. Germolec, D.R., Spalding, J., Yu, H.S., Chen, G.S., Simeonova, P.P., Humble, M.C., Bruccoleri, A., Boorman, G.A., Foley, J.F., Yoshida, T., Luster, M.I. (1998) Arsenic enhancement of skin neoplasia by chronic stimulation of growth factors. Am J Pathol 153;1775-1785.

29. Rossman, T.G., Uddin, A.N., Burns, F.J., and Bosland, M.C. (2001) Arsenite is a cocarcinogen with solar ultraviolet radiation for mouse skin: an animal model for arsenic carcinogenesis. Toxicol Appl Pharmacol 176; 64-71.

30. Chen, H., Liu, J., Zhao, C.Q., Diwan, B.A., Merrick, B.A., and Waalkes, M.P. (2001) Association of c-myc overexpression and hyperproliferation with arsenite-induced malignant transformation. Toxicol Appl Pharmacol 175; 260-268.

31. Chen, H., Li, S., Diwan, B.A., Barrett, J.C., Waalkes, M.P. (2004) Chronic inorganic arsenic exposure induces hepatic global and individual gene hypomethylation: implications for arsenic hepatocarcinogenesis. Carcinogenesis 25; 1779-1786.32. Huang, C., Ma, W.-Y., Li, J., Goranson, A., and Dong, Z. (1999). Requirement of Erk, but not JNK, for arsenite-induced cell transformation. J Biol Chem, 274(21), 14595-14601.

32. Huang, C., Ma, W.-Y., Li, J., Goranson, A., and Dong, Z. (1999). Requirement of Erk, but not JNK, for arsenite-induced cell transformation. J Biol Chem, 274(21), 14595-14601. 
33. Kachinskas, D.J., Philips, M.A., Qin, Q., and Rice, R.H. (1993). Arsenate suppression of involucrin expression in malignant human keratinocytes. FASEB $J$ 7, A1230.

34. Liu, J., Xie, Y., Ward, J.M., Diwan, B.A., and Waalkes, M.P. (2004)

Toxicogenomic analysis of aberrant gene expression in liver tumors and nontumorous livers of adult mice exposed in utero to inorganic arsenic. Toxicol Sci 77;249-57.

35. Andrew, A.S., Warren, A.J., Barchowsky, A., Temple, K.A., Klei, L., Soucy, N.V., O’Hara, K.A., and Hamilton, J.W. (2003) Genomic and proteomic profiling of responses to toxic metals in human lung cells. Environ Health Perspect 111;825835.

36. He, Q.Y., Yip, T.T., Li, M., and Chiu, J.F. (2003) Proteomic analyses of arsenicinduced cell transformation with SELDI-TOF Protein Chip technology. J Cell Biochem 88; 1-8.

37. Lau, A.T., He, Q.Y., and Chiu, J.F. (2004) A proteome analysis of the arsnite response in cultured lung cells: evidence for in vitro oxidative stress-induced apoptosis. Biochem J 382; 641-50.

38. Wang, Z.H., Yu, D., Chen, Y., and Hao, J.Z. (2005) Proteomic analysis of nuclear matrix proteins during arsenic trioxide induced apoptosis in leukemia K562 cells. Chin Med J 118;100-104. 
39. Chen, F., Zhang, Z., Bower, J., Lu, Y., Leonard, S.S., Ding, M., Castranova, V., Piwnica-Worms, H., and Shi, X. (2002) Arsenite-induced Cdc25C degradation is through the KEN-box and ubiquitin-proteasome pathway. Proc Natl Acad Sci USA $99 ; 1990-1995$.

40. Zhan, Q., Antinore, M.J., Wang, X.W., Carrier, F., Smith, M.L., Harris, C.C., and Fornace, A.J. Jr. (1999) Association with Cdc2 and inhibition of Cdc2/Cyclin B1 kinase activity by the p53-regulated protein Gadd45. Oncogene 18; 2892-2900.

41. Smith, M.L., Chen, I.T., Zhan, Q., Bae, I., Chen, C.Y., Gilmer, T.M., Kastan, M.B., O’Connor, P.M., and Fornace, A.J. Jr. (1994) Interaction of the p53-regulated protein Gadd45 with proliferating cell nuclear antigen. Science 266; 1376-1380.

42. Stivala, L.A., Prosperi, E., Rossi, R., and Bianchi, L. (1993) Invovement of proliferating cell nuclear antigen in DNA repair after damage induced by genotoxic agents in human fibroblasts. Carcinogenesis 14; 2569-2573.

43. Kastan, M.B., Zhan, Q., el-Deiry, W.S., Carrier, F., Jacks, T., Walsh, W.V., Plunkett, B.S., Vogelstein, B., Fornace, A.J. Jr. (1992) A mammalian cell cycle checkpoint pathway utilizing p53 and GADD45 is defective in ataxiatelangiectasia. Cell 71; 587-97.

44. Zhang, X., Ma, L., Enkemann, S.A., and Pledger, W.J. (2003) Role of Gadd45alpha in the density-dependent G1 arrest induced by p27(Kip1). Oncogene 22; 41664174. 
45. Carrier, F., Georgel, P.T., Pourquier, P., Blake, M., Kontny, H.U., Antinore, M.J., Gariboldi, M., Myers, T.G., Weinstein, J.N., Pommier, Y., and Fornace, A.J. Jr. (1999) Gadd45, a p53-responsive stress protein, modifies DNA accessibility on damaged chromatin. Mol Cell Biol 19; 1673-1685.

46. Fornace, A.J., Nebert, D.W., Hollander, C., Luethy, J.D., Papathanasiou, M., Fargnoli, J., and Holbrook, N.J. (1989) Mammalian genes coordinately regulated by growth arrest signals and DNA-damaging agents. Mol Cell Biol 9:4196-4203.

47. Yih, L-H, Peck, K., and Lee, T-C. (2002) Changes in gene expression profiles of human fibroblasts in response to sodium arsenite treatment. Carcinogenesis 23:867-876.

48. Graunke, D.M., Fornace, A.J., and Pieper, R.O. (1999) Presetting of chromatin structure and transcription factor binding poise the human GADD45 gene for rapid transcriptional up-regulation. Nuceicl Acids Res 27:3881-3890.

49. Zhan, Q., Chen, I-T, Antinore, M.J., and Fornace, A.J. (1998) Tumor suppressor p53 can participate in transcriptional induction of the GADD45 promoter in the absence of direct DNA binding. Mol Cell Biol 18:2768-2778.

50. Takahashi, S., Saito, S., Ohtani, N., and Sakai, T. (2001) Involvement of the Oct-1 regulatory element of the gadd 45 promoter in the p53-independent response to ultraviolet irradiation. Cancer Res 61:1187-1195.

51. Jin, S., Fan, F., Fan, W., Zhao, H., Tong, T., Blanck, P., Alomo, I., Rajasekaran, B., and Zhan, Q. (2001) Transcription factors Oct-1 and NF-YA regulate the p53- 
independent induction of the GADD45 following DNA damage. Oncogene 20:2693-2690.

52. Zhao, H., Jin, S., Fan, F., Fan, W., Tong, T., and Zhan, Q. (2000) Activation of the transcription factor Oct-1 in response to DNA damage. Cancer Res 60:62766280.

53. Daino, K., Ichimura, S., and Nenoi, M. (2003) Comprehensive search for X-ray responsive elements and binding factors in the regulatory region of the GADD45 $\alpha$ gene. J Radiat Res 44:311-318.

54. Yun, J. and Lee, W-H. (2003) Degradation of transcription repressor ZBRK1 through the ubiquitin-proteasome pathwayrelieves repression of Gadd45a upon DNA damage. Mol Cell Biol 23:7305-7314.

55. Zheng, L., Pan, H., Li, S., Flesken-Nikitin, A., Chen, P.L., Boywer, T.G., and Lee, W.H. (2000) Sequence-specific transcriptional corepressor function for BRCA1 through a novel zinc finger protein ZBRK1. Mol Cell 6; 757-768.

56. Marhin, W.W., Chen, S., Facchini, L.M., Fornace, A.J., and Penn, L.Z. (1997) Myc represses the growth arrest gene gadd45. Oncogene 14:2825-2834.

57. Zerbini, L.F., Wang, Y., Czibere, A., Correa, R.G., Cho, J-Y, Ijiri, K., Wei, W., Joseph, M., Gu, X., Grall, F., Goldring, M.B., Zhou, J-R, and Libermann, T.A.

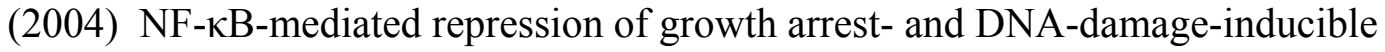
proteins $45 \alpha$ and $\gamma$ is essential for cancer cell survival. Proc Natl Acad Sciences USA 101:13618-13623. 
58. Tran, H., Brunet, A., Grenier, J.M., Datta, S.R., Fornace, A.J., DiStefano, P.S., Chiang, L.W., and Greenberg, M.E. (2002) DNA repair pathway stimulated by the forkhead transcription factor FOXO3a through the GADD45 protein. Science 296:530-534

59. Rishi, A.K., Sun, R.J., Gao, Y., Hsu, C.K.A., Gerald, T.M., Sheikh, M.S., Dawson, M.I., Reichert, U., Shroot, B., Fornace, A.J. Jr., Brewer, G., and Fontana, J.A. (1999) Post-transcriptional regulation of the DNA damage-inducible gadd45 gene in human breast carcinoma cells exposed to a novel retinoid CD437. Nucl Acids Res 27; 3111-3119.

60. Halliwell, B.; Gutteridge, J. M. C. Free Radicals in Biology and Medicine. New York: Oxford University Press, Inc.; 1999. 


\section{SECTION II}

Environmental Health Research in the Post-Genome Era: New

Fields, New Challenges, and New Opportunities 


\section{ABSTRACT}

The human genome sequence provides researchers with a genetic framework to eventually understand the relationship between gene-environment interactions. This wealth of information has led to the birth of several related areas of research including proteomics, functional genomics, pharmacogenomics, and toxicogenomics. Developing techniques such as DNA/protein microarrays, siRNA applications, 2-D gel electorphoresis and mass spectrometry in conjunction with advanced analytical software and the availability of internet databases offers a powerful set of tools to investigate an individual's response to specific stimuli. Here, we summarize these emerging scientific fields and techniques focusing specifically on their applications to the complexities of gene-environment interactions and their potential role in environmental biosecurity. 


\section{$\underline{\text { Introduction }}$}

Environmental exposure, genetic susceptibility, and age undergo a set of complex interactions to induce human disease (Rall and Groopman, 1994; National Institute for Envrionmental Health Sciences (NIEHS): Intro to NIEHS, 2002). The prevention and treatment of human disease relies on the ability to understand the exact cause and effect relationship among these factors and to identify which events are involved in the onset and progression of disease. The recently completed draft sequence of the human genome could create seemingly endless opportunities for the delineation of gene-environment interactions. By determining the relationship between environmental exposure and genetic susceptibility, the environmental health research community has the ability to unlock these mysteries.

Since the inception of the Human Genome Project in 1990 (Fink, 1990), new avenues of research such as proteomics, functional genomics, and toxicogenomics have rapidly emerged. In February 2001, two separate drafts of the human genome sequence were published (Venter et al, 2001; International Human Genome Sequencing Consortium (IHGSC), 2001). In April of 2003, the IHGSC finally announced the completion of the human genome sequence (Pennisi, 2003; National Human Genome Research Institute, 2003). New techniques including DNA microarrays, small-interfering RNA (siRNA), and protein microarrays have already yielded promising results towards improving health and treating human disease (Heller et al, 1997; Novina et al, 2002; Belov et al, 2001). By integrating information gathered from the human genome sequence, epidemiological surveys, and gene-association/susceptibility studies, it may be possible to determine how genes and environmental stressors are interrelated. These 
studies could lead to the generation of novel strategies for treating diseases with underlying genetic components. Here, we discuss advances in the new fields and techniques that have emerged with the promise of a complete human genome sequence and their applications to gene-environment interaction studies.

\section{Environmental Exposure and Genetic Susceptibility}

Humans are continually exposed to hazardous agents in the environment through air, water, soil, diet, and the workplace (Churg et al, 2003; Tsai et al, 1999; Malaka et al, 1990; Gambelunghe et al, 2003). Previously, there have been many studies focusing on the acute effects of high-dose exposure to environmental agents. However, much less data is available concerning the effects of low-dose chronic exposure to many environmental agents. Chronic exposure to an environmental toxin, even at a low dose, can be just as harmful to an organism as an acute exposure. For example, toxic agents such as cadmium have been shown to accumulate in tissues over time and lead to multiple adverse effects in exposed individuals (Hunder et al, 2001; Staessen et al, 1999). However, not all individuals who are exposed to an environmental agent will manifest disease, suggesting that many of the effects resulting from a low-dose chronic exposure to an agent may have a complex genetic and/or non-genetic basis. Further complications of exposure assessment include variations in the route of exposure, concentrations of the toxic substance, and the number and length of exposures, rendering each individual's exposure pattern unique.

It has long been thought that the genetic makeup of each individual plays a key role in the cellular response to a toxic agent (International SNP Map Working Group, 
2001). There are several types of genetic variations that have been observed in humans, including the loss of one or both alleles for a specific gene, alternative splicing variants, and the presence of single nucleotide polymorphisms (SNPs), which are the most common type of genetic variation. An example of the effect of genetic variation on a cellular process is illustrated by the different expression levels of several cellular antioxidant enzymes in Type 1 Diabetes patients (Hodgkinson et al, 2003). When cells and tissues are exposed to a toxic agent such as $\mathrm{Cr}(\mathrm{VI})$, the antioxidant enzymes are triggered as a defense system to repair the cellular damage. If, however, a large amount of cellular damage is induced by the $\mathrm{Cr}(\mathrm{VI})$ exposure, then the balance between the antioxidant defense mechanisms and the oxidants may be upset. The oxidant-induced damage may be permanent and lead to apoptotic or necrotic cell death (Ye et al, 1999). Environmental exposure to agents such as chromium, arsenic, and nickel has been shown to affect several cellular signaling pathways, suggesting that an individual's genetic variation in any gene involved in these pathways could potentially affect susceptibility (Barchowsky and O'Hara, 2003; O'Hara et al, 2003; reviewed in Chen and Shi, 2001). As a result, a Type I Diabetes patient that is subsequently exposed to an environmental insult may have a less effective antioxidant defense system than that of a non-diabetic.

There are several ways a toxic agent can elicit a cellular response. For example, an inappropriate activation or modification of proteins involved in the cell survival/DNA repair/apoptotic signaling pathways can lead to increased non-specific tyrosine phosphorylation (Qian et al, 2001). Toxic agents, such as nickel, arsenic, and cadmium may also inhibit enzymes responsible for protection from carcinogenic agents (Poirier and Vlasova, 2002). In addition, toxic agents have also been shown to induce mutations, 
such as the mutation of two domains of the insulin-like growth factor 1 receptor (IGF-1R) involved in a radio-resistant signaling pathway in mouse embryo fibroblasts ( $\mathrm{Yu}$ et al, 2003). The previous examples suggest that exposure to toxic agents occurs through many different mechanisms, each of which must be fully investigated in order to prevent and/or treat the diseases that result. In addition to the myriad of disease mechanisms that may exist, genetic influences may also play an important role in these mechanisms. Until recently, however, the tools and technology necessary to investigate the genetic influence on diseases of environmental exposure were inadequate. The sequencing of the human genome has provided us with a blueprint to begin studying the gene-environment interactions and the cellular signaling processes that lead to complex, geneticallyassociated diseases such as Parkinson's, Alzheimer's, and cancer.

\section{Single Nucleotide Polymorphisms (SNPS)}

One of the most promising immediate benefits of sequencing the human genome is the current effort to catalog all of the human SNPs. Persons displaying a SNP - a single nucleotide substitution, deletion, or addition in any given gene or regulatory region - are potentially at risk for responding to their environment in a different manner from those who contain the consensus "normal" allele of the given gene. Techniques to determine the effects of these polymorphisms are playing an important role in pharmaceutical research and in the investigation of disease onset. An example is the cytochrome P450 2D6 (CYP2D6) gene encoding debrisoquine 4-hydroxylase, which is involved in the metabolism of many drugs and some neurotoxins. The poor metabolizer 
polymorphisms of this gene have been implicated in the pathogenesis of neurotoxininduced Parkinson's disease (Payami et al, 2001).

SNPs are the most common type of genetic variation - purportedly occurring at a rate of 1 per 1300 bases with a grand total of 1.42 million located in the human genome and are thought to be the most likely candidates for complex polygenic susceptibility to disease (Venter et al, 2001; IHGSC, 2001; International SNP Map Working Group, 2001; Wolfsburg et al, 2001; Altshuler et al, 2000). Several disease genes have already been discovered; the IT15 gene responsible for Huntington's disease, the ADAMTS13 gene involved in thrombotic thrombocytopenic purpura, the lamin A gene (LMNA) which is thought to be the underlying cause of Hutchinson-Gilford progeria syndrome, and the CLN2 gene product associated with late-infantile neuronal ceroid lipofuscinosis (LINCL) (Huntington's Disease Collaborative Research Group, 1993; Levy et al, 2001; Eriksson et al, 2003; Sleat et al, 1997). However, most of these genes are linked to rare conditions in which the mutation of only one gene seems to cause the disease (International SNP Map Working Group, 2001). More complex genetic diseases in which mutations must be present in multiple genes are much more difficult to identify. The identification of such genes will require the characterization of all of the existing SNPs in combination with association studies of individuals at risk (Lander, 1996; Collins et al, 1997).

It has already been established that certain SNPs play a pivotal role in the manifestation of disease, either by increasing the risk for disease, by preventing disease progression, or by affecting transcriptional regulation. For example, an ApoE4 SNP has been shown to increase senile plaque density, rendering this SNP a risk factor for Alzheimer's disease (Hofmann, 2001). On the other hand, the deletion of base pair 32 of 
the CCR5 co-receptor gene prevents HIV uptake by T4 lymphocytes, rendering any individual possessing this SNP resistant to HIV infection (Lander, 1996; Hofmann, 2001). Finally, cases in which a SNP removes, adds, or alters a transcription factor binding site which lead to a disease phenotype have been documented (Ponomarenko et al, 2002; Ponomarenko et al, 2003). To date, most of the research of genetic disease has focused on mutations in single genes, mainly because complex genetic interactions are difficult to study (Collins et al, 1997). However, by performing gene-association studies utilizing an SNP catalog, researchers can study the complex interactions between multiple genes when exposed to an environmental toxicant (International SNP Map Working Group, 2001; Collins et al, 1997).

Many SNP databases are available for public use, including the dbSNP and the SNP Consortium database, both of which currently contain only human SNP data (International SNP Map Working Group, 2001; Smigelski et al, 2000; Wheeler et al, 2003). Other more specialized types of SNP databases have also been created, including the rSNP_Guide, which allows users to search for novel human transcription factor binding sites created, deleted, or altered by SNPs (Ponomarenko et al, 2002; Ponomarenko et al, 2003). By utilizing the vast array of information found in such databases, one can begin to explore the probable cause and effect relationship between SNPs and specific gene-environment interactions leading to disease susceptibility.

However, many questions remain to be answered concerning the role of genetic polymorphisms in disease progression, including the following: How do these SNPs facilitate disease? Is it a result of the polymorphic gene's inability to produce its functional protein product? Does the polymorphism destroy some binding sequence 
required for a particular signaling pathway? Or does the polymorphism interfere with or negate the immune response to that agent? Can prior exposure create a sensitization effect, i.e. does it influence genetic susceptibility to a second exposure by worsening the effects of subsequent exposure over time? Can genetic susceptibility change or breakdown over time as a person ages? These questions will have to be answered for all of the SNPs involved in a disease in order to fully understand the gene-environment relationship between exposure and disease.

\section{Environmental Genome Project (EGP)}

In light of all the questions surrounding genetic susceptibility and environmental exposure, the NIEHS founded the Environmental Genome Project (EGP) in 1997 (EGP History, 2003). The purpose of the EGP is to increase the available knowledge and information about the effects of environmental exposure and the role genetic variation plays in human susceptibility to disease. Specifically, the EGP focuses on re-sequencing parts of the human genome, looking for polymorphisms that may be involved in genetic susceptibility to a range of diseases (EGP - Overview, 2003). The EGP has identified a group of environmentally responsive genes and categorized them into the following eight groups: cell cycle, DNA repair, cell division, cell signaling, cell structure, gene expression, apoptosis, and metabolism (EGP - Environmentally Responsive Genes, 2003). The goal is to compare and cross-screen the re-sequenced regions of the human genome, analyzing each identified polymorphism and determining whether or not it is functionally significant. Discovering the identity of the functionally significant polymorphisms is crucial to linking genetic susceptibility to specific diseases. Together 
with thorough epidemiological surveys, genetic polymorphisms can help determine which environmental and genetic factors may interact to produce disease.

Although studying gene-environment interactions via SNP comparisons is a promising avenue of exploration, some problems may complicate these studies. For instance, disease is not always caused by a single trait; it sometimes involves several traits, and the algorithms available may not be able to deduce a correlation between broad sets of SNPs and environmental factors. Therefore, establishing clear-cut relationships between particular genes and their environmental inducers may not always be possible. These issues will have to be addressed in order to fully understand the mechanisms by which genes and their corresponding SNPs are influenced by their environment.

\section{Bioinformatics and the-omics explosion}

As the human genome project neared its completion, the new field of functional genomics began to surface. Functional genomics encompasses the identification and analysis of the entire gene and protein content of an organism (Fields et al, 1999; Strausberg and Austin, 1999). Since then, all of the questions originally proposed under the term functional genomics seem to have taken on their own personalities, and have each become their own -omics field. The fields of bioinformatics, proteomics, and structural genomics, are a few of the fields that have evolved in this manner. Developments in these fields will likely facilitate the understanding of the underlying mechanisms of gene-environment interactions and their relationship to human disease. 


\section{- Bioinformatics}

The field of bioinformatics collects, analyzes, and disseminates the raw sequence data of a genome (D Trends, 2003). Researchers are currently trying to create better analytical software and more powerful algorithms to determine which specific sequences correspond to genes or their regulatory regions, and which sections do not play a role in the production of proteins or their regulation. These powerful computer programs will allow bioinformaticians to complete an annotated version of the human genome revealing the number of genes it contains. They will also help to predict the regulatory regions, functionally significant regions, and transcription factor binding sites in unknown genes.

\section{- Proteomics}

The term "proteome", coined by Marc Wilkins, refers to the total set of proteins encoded by a particular genome (Wilkins et al, 1996). Even before the determination of the complete sequence of the genome, proteomics scientists had already begun to tackle the proteome via techniques involving the coupling of 2D polyacrylamide gel electrophoresis and chemical composition analysis by mass spectrometry (Wilkins et al, 1996). By determining the complete contents of the proteome, proteomics scientists hope to discover new protein biomarkers for diseases by examining differences in protein expression levels, post-translational modifications, and the differential expression of proteins between disease and non-disease states. With the development of highthroughput protein analysis methods, such as protein arrays, the identification and cataloging processes can be streamlined. A list of several databases containing 
information about protein sequences, 2D gel information, and 3D protein structures is available at the Expert Protein Analysis System (ExPASy) website (Fig. 1) (James, 1997).

\section{- Structural Genomics}

With the increasing amount of genomic and proteomic data available, structural genomics has found its own niche. The aim of structural genomics is to characterize the structures of representative proteins for each protein family. Several methods, particularly x-ray crystallography and nuclear magnetic resonance (NMR), are used to provide a set of reference structures that will serve to help determine the structures of similar families of proteins. The Protein Structure Initiative (PSI) sponsored by the National Institute of General Medical Sciences has attempted to create a database of the structures of all proteins determined to date (See Fig. 1 - PSI website). Structural genomics scientists can then use the information gained through DNA coding sequences to predict primary protein sequence, which can be further analyzed and compared to known three dimensional structures by computer homology modeling techniques (Yao, 2002).

Computer homology modeling methods play a major role in predicting the tertiary structure of proteins by comparing the sequence of a protein of unknown structure to the sequences of structures that have already been determined via the use of computer databases. Examples of such databases include Entrez's Molecular Modeling Database and the ModBase database (Wheeler et al, 2003; Yao 2002; Chen et al, 2003). These databases have been employed to determine the physical structure of many proteins and 
allow public access to the structure and functional domain data generated for known proteins. The identification of a protein's tertiary structure leading to the recognition of common interaction domains, can offer critical information concerning that protein's function. Recognition of these common binding domains may help to predict novel interactions with other proteins or cellular constituents. Thus, these results could be extrapolated from database resources and used to increase the rate at which candidate proteins can be examined in biological systems - all based solely on their sequence identity and homology to similar proteins.

In addition to comparing the primary sequence of two proteins, the structural databases can be used to compare the tertiary structures of two proteins. Comparing the tertiary structure of proteins may be helpful when comparing two proteins that are functionally equivalent, but evolutionarily diverse (Holm and Sander, 1996). With new technologies developing in the field of structural genomics, the goal of structurally characterizing the entire proteome may soon be attained, allowing researchers to investigate gene-environment interactions at the proteomic level.

\section{Using Bioinformatics to Fuel New Directions in Environmental Health Research}

Bioinformatics, proteomics, and structural genomics have produced a large amount of sequence and structural data very quickly. The need for interpretation of this massive quantity of information has led to the development of many new specific disciplines including, but by no means limited to, metabolomics, pharmacogenomics, and toxicogenomics. In addition to these specialized fields, more comprehensive fields such as comparative genomics and systems biology have evolved, both of which attempt to 
make more global inferences from a large scale interpretation of all genomes sequenced to date (Yao, 2002).

\section{- Metabolomics}

The field of metabolomics attempts to decipher the different interactions between signaling pathways by characterizing differences in the metabolome - all of the metabolites present at any given time in a biological sample (Muller and Kersten, 2003). Metabolomic profiles have been used to determine genotypic differences between Arabidopsis thaliana plants through the use of neural networks and to study metabolic fluxes in tumor tissue (Taylor et al, 2002; Griffiths and Stubbs, 2003). Raamsdonk et al, has recently shown that genes exhibiting no overt phenotype can be studied using a method called functional analysis by co-responses in yeast (FANCY) that detects changes in metabolite concentration of a cell rather than an overall growth effect (Raamsdonk et al, 2001). Metabolomics studies have also been shown to be useful in the discovery of new toxicity biomarkers, such as the study by Lindon et al, in which ${ }^{1} \mathrm{H}-\mathrm{NMR}$ spectroscopy was used to identify novel biomarkers in rat bodily fluids (Lindon et al, 2002). EcoCyc, a database that describes the metabolic and signal transduction pathways of Escherichia coli, and MetaCyc, which contains metabolic and signal transduction data for many other organisms have recently been developed (Karp et al, 2000). Since heart disease has been linked to aberrant cholesterol metabolism, advances in the field of metabolomics could provide major contributions to environmental health researchers investigating the mechanisms responsible for heart disease. 


\section{- Pharmacogenomics}

Pharmacogenomics is a field which aims to identify and characterize the various polymorphisms, including SNPs, present in different individuals that may affect a patient's response to a drug (Altman and Klein, 2002). Examples of an important class of highly polymorphic genes include the cytochrome P450 (CYP450) enzymes, many of which are responsible for the metabolism of an array of currently available pharmaceuticals. Currently, new technical avenues are being explored to determine a patient's genetic compatibility with a drug before a treatment is prescribed. This type of precautionary testing would protect a patient in the event that he or she possessed a polymorphism affecting the metabolism of that drug. Although it has been suggested that less than $1 \%$ of SNPs affect the predicted protein coding regions in the human genome (Venter et al, 2001), the SNPs that do affect the coding regions can nonetheless have a crucial effect on the treatment of patients. For example, potentially toxic thiopurine drugs, such as 6-mercaptopurine which is metabolized by thiopurine methyltransferase (TPMT), are administered to children with acute lymphoblastic leukemia (Weinshilboum, 2001). Since thiopurines have a very narrow therapeutic index and the levels of TPMT are controlled by a common polymorphism, it is necessary to individualize thiopurine therapy to prevent fatal thiopurine toxicity (Weinshilboum, 2001). Other examples have also begun to pave the way for the individualization of medical treatment. The new Genentech drug Herceptin is being used to treat only the $20-30 \%$ of breast cancer patients that overexpress the her-2/neu receptor (Service, 2003). Advances in the field of 
pharmacogenomics could revolutionize the way a doctor prescribes drugs for his or her patients.

\section{- Toxicogenomics}

Toxicogenomics is dedicated to the elucidation of the role genes play in response to environmental toxicants and stressors (Hamadeh et al, 2002). NIEHS has recently developed the Toxicogenomics Research Consortium (TRC) in conjunction with the National Center for Toxicogenomics Microarray Group (NMG) and has charged them with the specific tasks of: identifying sites of genetic variability throughout the human genome, developing standards for the current microarray technology being used to assess biological responses to environmental stressors/toxicants, and applying this expression technology in a manner that helps to elucidate the mechanisms of toxicity produced in response to environmental exposure (Medlin, 2002; National Center for Toxicogenomics

- TRC, 2003). The TRC's overall goal is to study the relationship between environmental exposure and disease, and to show how these gene-environment interactions affect human health. It may be useful to try to develop genome and proteome "fingerprints" of the different toxicants using array technology, in order to thoroughly investigate the mechanism of action of these toxins. The Comparative Toxicogenomics Database (CTD) has been launched in order to provide an annotated guide to toxicologically significant genes (Mattingly et al, 2003). 


\section{- Comparative genomics}

Comparative genomics encompasses the effort to compare all known complete genomic sequences to that of the human genome. Complete genomes have now been sequenced for many of the most popular model organisms currently used in research, including the $A$. thaliana plant (Arabidopsis Genome Initiative, 2000), the worm Caenorhabditis elegans (C. elegans Sequencing Consortium, 1998), the fruit fly Drosophila melanogaster (Adams et al, 2000), the yeasts Saccharomyces cerevisiae (Goffeau et al, 1996) and Schizosaccharomyces pombe (Maier et al, 1992), and the laboratory mouse Mus musculus (Mouse Genome Sequencing Consortium (MGSC), 2002). The comparative analysis of all of the sequenced genomes allows the determination of which human genes have homologous genes in different model organisms. This allows researchers to make more informed decisions about which model organism to use for specific studies. If a particular drug is known to exert toxic effects in a mouse due to a murine-specific gene, then another model organism could be chosen based on a comparative genomic analysis of several suitable organisms. Thus, some pharmaceutical studies use non-rodent models, such as dogs and primates, in order to assess the toxicological effects of certain pharmaceuticals that are not suitable for the mouse model (reviewed in Smith et al, 2001). Comparative genomics can contribute to environmental health research in much the same way, by offering alternative model systems and allowing the elucidation of evolutionarily conserved mechanisms in response to disease. Perhaps similar genetic association patterns may surface between humans and non-rodent organisms that are affected by similar diseases. 


\section{- Comparative Genomics: Sequencing of the Mouse Genome}

In December 2002, the long-awaited draft sequence of the laboratory mouse genome, Mus musculus, was finally published (MGSC, 2002). The comparative genomic analyses of the human and mouse genomes may prove to be a major factor in decoding the language of the human genome. Already 342 syntenic segments have been found between both genomes, marked differences in $\mathrm{G} / \mathrm{C}$ distribution between the two sequences have been discovered, and upon examination of $\mathrm{CpG}$ island content, the human genome exhibits about twice as many CpG islands as the mouse genome (MGSC, 2002). Differences in the amount of sequence repeats in the mouse and human genomes is thought to arise from the activity of transposable elements, which appear to be more active in the mouse than in the human (Venter et al, 2001; IHGSC, 2001; MGSC, 2002). Since the mouse is the most studied model for human disease, with $99 \%$ of its genes corresponding to a human homolog, the comparison of the mouse and human genome sequences will have a significant impact on the future directions of model-driven research (MGSC, 2002). In addition to the identification of homologous gene pairs, the sequence identities of many orthologous disease-associated genes have been compared with an overall amino acid identity approximating $90.3 \%$ (MGSC, 2002). These data allow for a more refined extrapolation of mouse experimental data to human disease states.

Currently, there is a Human-Mouse Homology Map sponsored by NCBI that allows the comparison of mouse and human homologous segments of DNA. Several websites also offer access to the entire sequence of the mouse genome, including NCBI's Genome Resources website, the Ensembl Mouse Genome Server, and the USC Genome Bioinformatics website (MGSC, 2002; Wheeler et al, 2003). Additional mouse 
informatics databases can be found at the Jackson, Harwell, and RIKEN websites (See Fig. 1) (MGSC, 2002).

Aside from comparison applications, the mouse genome sequence will contribute to the generation of new knockout mice. A new transgenic approach by Lois et al. shows that an entire mouse can be made to express exogenous genes introduced to the organism via a lentiviral vector system (Lois et al, 2002). This lentiviral vector system could be combined with the new siRNA technology (discussed later) to produce knockout mice in a much more efficient and cost effective manner than traditional methods. It may even be possible to expand the lentiviral technique for use in fully grown mice to knockout embryonic lethal genes in a tissue-specific manner. Techniques of this caliber would provide extremely valuable in vivo data on signaling pathways in the mouse that would otherwise be impossible to study.

\section{- Systems Biology}

In addition to the birth of comparative genomics, the availability of the complete human and mouse genome sequences has also catalyzed the emergence of systems biology, which is the attempt to systematically study all of the physiological processes in a cell or tissue by global measurement of differentially perturbed states. The ultimate goal of systems biology is the integration of data from these observations into models that will eventually represent and simulate all processes of life, including the induction of a diseased state (Ideker et al, 2001; Kitano, 2002). Advances in proteomics could soon make the systems biology approach possible. Examples of systems biology approaches include the galactose metabolism system developed by Ideker et al., the PhysioLab® 
technology created by ENTELOS, and the Cardiome Project reviewed by

Bassingthwaighte (Ideker et al, 2001; Bassingthwaighte, 2000; ENTELOS, 2003).

\section{Current Technology - Global Transcriptional Analysis}

The increase in new areas of science prompted by the sequencing of the human genome coincides with a sudden increase in new technology that can help discover links between genes and causation of disease in response to environmental agents. By looking at the expression of a large number of genes at the same time, it is possible to check for global trends of expression specific to disease states. These trends may not be apparent to a researcher using traditional time-consuming methods of gene expression measurement, such as a Northern blot, which relies on a priori knowledge of regulation events. Several methods have been developed to assess transcription on a global level, including DNA microarrays, serial analysis of gene expression (SAGE), and massively parallel signature sequencing (MPSS).

\section{- Global Transcriptional Analysis - DNA microarrays}

One of the most powerful techniques is the DNA microarray, a high throughput screening method that measures the effects of a stimulus on the mRNA expression of the entire transcriptome in one comprehensive assay (Schena et al, 1995; Fodor et al, 1993). Microarray technology utilizes a defined set of probes, each of which represents a specific transcript. Each probe is arrayed on glass slides to form a microscopic highdensity spot. Total RNA is then isolated from treated and/or control samples and differentially labeled with fluorescent dyes. Next, a mixed population of labeled RNA 
targets is hybridized to the set of probes. Finally, the amount of fluorescence is measured by image analysis software and the increase/decrease in gene expression is determined via statistical analysis of fluorescence intensity. Several databases have been created to store microarray data, making it available to the public. These include but are not limited to the Stanford Microarray Database and the NCBI Gene Expression Omnibus database (See Fig. 1).

An attractive advantage to the microarray assay is that the large amounts of expression information obtained through one assay can save a tremendous amount of time by eliminating the need for blind usage of Northern blotting, RT-PCR, western blotting, and enzymatic assays to analyze gene expression. These time-consuming techniques can now be utilized on a smaller scale, as a subsequent validation method, to provide connections for the underlying mechanisms of the signaling pathways (Chin and Kong, 2002). In addition to the standard use of the assay for gene expression, genomic microarrays could potentially be employed to detect single nucleotide polymorphisms (SNPs), since the hybridization between mismatches, even of a 1 base pair magnitude, can be detected upon quantification of the hybridized probe or by enzymatic treatment in certain systems (Kolchinsky and Mirzabekov, 2002; Hacia and Collins, 1999).

As more human genes are identified and characterized, the development of microarrays can be tailored to include specific subsets of related genes that might be of interest to a researcher. One example would be the development of carcinogenesis chips that contain oligo probes specific for all known genes involved in cancer pathology. Toxicology laboratories in the United Kingdom have recently developed a set of toxicology tailored microarrays known as ToxBlot and ToxBlot II, which are specifically 
for use in toxicogenomic assays (Pennie, 2000; Pennie, 2002). Subset specific microarray databases, such as the Comparative Toxicogenomics Database (CTD) which contains toxicogenomic microarray data, are also under development (Mattingly et al, 2003; Medlin, 2002). These types of specialty-tailored microarrays could become more and more important for the initiation of hypothesis-driven research as we extrapolate information about the individual genes comprising the human genome.

One of the most useful applications of microarrays is the elucidation of uniquely affected transcripts in response to a stimulus, producing a so-called fingerprint pattern. It has recently been shown that microarray data can be useful in diagnosing diseased states in rats by examining the gene expression pattern of white blood cells, producing a fingerprint expression pattern unique to a specific disease state (Tang et al, 2001). Previous studies have also shown that different inflammatory diseases such as rheumatoid arthritis and inflammatory bowel disease exhibit a differential display of gene expression upon microarray analysis (Heller et al, 1997). Moreover, lesions of multiple sclerosis subjected to microarray analysis also produced expression profiles different from that of normal tissue from the same individual (Whitney et al;. 1999). Most recently, several laboratories have been able to identify a disease state and even predict the prognosis of an individual based on the patient's gene expression profile (Perou et al, 2000; Sorlie et al, 2001; Brenton et al, 2001; Gruvberger et al, 2001). These molecular fingerprints of disease produced by microarrays may be able to revolutionize the way we diagnose disease states. Diagnostic microarrays could also be used to identify and assess the severity of environmental exposure even if symptoms have not yet surfaced. With 
more research pending, this type of disease diagnosis may become an increasingly powerful tool in the individualization of health care treatment.

In addition to the fingerprint approach to microarray diagnostics, microarrays could also be instrumental for facilitating the identification of biomarkers specific for many different types of disease processes (Gerhold et al, 2002; Chin and Kong, 2002). It has been demonstrated that microarrays can detect alterations in gene expression in pathological states, such as microbial colonization of the gut and the onset of inflammation (Heller et al, 1997; Hooper and Gordon, 2001). Gel pad microarrays have even been used for identification of all types of pathogens - viruses, bacteria, prokaryotes - and the determination of tuberculosis antibiotic resistance, genetic mutations, SNP markers, and chromosomal rearrangements (Kolchinsky and Mirzabekov, 2002). The identification of new biomarkers will allow for the expansion of the available cache of simple diagnostic tests that can be performed in the laboratories at hospitals, instead of relying on more technically complicated diagnostic methods, rendering faster and more definitive results.

Microarray technology also has practical uses and applications in the environmental health research laboratory. Screening patients for a genetic risk factor is currently feasible only for a small subset of rare diseases that depend on the mutation of a single gene. With the newly emerging genetic technology, it is possible that the list can be expanded to include more diseases, particularly those that are influenced by more than one gene, such as diseases resulting from low-dose, chronic exposure to a hazardous agent. This could potentially save many lives by identifying the diseases much earlier, 
allowing doctors to prevent and/or pre-treat diseases before symptoms appear and the disease's course has already damaged the patient's body beyond repair (Grody, 2003).

As there is always a down side to every promising technique, there are also plenty of disadvantages plaguing the microarray. The microarrays currently used in most laboratories are not extremely sensitive and may exhibit probe hybridization technical problems (Kolchinsky and Mirzabekov, 2002). The reliability of the assay is compromised for genes with repetitive sequence elements or nucleic acids that strongly favor a secondary structure (Hacia and Collins, 1999). Additionally, since mRNA is transiently expressed, the expression information obtained through microarray analysis is limited to a "snapshot" of a biological process. Furthermore, early microarray data has not been continuously subjected to a set of globally accepted standards, and therefore much of the microarray data already generated and available in the public databases may be non-comparable or misleading if not examined carefully and analyzed using the appropriate statistical methods (Nadon and Shoemaker, 2002).

Microarray technology has also been criticized for creating a large number of false positives and negatives, for difficulty in reproduction of results between assays and laboratories, and for providing too much information for realistic interpretation. The Microarray Gene Expression Data (MGED) Society has begun to address some of these issues, and is currently trying several approaches such as: developing standards that will help to reduce variability between assays and laboratories which would increase reproducibility, requiring annotation of microarray data provided in databases - the minimal information about a microarray experiment (MIAME) standards, and developing computer software allowing microarray data to be exchanged between laboratories 
(Brazma et al, 2001 ). With these improvements looming in the not-so-distant future, microarrays should prove to be an extremely useful tool in the quest for understanding gene-environment interactions.

\section{- Global Transcriptional Analysis - MPSS and SAGE}

Although DNA microarrays are the most common way to examine transcription on a global scale, MPSS and SAGE offer certain advantages over the DNA microarray. The SAGE technique relies on a set of gene-specific probes complexed with streptavidin beads, each containing a specific tag sequence. The probes and tag sequences are cleaved from the beads by restriction enzymes and combined to form a unique set of markers for each transcript. The transcripts are subjected to PCR and sequenced to determine their identity (Velculescu et al, 1995). A SAGEmap database has been developed for the dissemination of SAGE data (See Fig. 1) (Lash et al, 2000). Another technique, MPSS, is very similar to SAGE. The designers of MPSS have generated a large set of microbeads, each containing a unique tag attached to a gene-specific probe. The beads containing the tag-probe complex are then mixed with RNA, allowing for hybridization between the RNA and its specific tag-probe complex, and placed into a flow cell where up to a million transcripts can be sequenced simultaneously (Brenner et al, 2000).

There are a few advantages to using the SAGE or MPSS approaches over microarrays. One advantage is that SAGE and MPSS are thought to be more sensitive than microarrays. They can detect very low levels of transcripts in a system, whereas microarray experiments may tend to omit some of these low level transcripts. Since the quantitation of MPSS relies on counting the number of beads with a specific tag instead 
of hybridizations between a probe and target DNA that may or may not be absolute, the statistical analysis of MPSS is far more robust than that of DNA microarrays (Brenner et al, 2000). MPSS is also a much faster technique for global transcriptional analysis than SAGE, since a million transcripts can be sequenced at a time. MPSS also simplifies many of the steps required for preparing a DNA microarray experiment, thus reducing the margin of error in an MPSS experiment.

\section{Current Technology - siRNA}

siRNA can also be very useful for the elucidation of signaling pathways induced by different environmental agents, particularly now that the complete human genome sequence is available. RNA interference (RNAi) is a naturally occurring mechanism in which the presence of dsRNA can lead to gene silencing through siRNA intermediates. siRNAs are 21-23 base pair sequences that are created from larger dsRNA molecules by an enzyme of the RNase III family called Dicer. The siRNA fragments then associate with a nuclease complex termed the RNA-induced silencing complex (RISC). RISC unwinds the siRNA fragments and allows the single-stranded fragment to target complementary RNA inside a cell, which somehow activates the nuclease activity of the RISC complex (reviewed in Ambion, 2003).

RNAi was first discovered in the worm, and has been a commonly utilized technique in the invertebrate world (Fire et al, 1998; Zamore, 2001). Until recently, RNAi was thought to be an application that could only be used in invertebrate studies, since a double stranded RNA greater than 30 base pairs in length seemed to activate the PKR kinase anti-viral mechanism and induce apoptosis in mammalian cells (Ambion, 
2003; Zamore, 2001). However, it was recently discovered that the 21-23 nucleotide siRNA fragments could bypass the apoptotic mechanism and produce a gene-silencing effect in mammalian cells (Elbashir et al, 2001). Although the precise details of the mechanism of siRNA-silencing are not entirely known, it is still an extremely useful laboratory technique. The short siRNA fragments can be synthetically produced by silencing vectors, and transfected into mammalian cells, resulting in a decrease of a specific protein from the system (Elbashir et al, 2001). An advantage of siRNA over the conventional practice of over-expressing dominant-negative mutants in cellular systems, is that the siRNA removes endogenously expressed mRNA. This method is also much easier than creating knockout mutations in cell lines, since it requires only the synthesis of siRNA fragments and a transfection.

Several labs have recently suggested that siRNA technology could have clinical applications, such as the inhibition of HIV-1 replication, in addition to its research applications (Jacque et al, 2002; Novina et al, 2002). Capodici et al. have shown that they can inhibit HIV-1 infection and replication by transfecting primary $\mathrm{CD} 4^{+} \mathrm{T}$ cells with HIV-1 specific siRNA (Capodici et al, 2002). In addition, Qin et al. have developed a lentiviral-mediated delivery system for siRNA complementary to CCR5 mRNA, the main HIV-1 co-receptor in primary $\mathrm{CD}^{+} \mathrm{T}$ cells (Qin et al, 2003). This application seems to lead to the prevention of HIV-1 infection, mimicking the natural immunity to HIV-1 seen in individuals who lack both CCR5 co-receptor genes (Qin et al, 2003; Dean et al, 1996). Future siRNA research utilizing approaches such as these, could lead to the use of siRNA and retroviral gene therapy applicable not only to HIV-1 infection, but to environmentally-induced disease states as well. 
siRNA could become a very powerful tool for the environmental health research community. Once the sequence of a particular gene that responds to an environmental toxin is known, siRNA can be easily exploited to reveal the consequences of removing that protein from a cellular system. Other suggested uses for the siRNA technology that could benefit environmental health research include the development of siRNA chips. These chips would consist of an array of unique siRNA probes fixed to a tissue culture slide. Cells could then be grown on these chips to show a range of siRNA suppression based on the siRNA vector the cell takes up, allowing for a high-throughput format for siRNA studies (Zamore, 2001). In addition, a new type of ssRNA, termed microRNA (miRNA) or small temporal RNA (stRNA), is thought to function in translation suppression. These ssRNA molecules may be useful for genetic-silencing experiments as well (Zamore, 2001; Dennis, 2002).

\section{Emerging Technology-Peptide/Protein Microarrays}

With the recent push towards high throughput technology, it only seems natural that peptide arrays would follow the advent of DNA microarrays. The set up of a peptide microarray is very similar to that of a DNA microarray. In both cases, a set of unique probes, or capture agents, are attached to a glass slide, or some other form of solid support system. The main difference between the two assays is the type of capture agent that is attached to the slide. In the protein microarray, the capture agent can range from antibodies, epitopes, and small molecules to sets of recombinant proteins (Tyers and Mann, 2003). On the contrary, cDNA or oligonucleotide probes are used in DNA microarrays. The different probes in a protein microarray are chosen depending on what 
type of assay the researcher wants to run. Examples of peptide microarray assays include binding assays, enzymatic activity assays, protein identification assays, and cell adhesion assays (Reimer et al, 2002; MacBeath, 2002).

One potential application of a protein microarray is the enzymatic kinase assay. In this assay, a purified ${ }^{32} \mathrm{P}$-labeled kinase can be applied to an array utilizing peptides as capture agents. Each protein probe that is phosphorylated by that specific kinase would then bear the radio-label (MacBeath and Schreiber, 2000). Alternative uses of the protein microarray include the use of antibody probes, which could detect specific proteins from a mixed solution of total protein isolated from a test subject (Belov et al, 2001). The development of yet another peptide microarray assay includes the placement of different proteins onto the glass slide and washing the slide with a mixture of differentially fluorescent labeled proteins in order to determine protein binding interactions (MacBeath and Schreiber, 2000). Assays such as these could advance the discovery of biomarkers important for the identification of diseased-state phenotypes. These assays may also help elucidate exciting new protein-protein interactions.

Although peptide microarray technology is still in its infancy, the advantages are apparent. In particular, the arrays offer a high-throughput advantage over traditional methods such as yeast-two hybrid screens, fluorescence resonance energy transfer (FRET), and the traditional biochemical assays coupled to mass spectrometric analysis (reviewed in Phizicky et al, 2003). Protein microarrays can also help fill in the gaps left by DNA microarrays, since DNA arrays are indifferent to some forms of genetic regulation, such as post-translational regulation and protein degradation. The development of solid protein profiling techniques and applications would allow 
researchers to supplement the information gained through DNA microarray studies. In addition, a global analysis of the entire proteome could lead to the quick discovery of protein-protein interactions that may have taken years to notice with a small scale approach.

Currently, however, it is not yet technically possible to determine the entire content of a proteome with a protein microarray. Several complicating factors, such as the existence of unknown differential splice variants and post-translational regulation events undergone by many proteins, make it difficult to develop capture agents for these currently unknown proteins. Difficulties also arise during the production of the capture agents that are needed to specifically interact with only a single protein. Another disadvantage of protein arrays that measure specific binding to a set of capture agents is that attachment to the slide must not alter the structure or function of the capture agents (MacBeath, 2002). Yet another issue relates to the difficulty of synthesizing the proteins on the glass slide, possibly creating a bias as to which proteins get studied, e.g. the easiest ones to synthesize on the slide. Other concerns have been voiced about the difficulties of miniaturizing the protein microarrays while maintaining sensitivity and the need for algorithms that are advanced enough to handle a protein array format.

One of the most important issues of implementing protein microarrays is the difficulty in producing large numbers of highly pure recombinant proteins. However, recent advances in protein complex purification involving the tandem affinity purification method combined with RNAi (known as iTAP) by Forler et al. are a step in the right direction (Forler et al, 2003). The sequence of the human genome may also help to remediate this shortcoming by allowing the development of a perfectly normalized 
human cDNA clone library spanning the entire proteome. In fact, the FlexGene Consortium has recently announced their mission to develop a complete cDNA collection specifically for this purpose (Tyers and Mann, 2003).

New advances in nanotechnology may also help to overcome many of the technical issues with the newly developing protein arrays. Some of these new advances include the research of Ouyang and colleagues, who have demonstrated a soft-landing mass-spec technique to separate protein mixtures and spot proteins in a microarray format. An array of proteins was created by their soft-landing technique that allowed proteins to retain their biological activity (Oyuang et al, 2003). Other advances in nanotechnology that may assist protein array implementation include the development of new protein capture agents, such as the mixed-element capture agents (MECAs) developed by Bachhawat-Sikder and Kodadek. MECAs comprised of two small proteins attached together with a variable linker region and were shown to bind their target molecules with high affinity and sensitivity, making them good candidates for protein array capture agents (Bachhawat-Sikder and Kodadek, 2003).

Despite the immaturity of peptide microarray technology, results from primitive protein array assays have already indicated the usefulness and incredible versatility of the assay. Analogous applications to those of DNA microarrays, such as using protein profiling to obtain a characteristic fingerprint of a single disease, have already been developed. In fact, protein microarray profiling has recently been used to fingerprint different leukemia types, which may someday become a widely used diagnostic tool (Service, 2003; Belov et al, 2001). In addition to fueling new research applications, protein profiling could soon take its place next to the DNA microarray as a new 
diagnostic tool. Together with DNA microarray technology, peptide microarrays may also help to revolutionize many aspects of the health care field, including applications to diagnostics and assistance with the personalization of disease treatment.

\section{$\underline{\text { Biosecurity and Bioterrorism }}$}

We have all probably noticed the increased attention focused on bioterrorism in the United States since the attacks of September 11, 2001 and the subsequent reports of inhalation anthrax in October, 2001 (Jernigan et al, 2001). Traditionally, biowarfare research has mainly been conducted by military scientists in government facilities. However, in 2003 alone, approximately $\$ 1.75$ billion has been poured into biological weapons research, much of which is being allocated to the private and academic sectors to develop biowarfare research programs and facilities (Fauci, 2002). Biosecurity and bioterrorism are a definite concern for the environmental health research community. In response to the increasing threat of the use of biological and chemical weapons in a terrorist attack, the Centers for Disease Control and Prevention (CDC) has compiled a list of biological agents that would most likely be used in a terrorist attack (Rotz et al, 2002) (See Table 1). The dissemination of aerosolized particles of many of these agents into the environment is considered to be extremely dangerous. Therefore, it is the responsibility of environmental health researchers to help develop new methods of detecting chemical-biological (CB) agents and aide in the advancement of toxicology and genetic interaction studies pertaining to novel vaccines and treatments. 


\section{Preparedness in the Case of a CB Attack}

In the past, emphasis has been placed on the ability of health care facilities to communicate with each other and coordinate treatments in the event of a CB attack. Such emphasis has prompted the development of many new training and preparedness programs, including preparedness programs at the state and federal levels and nongovernmental professional programs, such as the Clinicians' Biodefense Network (CBN). The CBN aims to link clinicians to health experts and biomedical researchers, allowing for rapid communication and the distribution of updated information concerning biodefense during times of crisis (Radonovich, 2002). However, education and preparedness of healthcare workers is not enough to protect the mass population.

Today, more emphasis has been placed on developing countermeasures in the event of a biological attack, and there has been an overwhelming push by the government and the public for further research into biosecurity efforts. It thus follows, that the determination of the gene-environment interactions that can occur in response to biological or chemical weapon attacks should be a major priority in the environmental health research community. The development of rapid and standard laboratory tests detecting exposure to a specific kind of $\mathrm{CB}$ agent that could be widely and economically distributed to health care facilities would greatly enhance our ability for the early detection and response to certain types of potential attacks. Candidate assays for these tests include the identification of specific biomarkers for exposure to $\mathrm{CB}$ weapons. Biomarkers could easily be assayed for changes in exposed victims and would greatly aid in the early clinical recognition of such an attack. With the recent anthrax attacks, an early screening method for potential biomarkers specific to anthrax infection applied to 
all who were suspected of anthrax exposure would have improved the ability of the nation's public health system to respond, and in turn could have possibly saved lives and prevented the needless distribution of large amounts of Cipro (ciprofloxacin, the antibiotic used to treat anthrax infections) (Jernigan et al, 2001; Rosenberg, 2003). With the information gained from the completion of the human genome sequence, and the multitude of emerging technologies available, there are many opportunities for the exploration of bioterrorism countermeasures.

\section{Preparedness in Case of a CB Terrorist Attack-Mass Vaccination}

Many of the vaccines and treatments used to prevent the spread and disease manifestations of potential bioterrorism agents were manufactured over 20 years ago; in the case of the smallpox virus, the vaccine used to eradicate the disease in 1980 is the only currently available vaccination (Lofquist et al, 2003; Fauci, 2002; WHO, 1980). Previous data has suggested that a smallpox outbreak would spread slowly (Eichner and Dietz, 2003). The current recommended public health response to a smallpox outbreak is a ring vaccination strategy in which individual cases are isolated, quarantined, and their contacts vaccinated (Whitley, 2003). However, some scientists have shown that this approach may not be as effective as an immediate mass vaccination in the event of a biological attack on an urban center (Kaplan et al, 2002), suggesting that new strategies should be considered.

Several setbacks have surfaced during discussions concerning vaccination to protect the mass population in the event of a biological attack. One of the most important is the lack of interest from pharmaceutical companies to develop and produce vaccines 
for biological warfare agents. Most of the larger companies are unwilling to develop these vaccines because of financial concerns, liability issues, efficacy questions, and regulatory limitations (Rosenthal and Clifford, 2002; Langford and Myers, 2002). Another concern is the high rate of complications in the vaccines that have been licensed and are used exclusively in the military, but not in the general public. The high occurrence of adverse effects in such a small population (reported to be $>30 \%$ in some instances) suggests that the benefits of vaccination in the case of a potential threat may not outweigh the risks of vaccine complications (Frey et al, 2002). However, identification of SNPs in certain populations via microarray analysis may help to determine which subset of the population should not be vaccinated in preparation for a biological attack. The identification of these individuals would result in a decrease in the number of unnecessary complications/deaths that could occur in the event of a mass vaccination, should a bioterrorism situation arise. Other measures would need to be taken to protect these individuals. Although the United States currently has licensed vaccines for smallpox and anthrax, it does not have these for many of the other agents listed as potential biological warfare agents by the CDC and researchers are working fervently to develop them (See Table 1). Newly developed Ebola vaccines have recently been shown to protect mice, guinea pigs, and non-human primates from lethal doses of the virus (Vanderzanden et al, 1998; Xu et al, 1998; Sullivan et al, 2000).

In addition to vaccination, other methods of preparedness have been discussed. Recently, a set of guidelines has been published by the CDC's National Institute for Occupational Safety and Health (NIOSH), outlinining the procedures building officials should follow to protect private, public, and government buildings from chemical, 
radiological, and biological terrorism (NIOSH, 2002). A second set of guidelines has been published by the Office of Health and Safety to ensure laboratory security and emergency response preparedness for laboratories that work with CB agents deemed fit for terrorist attacks (Richmond and Nesby-O'Dell, 2002). In order to further protect building environments from a CB attack, engineers have also been trying to develop a set of biomaterials that can metabolize $\mathrm{CB}$ agents. The approach is designed to allow the incorporation of these materials into equipment, such as the countertops of an office building or the sorting machines used in post offices (reviewed in Russell et al, 2003). The development of such materials combined with the protective measures outlined by NIOSH and OHS could allow for widespread protection from attacks in almost any building or environment, while diminishing public fear of an attack.

\section{Early Detection of CB Agents in the Environment}

Although much has been discussed concerning early disease recognition, improved surveillance/communication methods, and the limitation of potentially sensitive scientific information (Zilinskas and Tucker, 2002; Atlas et al, 2003; Chyba, 2001; Kwik et al, 2003), less has been suggested concerning our ability to detect a CB attack before clinical disease is recognized in victims. The early detection of the agent itself in the environment, which could help prevent the spread of the infection in the case of a biological attack and limit the number of victims affected by the agent, would be more advantageous than the early detection of diseases caused by these agents.

One of the most effective ways to deliver a biological weapon is the release of aerosolized particles into the environment. Implementing a biological agent monitoring 
system that can detect a CB agent by sampling the air would greatly enhance our ability to evacuate enclosed areas deemed ideal for CB attack (Wyatt, 2002). Testing has recently begun at San Francisco International Airport for one of the first CB agent defense systems (Larkin, 2003). The system, known as PROACT (Protective and Response Options for Airport Counter-Terrorism) and produced by Sandia National Laboratories in Livermore, CA, is designed to monitor the air at large indoor public meeting areas for CB agents as a measure to deter chemical attacks such as the 1995 sarin attack in the Tokyo subway system (Frischknecht, 2003; Larkin, 2003). Details of the mechanism of action of the device have not yet been disclosed. However, if it proves to be reliable, the device may spread to other airports across the nation.

Immunological methods to detect biological warfare agents are also being investigated for use in an early warning detection system. A miniature biochip system based on an ELISA assay has recently been developed by Stratis-Cullum et al. In this system, air samples containing aerosolized spores of Bacillus globigii were applied to a minature ELISA biochip, where a novel alkaline phosphatase substrate, dimethylacridinone phosphate (DDAO-P) was cleaved by an alkaline phosphatase (AP) enzyme (Stratis-Cullum et al, 2003). The DDAO formed as a result of AP cleavage can be excited by a miniature diode laser and the voltage output read on a laptop computer. Although this highly sensitive, portable device was used for the detection of B. globigii spores, it could be used to detect other aerosolized forms of biological weapons.

Another immunoassay, the multiplexed liquid array, has been shown to be useful in the simultaneous detection of many different biological agents (McBride et al, 2003). McBride and colleagues used a set of polystyrene microbeads conjugated to biowarfare 
agent-specific antibodies, each of which displays a unique spectral pattern. Once the microbeads are exposed to antigen, a secondary antibody conjugated to the fluorescent reporter phycoerythrin (PE) is applied, and the beads are assayed in a flow cytometer. The presence of the unique spectral pattern detects the type of antibody that reacted with a biowarfare agent, while the PE is detected simultaneously to quantify the amount of agent present in the air. These types of assays are candidates for use in early warning detection systems because they are rapid, easily detected, and are part of a portable unit.

\section{Environmental Health Research, the Human Genome Project, and Biosecurity}

The DNA microarray and protein microarray applications discussed previously can also be applied to bioterrorism. These techniques can be useful in leading us towards unique physiological responses that may occur when an individual has been exposed to these agents, providing scientists with a much narrower spectrum of therapeutic targets to focus on during their research. The genomes of several potential biowarfare agents have already been sequenced, including that of Bacillus anthracis (Read et al, 2003).

Microarrays have already been used to study the effects of the $B$. anthracis virulence factors $\operatorname{atx} A$ and $\operatorname{acp} A$. These studies suggest that atx $A$ is a global regulator of many new genes that could potentially exhibit virulence effects (Bourgogne et al, 2003). By treating human protein arrays with a mixture of proteins from a biowarfare agent, one could infer interactions between the proteins of the agent and human proteins, leading to new drug targets, new signaling pathways, and new routes of infection. Implementing the use of databases containing collections of array data would allow the expression effects of these agents to be cross-referenced, possibly leading to the identification of a few candidate 
therapeutic targets that could be used for the treatment of diseases induced by CB agents. As suggested earlier, microarrays may also prove to be important in the identification of novel or weaponized infectious agents. Microarrays played a large role in the identification and characterization of the Severe Acute Respiratory Syndrome (SARS) coronavirus that plagued China, Canada, and Vietnam, among others (Ksiazek et al, 2003). Additional applications include the use of microarrays to differentiate between a large spectrum of possible viral infections and to determine the genotype of these pathogens (Wang et al, 2002).

\section{Novel Treatments in a CB attack}

In addition to being concerned about preparedness in the case of an attack, novel treatments of diseases caused by such CB agents should be thoroughly investigated. One of the easiest ways to weaponize a bacterial strain for use in a biological warfare attack is to engineer antibiotic resistance genes into the strain. Since this is not an extremely difficult task, the need for non-antibiotic treatment of weaponized strains of biological agents is an important matter. A novel approach to treating victims of a CB attack, developed by Fischetti, is the use of purified bacteriophage lysins to specifically lyse targeted bacteria, including those exhibiting antibiotic resistance. Fischetti's group demonstrated that PlyG, a gamma phage lysin specifically targeting B. anthracis, effectively killed spores in vivo. PlyG treated mice had a $72 \%$ survival rate versus a $10 \%$ survival rate for untreated mice (Fischetti, 2003). In addition to the bacterial lysin approach, it may also be possible to deliver siRNA through a viral gene therapy 
mechanism as a therapeutic countermeasure to interfere with an agent's ability to replicate.

\section{Future Directions}

In order for scientists to get the maximum benefit from the current technology available, significant technological and organizational improvements must be made. Advanced software is required for bioinformaticians to accurately recognize common binding domains, promoter regions, and transcriptional regulatory elements. The development of user-friendly, organized databases providing DNA and RNA sequences, protein interactions, protein structures with correct annotations, microarray data, and a variety of animal genome sequences appear necessary to solve the puzzle of signaling pathways, which can have profound effects on human disease states.

There are also many different forms of data that need to be explored on a multilevel scale. Genomes, transcriptomes, proteomes, and metabolomes are not separate entities and each -omic level must be taken into consideration when integrating the different types of information available. For example, many proteins are multi-functional and may act at the level of transcription as well as participating in a cellular signaling cascade. We must be able to view each piece of information from a global standpoint.

With the surge in the development of new techniques and fields of expertise, the environmental health research community can use the information provided by the genetic code to its advantage. The improved identification of environmentally hazardous agents via gene and protein expression analysis as a diagnostic tool in health care facilities could soon become a reality, allowing for better assessment of environmentally 
induced health risks and ultimately more accurate treatments. The elucidation of biological responses to toxic environmental agents and the mechanisms by which these agents cause cellular damage may aid in developing new drug targets and/or novel therapeutic options. Transcriptome expression patterns could soon be identified for individual toxicants and stressors, which may improve exposure assessment methods. Additionally, the discovery of new biomarkers activated in response to environmentally hazardous agents and the use of array expression analysis may soon be indispensable tools for diagnosing a disease, determining its stage, predicting its course, and thus dictating its treatment on an individual basis. The identification of susceptibility factors through SNP screening could lead to a better assessment of risk factors for potentially susceptible individuals and possibly even lead to prevention of adverse effects or even some diseases altogether.

\section{Concluding Remarks}

In conclusion, the elucidation of a first draft of the human genome sequence has provided the environmental health research community with a wealth of information and a genetic framework that can greatly contribute to our understanding of geneenvironment interactions. Determining the actual extent of polymorphisms and assigning function to the remaining $40 \%$ of predicted proteins with unknown molecular function (Venter et al, 2001), are only a few examples of the challenges still ahead. However, with the current information available and by using these new techniques and the expertise of those involved in the emerging fields of environmental health research, we can close in on our common goal of providing the world with better treatments and 
knowledge to prevent the atrocious diseases that can result from exposure to harmful environmental factors.

\section{Acknowledgements}

We would like to thank Dr. Jose Centeno of the Armed Forces Institute of Pathology and Matthew Hirsch of West Virginia University for their comments and suggestions regarding this manuscript. 


\section{Figures and Tables}

\section{Figure 1: Webguide to Bioinformatics Sites and Useful Database Links}

Bioinformatics Sites

HGP Timeline

Environmental Genome Project

NCBI Gene Expression Omnibus Database

FlexGene Consortium cDNA database

NCBI Genome Resources

University of Southern California Genome Bioinformatics

Cancer Genome Anatomy Project

HyperCLDB - Cell Line Database

Gene Ontology Consortium

\section{SNP Sites}

dbSNP

SNP Consortium Database

rSNP Guide

Debbie Nickerson Lab SNP catalogs

Proteomics and Structural Genomics Sites

Entrez Molecular Modeling Database

ModBase Database

Ann Stock Lab - Structural Genomics Links

Protein Structure Initiative

ExPASy Molecular Biology Server

RCSB Protein Data Bank

Danish Cancer Society - 2D Protein Database

Philip Andrews Lab - Proteomics Links

TRANSFAC - Transcription Factor Database

\section{Pharmacogenomics Sites}

HGP - Pharmacogenomics

Pharmacogenomics and Pharmacogenetics Knowledge Base
http://www.ornl.gov/TechResources/Human Genome/project/timeline.html http://www.niehs.nih.gov/envgenom/home.htm

http://www.ncbi.nlm.nih.gov/geo

http://www.hip.harvard.edu

http://www.ncbi.nlm.nih.gov/genome/guide/mouse/

http://genome.ucsc.edu

http://cgap.nci.nih.gov

http://www.biotech.ist.unige.it/cldb/indexes.html

http://www.geneontology.org

http://www.ncbi.nlm.nih.gov/SNP

http://snp.cshl.org

http://www.mgs.bionet.nsc.ru/mgs/systems/rsnp/

http://droog.mbt.washington.edu

http://www.ncbi.nlm.nih.gov/entrez/query.gcfi?db=Structure

http://guitar.rockefeller.edu/modbase

http://stock.cabm.rutgers.edu/links/

http://www.structuralgenomics.org/

http://us.expasy.org/

http://www.rcsb.org/pdb/

http://proteomics.cancer.dk/

http://www.proteome.med.umich.edu/andrewslab/links/proteomics.htm

http://www.gene-regulation.com/

http://www.ornl.gov/TechResources/Human Genome/medicine/pharma.html http://www.pharmgkb.org/index.jsp 


\section{Toxicogenomics Sites}

Toxicogenomics Research Consortium

National Center for Toxicogenomics Microarray Group

Toxicology and Environmental Health

\section{Comparative Genomics and Systems Biology Sites}

Harvard-Lipper Center for Computational Genetics

Princeton Model Organism Virtual Libraries

ENTELOS - Virtual Obesity Model

Virtual Heart Project

Mouse Genome Informatics

Ensembl Mouse Genome Server

The Jackson Lab - Mouse Informatics

Harwell Mouse Informatics

RIKEN Mouse Informatics

\section{Microarray Sites}

The Brown Lab Microarray Database

Microarray Gene Expression Database (MGED)

Stanford Microarray Database

Microarray Gene Expression Data (MGED) Society

Telechem International E-Library

The Institute for Genimic Research (TIGR)

TIGR Microarray Software Suite

TIGR Gene Indices

TIGR Microarray Tools

MIAMExpress

The Churchill Lab Microarray Statistical Software

MIAME Checklist

\section{SAGE and MPSS Sites}

NCBI's SAGEmap

Arabidopsis MPSS Database http://www.niehs.nih.gov/dert/trc/home.htm

http://www.niehs.nih.gov/nct/nmc.htm

http://www.sis.nlm.nih.gov/Tox/ToxMain.htm/

http://arep.med.harvard.edu

http://www.molbio.princeton.edu/scientific.php

www.entelos.com

www.physiome.org

http://www.ensembl.org/Mus musculus/

http://www.informatics.jax.org

http://www.har.mrc.ac.uk/

http://genome.rtc.riken.go.jp/

http://cmgm.stanford.edu/pbrown/index.html

http://www.mged.org

http://genome-www5.stanford.edu/MicroArray/SMD

http://www.mged.org

http://arrayit.com/e-library/

http://www.tigr.org

http://www.tigr.org/software/tm4

http://www.tigr.org/tdb/tqi

http://pga.tigr.org/tool.shtml

http://www.ebi.ac.uk/miamexpress/

http://www.jax.org/staff/churchill/labsite/software/index.html

http://www.mged.org/Workgroups/MIAME/miame checklist.html

http://www.ncbi.nlm.nih.gov/SAGE/

http://mpss.udel.edu/at/java.htm 
Table 1: CDC's List of Potential Biological Warfare Agents ${ }^{1}$

\begin{tabular}{ll}
\hline Category A & Category B \\
\hline Bacillus anthracis & Brucella species \\
Clostridium botulinum toxin & Clostridium perfringens $\varepsilon$-toxin \\
Yersinia pestis & Food Safety Threats (i.e. Salmonella \\
Variola major (Smallpox) & species, E. coli O157:H7, and Shigella) \\
Francisella tularensis & Burkholderia mallei \\
Viral Hemorrhagic fevers (i.e. Ebola, & Burkholderia pseudomallei \\
Marburg, Lassa, and Machupo) & Chlamydia psittaci \\
& Coxiella burnetii \\
& Ricin toxin \\
& Staphylococcal enterotoxin B \\
& Rickettsia prowazekii \\
& Viral encephalitis (i.e. alphaviruses) \\
& Water Safety Threats (i.e. Vibrio cholerae, \\
Nipah virus and hantavirus. & and Cryptosporidium parvum) \\
& \\
19dapted from the CDC website at www.bt.cdc.gov/agent/agentlist-category.asp
\end{tabular}




\section{$\underline{\text { References }}$}

Adams, M.D. et al. 2000. The genome sequence of Drosophila melanogaster. Science 287:2185-2195.

Altman, R.B., and Klein, T.E. 2002. Challenges for biomedical informatics and pharmacogenomics. Annu. Rev. Pharmacol. Toxicol. 42:113-133.

Altshuler, D., Pollara, V.J., Cowles, C.R., Van Etten, W.J., Baldwin, J., Linton, L., and Lander, E.S. 2000. An SNP map of the human genome generated by reduced representation shotgun sequencing. Nature 407:513-516.

Ambion, Inc. 2002. RNA interference and gene silencing - history and overview. http://www.ambion.com/hottopics/rnai Acessed 12/2/2003.

Arabidopsis Genome Initiative. 2000. Analysis of the genome sequence of the flowering plant Arabidopsis thaliana. Nature 408:796-815.

Atlas, R. et al. 2003. Statement on the consideration of biodefence and biosecurity. Nature 421:771 
Bachhawat-Sikder, K., and Kodadek, T. 2003. Mixed-element capture agents: a simple strategy for the construction of synthetic, high-affinity protein capture ligands. J. Am. Chem.Soc. 125:9550-9551.

Barchowsky, A., and O’Hara, K.A. 2003. Metal-induced cell signaling and gene activation in lung diseases. Free Radic. Biol. Med. 34:1130-1135.

Bass, B.L. 2001. The short answer. Nature 411:428.

Bassingthwaighte, J.B. 2000. Strategies for the physiome project. Ann. Biomed. Eng. 28:1043-1058.

Belov, L., de la Vega, O., dos Remedios, C.G., Mulligan, S.P., and Christopherson, R.I. 2001. Immunophenotyping of leukemias using a cluster of differentiation antibody microarray. Cancer Res. 61:4483-4489.

Brazma, A. et al. 2001. Minimum information about a microarray experiment (MIAME) - toward standards for microarray data. Nat. Genet. 29:365-371.

Brenner, S. et al. 2000. Gene expression analysis by massively parallel signature sequencing (MPSS) on microbead arrays. Nat. Biotech. 18:630-634. 
Brenton, J.D., Aparicio, S.A.J.R., and Caldas, C. 2001. Molecular profiling of breast cancer: portraits but not physiognomy. Breast Cancer Res. 3:77-80.

Buorgogne, A., Drysdale, M., Hilsenbeck, S.G., Peterson, S.N., and Koehler, T.M. 2003. Global effects of virulence gene regulators in a Bacillus anthracis strain with both virulence plasmids. Infect. Immun. 71:2736-2743.

C. elegans Sequencing Consortium. 1998. Genome sequence of the nematode $C$. elegans: a platform for investigating biology. Science 282:2012-2018.

Capodici, J., Kariko, K., and Weissman, D. 2002. Inhibition of HIV-1 infection by small interfering RNA-mediated RNA interference. J. Immunol. 169:5196-5201.

Chen, F., and Shi, X. 2002. Intracellular signal transduction of cells in response to carcinogenic metals. Crit. Rev. Oncol. Hematol. 42:105-121.

Chen, J., et al. 2003. MMDB: Entrez's 3D-structure database. Nucleic Acids Res. $31: 474-477$.

Chin, K-V., and Kong, A-N.T. 2002. Application of DNA microarrays inpharmacogenomics and toxicogenomics. Pharm. Res. 19:1773-1778. 
Churg, A., Brauer, M., del Carmen Avila-Casado, M., Fortoul, T.I., and Wright, J.L. 2003. Chronic exposure to high levels of particulate air pollution and small airway remodeling. Environ. Health Perspect. 111:714-718.

Chyba, C.F. 2001. Biological security in a changed world. Science 293:2349.

Collins, F.S., Guyer, M.S., and Chakravarti, A. 1997. Variations on a theme: cataloging human DNA sequence variation. Science 278:1580-1581.

Dean, M. et al. 1996. Genetic restriction of HIV-1 infection and progression to AIDS by a deletion allele of the CKR5 structural gene. Science 273:1856-1862.

Dennis, C. 2002. The genome's guiding hand? Nature 420:732.

D-Trends Bioinformatics. http://www.d-trends.com/Bioinformatics/bioinformatics.html Accessed 11/20/2003.

ENTELOS. 2003. PhysioLab® Technology. http://www.entelos.com/science/physiolabtech.html. Accessed 12/5/2003.

Environmental Genome Project: Environmentally Responsive Genes http://www.niehs.nih.gov/envgenom/egp6.htm Accessed 11/20/2003 
Environmental Genome Project: History http://www.niehs.nih.gov/envgenom/egp2.htm Accessed 11/20/2003

Environmental Genome Project: Overview

http://www.niehs.nih.gov/envgenom/egp3.htm Accessed 11/20/2003

Eichner, M., and Dietz, K. 2003. Transmission potential of smallpox: estimates based on detailed data from an outbreak. Am. J. Epidemiol. 158:110-117.

Elbashir, S.M., Harborth, J., Lendeckel, W., Yalcin, A., Weber, K., and Tuschl, T. 2001. Duplexes of 21-nucleotide RNAs mediate RNA interference in cultured mammalian cells. Nature 411:494-498.

Eriksson, M. et al. 2003. Recurrent de novo point mutations in lamin A cause Hutchinson-Gilford progeria syndrome. Nature 423:293-298.

Fauci, A.S. 2002. Bioterrorism: defining a research agenda. Food and Drug Law Journal 57:413-417

Fields, S., Kohara, Y., and Lockhart, D.J. 1999. Functional genomics. Proc. Natl. Acad. Sci. USA. 96:8825-8826. 
Fink, L. 1990. Five-year plan goes to capitol hill. Human Genome News 2(1)

http://www.ornl.gov/sci/techresources/Human_Genome/publicat/hgn/v2n1/04five.shtml Accessed 11/20/2003.

Fire, A., Xu, S., Montgomery, M.K., Kostas, S.A., Driver, S.E., and Mello, C.C. 1998. Potent and specific genetic interference by double-stranded RNA in Caenorhabditis elegans. Nature 391:806-811.

Fischetti, V.A. 2003. Novel method to control pathogenic bacteria on human mucous membranes. Ann. N.Y. Acad. Sci. 987:207-214.

Fodor, S.P., Rava, R.P., Huang, X.C., Pease, A.C., Holmes, C.P., and Adams, C.L. 1993. Multiplexed biochemical assays with biological chips. Nature 364:555-556.

Forler, D., Kocher, T., Rode, M., Gentzel, M., Izaurralde, E., and Wilm, M. 2003. An efficient protein complex purification method for functional proteomics in higher eukaryotes. Nat. Biotech. 21:89-92.

Frey, S.E. et al. 2002. Clinical responses to undiluted and diluted smallpox vaccine. $N$. Engl. J. Med. 346:1265-1274.

Frischknecht, F. 2003. The history of biological warfare. EMBO Rep. 4:S47-S52. 
Gambelunghe, A., Piccinini, R., Ambrogi, M., Villarini, M., Moretti, M., Marchetti, C., Abbritti, G., and Muzi, G. 2003. Primary DNA damage in chrome-plating workers. Toxicology 188:187-195.

Gerhold, D.L., Jensen, R.V., and Gullans, S.R. 2002. Better therapeutics through microarrays. Nat. Genet. 32 Suppl:547-552.

Goffeau, A. et al. 1996. Life with 6000 genes. Science 274:546-567.

Griffiths, J.R., and Stubbs, M. 2003. Opportunities for studying cancer by metabolomics: preliminary observations on tumors deficient in hypoxia-inducible factor 1. Adv. Enzyme Regul. 43:67-76.

Grody, W.W. 2003. Molecular genetic risk screening. Annu. Rev. Med. 54:473-490.

Gruvberger, S., Ringner, M., Chen, Y., Panavally, S., Saal, L.H., Borg, A., Ferno, M., Peterson, C., and Meltzer, P.S. 2001. Estrogen receptor status in breast cancer is associated with remarkably distinct gene expression patterns. Canncer Res. 61:59795984.

Hacia, J.G., and Collins, F.S. 1999. Mutational analysis using oligonucleotide microarrays. J. Med. Genet. 36:730-736. 
Hamadeh, H.K., Amin, R.P., Paules, R.S., and Afshari, C.A. 2002. An overview of toxicogenomics. Curr. Issues Mol. Biol. 4:45-56.

Hannon, G.J. 2002. RNA interference. Nature 418:244-251.

Heller, R.A., Schena, M., Chai, A., Shalon, D., Bedilion, T., Gilmore, J., Woolley, D.E., and Davis, R.W. 1997. Discovery and analysis of inflammatory disease-related genes using cDNA microarrays. Proc. Natl. Acad. Sci. USA 94:2150-2155.

Hodgkinson, A.D., Bartlett, T., Oates, P.J., Millward, B.A., and Demaine, A.G. 2003. The response of antioxidant genes to hyperglycemia is abnormal in patients with type I diabetes and diabetic nephropathy. Diabetes 52:846-851.

Hofmann, E. 2001. What can medicine learn from the human DNA sequence? Biochemistry 66:1144-1152.

Holm, L., and Sander, C. 1996. Mapping the Protein Universe. Science 273:595-603. Hunder, G., Javdani, J., Elsenhans, B., and Schumann, K. 2001. ${ }^{109}$ Cd accumulation in the calcified parts of rat bones. Toxicology 159:1-10.

Hooper, L.V., and Gordon, J.I. 2001. Commensal host-bacterial relationships in the gut. Science 292:1115-118. 
Huntington's Disease Collaborative Research Group. 1993. A novel gene containing a trinucleotide repeat that is expanded and unstable on Huntington's disease chromosomes. Cell 72:971-983.

Ideker, T., Thorsson, V., Ranish, J.A., Christmas, R., Buhler, J., Eng, J.K., Bumbarner, R., Goodlett, D.R., Aebersold, R., and Hood, L. 2001. Integrated genomic and proteomic analyses of a systematically perturbed metabolic network. Science 292:929934.

International Human Genome Sequencing Consortium. 2001. Initial sequencing and analysis of the human genome. Nature 409:860-921.

International SNP Map Working Group. 2001. A map of human genome sequence variation containing 1.42 million single nucleotide polymorphisms. Nature 409:928933.

Jacque, J-M., Triques, K., and Stevenson, M. 2002. Modulation of HIV-1 replication by RNA interference. Nature 418:435-438.

James, P. 1997. Protein identification in the post-genome era: the rapid rise of proteomics. Q. Rev. Biophys. 30:279-331. 
Jernigan, J.A. et al. 2001. Bioterrorism-related inhalational anthrax: the first 10 cases reported in the United States. Emerg. Infect. Dis. 7:933-944.

Kaplan, E.H., Craft, D.L., and Wein, L.M. 2002. Emergency response to a smallpox attack: the case for mass vaccination. Proc. Natl. Acad. Sci. USA 99:10935-10940.

Karp, P.D., Riley, M., Saier, M., Paulsen, I.T., Paley, S.M., and Pellegrini-Toole, A. 2000. The EcoCyc and MetaCyc databases. Nucleic Acids Res. 28:56-59.

Kitano, H. 2002. Computational systems biology. Nature 420:206-210.

Kolchinsky, A., and Mirzabekov, A. 2002. Analysis of SNPs and other genomic variations using gel-based chips. Hum. Mutat. 19:343-360.

Ksiazek, T.G. et al. 2003. A novel coronavirus associated with Severe Acute Respiratory Syndrome. N. Engl. J. Med. 348:1953-1966.

Kwik, G., Fitzgerald, J., Inglesby, T.V., and O’Toole, T. 2003. Biosecurity: responsible stewardship in an age of catastrophic terrorism. Biosecurity and Bioterrorism: Biodefense Strategy, Practice, and Science 1:27-35.

Lander, E.S. 1996. The new genomics: global views of biology. Science 274:536-539. 
Langford, M.J., and Myers, R.C. 2002. Difficulties associated with the development and licensing of vaccines for protection against bio-warfare and bio-terrorism. Dev. Biol. (Basel) 110:107-112.

Larkin, M. 2003. Chemical and bio-warfare detection system piloted at US airport. Lancet Infect. Dis. 3:260.

Lash, A.E., Tolstoshev, C.M., Wagner, L., Schuler, G.D., Strausberg, R.L., Riggins, G.J., and Altschul, S.F. 2000. SAGEmap: A public gene expression resource. Genome Res. 10:1051-1060.

Levy, G.G. et al. 2001. Mutations in a member of the ADAMSTS gene family cause thrombotic thrombocytopenic purpura. Nature 413:488-494.

Lindon, J.C., Nicholson, J.K., Holmes, E., and Everett, J.R. 2000. Metabonomics: metabolic processes studied by NMR spectroscopy of biofluids. Concepts in Magnetic Resonance 12:289-320.

Lofquist, J.M., Weimert, N.A., and Hayney, M.S. 2003. Smallpox: a review of clinical disease and vaccination. Am. J. Health-Syst. Pharm. 60:749-756.

Lois, C., Hong, E.J., Pease, S., Brown, E.J., Baltimore, D. 2002. Germline transmission and tissue-specific expression of transgenes delivered by lentiviral vectors. Science 295:868-872. 
MacBeath, G., and Schreiber, S.L. 2000. Printing proteins as microarrays for highthroughput function determination. Science 289:1760-1763.

MacBeath, G. 2002. Protein microarrays and proteomics. Nat. Genet. 32 Suppl:526532.

Maier, E. Hoheisael, J.D., McCarthy, L., Mott, R., Grigoriev, A.V., Monaco, A.P., Larin, Z., and Lehrach, H. 1992. Complete coverage of the Schizosaccharomyces pombe genome in yeast artificial chromosomes. Nat. Genet. 1:273-277.

Malaka, T., and Kodama, A.M. 1990. Respiratory health of plywood workers occupationally exposed to formaldehyde. Arch. Environ. Health 45:288-294.

Mattingly, C.J., Colby, G.T., Forrest, J.N., and Boyer, J.L. 2003. The Comparative Toxicogenomics Database (CTD). Environ. Health Perspect. 111:793-795.

McBride, M.T., Gammon, S., Pitesky, M., O’Brien, T.W., Smith, T., Aldrich, J., Langlois, R.G., Colston, B., and Venkateswaran, K.S. 2003. Multiplexed liquid arrays for simultaneous detection of simulants of biological warfare agents. Anal. Chem. 75:1924-1930. 
Medlin, J. 2002. Toxicogenomics Research Consortium sails into uncharted waters. Environ. Health Perspect. 110:A744-A747.

Mouse Genome Sequencing Consortium. 2002. Initial sequencing and comparative analysis of the mouse genome. Nature 420:520-562.

Muller, M., and Kersten, S. 2003. Nutrigenomics: goals and strategies. Nat. Rev. Genet. 4:315-322.

Nadon, R., and Shoemaker, J. 2002. Statistical issues with microarrays: processing and analysis. Trends Genet. 18:265-271.

National Center for Toxicogenomics: Toxicogenomics Research Consortium. http://www.niehs.nih.gov/nct/trc.htm Accessed 11/20/2003.

National Human Genome Research Institute. 2003. International consortium completes human genome project. http://www.genome.gov/11006929 Accessed 11/20/2003.

National Institute for Environmental Health: Introduction to NIEHS. http://www.niehs.nih.gov/external/intro.htm Accessed 11/20/2003.

National Institute for Occupational Safety and Health. Guidance for protecting building environments from airborne chemical, biological, or radiological attacks. Cincinnati, Ohio: U.S. Department of Health and Human Services, CDC, National Institute for 
Occupational Safety and Health, 2002; DHHS publication no. NIOSH2002-139.

Novina, C.D., Murray, M.F., Dykxhoorn, D.M., Beresford, P.J., Riess, J., Lee, S-K., Collman, R.G., Lieberman, J., Shankar, P., and Sharp, P.A. 2002. siRNA-directed inhibition of HIV-1 infection. Nat. Med. 8:681-686.

O’Hara, K.A., Klei, L.R., and Barchowsky, A. 2003. Selective activation of Src family kinases and JNK by low levels of chromium (VI). Toxicol. Appl. Pharmacol. 190:214223.

Ouyang, Z., Takats, Z., Blake, T.A., Gologan, B., Guymon, A.J., Wiseman, J.M., Oliver, J.C., Davisson, V.J., and Cooks, R.G. 2003. Preparing protein microarrays by soft landing of mass-selected ions. Science 301:1351-1354.

Payami, H., Lee, N., Zareparsi, S., Gonzales McNeal, M., Camicioli, R., Bird, T.D., Sexton, G., Gancher, S., Kaye, J., Calhoun, D., Swanson, P.D., and Nutt, J. 2001. Parkinson's disease, CYP2D6 polymorphism, and age. Neurology 56:1363-1370.

Pennie, W.D. 2000. Use of cDNA microarrays to probe and understand the toxicological consequences of altered gene expression. Toxicol. Lett. 112-113:473-477.

Pennie, W.D. 2002. Custom cDNA microarrays; technologies and applications. Toxicology 181-182:551-554. 
Pennisi, E. 2003. Reaching their goal early, sequencing labs celebrate. Science 300:409

Perou, C.M. et al. 2000. Molecular portraits of human breast tumors. Nature 406:747752.

Phizicky, E., Bastiaens, P.I.H., Zhu, H., Snyder, M., and Fields, S. 2003. Protein analysis on a proteomic scale. Nature 422:208-215.

Poirier, L.A., and Vlasova, T.I. 2002. The prospective role of abnormal methyl metabolism in cadmium toxicity. Environ. Health Perspect. 110 Suppl 5:793-795.

Ponomarenko, J.V., Orlova, G.V., Merkulova, T.I., Gorshkova, E.V., Fokin, O.N., Vasiliev, G.V., Frolov, A.S., and Ponomarenko, M.P. 2002. rSNP_Guide: an integrated database-tools system for studying SNPs and site-directed mutations in transcription factor binding sites. Hum. Mutat. 20:239-248.

Ponomarenko, J.V., Merkulova, T.I., Orlova, G.V., Fokin, O.N., Gorshkova, E.V., Frolov, A.S., Valuev, V.P., and Ponomarenko, M.P. 2003. rSNP_Guide, a database system for analysis of transcription factor binding to DNA with variations: applications to genome annotation. Nucleic Acids Res. 31:118-121. 
Qian, Y., Jiang, B-H., Flynn, D.C., Leonard, S.S., Wang, S., Zhang, Z., Ye, J., Chen, F., Wang, L., and Shi, X. 2001. Cr(VI) increases tyrosine phosphorylation through reactive oxygen species-mediated reactions. Mol. Cell Biochem. 222:199-204.

Qin, X-F., An, D.S., Chen, I.S.Y., and Baltimore, D. 2003. Inhibiting HIV-1 infection in human $\mathrm{T}$ cells by lentiviral-mediated delivery of small interfering RNA against CCR5. Proc. Natl. Acad. Sci. USA 100:183-188.

Raamsdonk, L.M. et al. 2001. A functional genomics strategy that uses metabolome data to reveal the phenotype of silent mutations. Nat. Biotech. 19:45-50.

Radonovich, L. 2002. Hopkins center to launch Clinicians' Biodefense Network. Biodefense Quarterly 4 (Autumn)

Rall, D.P., and Groopman, J.D. 1994. Workshop C: The ambient environment monitoring effects and initiating changes. Prev. Med. 23:554-555.

Read, T.D. et al. 2003. The genome sequence of Bacillus anthracis Ames and comparison to closely related bacteria. Nature 423:81-86.

Reimer, U., Reineke, U., and Schneider-Mergener, J. 2002. Peptide arrays: from macro to micro. Curr. Opin. Biotechnol. 13:315-320. 
Richmond, J.Y., and Nesby-O'Dell, S.L. 2002. Laboratory security and emergency response guidance for laboratories working with select agents. MMWR 51:1-8.

Rosenberg, B.H. 2002. Analysis of the anthrax attacks. http://www.fas.org/bwc/news/anthraxreport.htm Accessed 11/20/2003.

Rosenthal, S.R., and Clifford, J.C.M. 2002. Development of vaccines for bio-warfare agents. Dev. Biol. (Basel) 110:99-105.

Rotz, L.D., Khan, A.S., Lillibridge, S.R., Ostroff, S.M., and Hughes, J.M. 2002. Public Health Assessment of Potential Biological Terrorism Agents. Emerg. Infect. Dis. 8:225230.

Russell, A.J., Berberich, J.A., Drevon, G.F., and Koepsel, R.R. 2003. Biomaterials for mediation of chemical and biological warfare agents. Annu. Rev. Biomed. Eng. 5:1-27.

Schena, M., Shalon, D., Davis, R.W., Brown, P.O. 1995. Quantitative monitoring of gene expression patterns with a complementary DNA microarray. Science 270:467-470.

Service, R.F. 2003. Recruiting genes, proteins for a revolution in diagnostics. Science 300:236-239. 
Sleat, D.E., Donnelly, R.J., Lackland, H., Liu, C-G., Sohar, I., Pullarkat, R.K., and Lobel, P. 1997. Association of mutations in a lysosomal protein with classical Late-infantile Neuronal Ceroid Lipofuscinosis. Science 277:1802-1805.

Smigelski, E.M., Sirotkin, K., Ward, M., and Sherry, S.T. 2000. dbSNP: a database of single nucleotide polymorphisms. Nucleic Acids Res. 28:352-355.

Smith, D., Trennery, P., Farningham, D., and Klapwijk, J. 2001. The selection of marmoset monkeys (Callithrix jacchus) in pharmaceutical toxicology. Lab. Anim. $35: 117-130$.

Sorlie, T. et al. 2001. Gene expression patterns of breast carcinomas distinguish tumor sublasses with clinical implications. Proc. Natl. Acad. Sci. USA 98:10869-10874.

Staessen, J.A., Roels, H.A., Emelianov, D., Kuznetsova, T., Thijs, L., Vangronsveld, J., and Fagard, R. 1999. Environmental exposure to cadmium, forearm bone density, and risk of fractures: prospective population study. Lancet 353:1140-1144.

Stratis-Cullum, D.N., Griffin, G.D., Mobley, J., Vass, A.A., and Vo-Dinh, T. 2003. A miniature biochip system for detection of aerosolized Bacillus globigii spores. Anal. Chem. 75:275-280. 
Strausberg, R.L., and Finley Austin, M.J. 1999. Functional genomics: technological challenges and opportunities. Physiol. Genomics 1:25-32

Sullivan, N.J., Sanchez, A., Rollin, P.E., Yang, Z-Y., and Nabel, G.J. 2000.

Development of a preventive vaccine for Ebola virus infection in primates. Nature 408:605-609.

Tang, Y., Lu, A., Aronow, B.J., and Sharp, F.R. 2001. Blood genomic responses differ after stroke, seizures, hypoglycemia, and hypoxia: blood genomic fingerprints of disease. Ann. Neurol. 50:699-707.

Taylor, J., King, R.D., Altmann, T., and Fiehn, O. 2002. Application of metabolomics to plant genotype discrimination using statistics and machine learning. Bioinformatics 18 Suppl. 2:S241-S248.

Tsai, S-M., Wang, T-N., and Ko, Y-C. 1999. Mortality for certain diseases in areas with high levels of arsenic in drinking water. Arch. Environ. Health 54:186-193.

Tyers, M., and Mann, M. 2003. From genomics to proteomics. Nature 422:193-197.

Vanderzanden, L., Bray, M., Fuller, D., Roberts, T., Custer, D., Spik, K., Jahrling, P., Huggins, J., Schmaljohn, A., and Schmaljohn, C. 1998. DNA vaccines expressing either 
the GP or NP genes of Ebola virus protect mice from lethal challenge. Virology 246:134-144.

Velculescu, V.E., Zhang, L., Vogelstein, B., and Kinzler, K. 1995. Serial analysis of gene expression. Science 270:484-487.

Venter, J.C. et al. 2001. The sequence of the human genome. Science 291:1304-1351.

Wang, D., Coscoy, L., Zylberberg, M., Avila, P.C., Boushey, H.A., Ganem, D., and DeRisi, J.L. 2002. Microarray-based detection and genotyping of viral pathogens. Proc. Natl. Acad. Sci. USA 99:15687-15692.

Weinshilboum, R. 2001. Thiopurine pharmacogenetics: clinical and molecular studies of thiopurines methyltransferase. Drug Metab. Dispos. 29:601-605.

Wheeler, D.L., Church, D.M., Federhen, S., Lash, A.E., Madden, T.L., Pontius, J.U., Schuler, G.D., Schriml, L.M., Sequeira, E., Tatusova, T.A., and Wagner, L. 2003. Database resources of the National Center for Biotechnology. Nucleic Acids Res. 31:2833.

Whitley, R.J. 2003. Smallpox: a potential agent of bioterrorism. Antiviral Res. 57:712. 
Whitney, L.W., Becker, K.G., Tresser, N.J., Caballero-Ramos, C.I., Munson, P.J., Prabhu, V.V., Trent, J.M., McFarland, H.F., and Biddison, W.E. 1999. Analysis of gene expression in multiple sclerosis lesions using cDNA microarrays. Ann. Neurol. 46:425428.

Wilkins, M.R., Pasquali, C., Appel, R.D., Ou, K., Golaz, O., Sanchez, J.C., Yan, J.X., Gooley, A.A., Hughes, G., Humphery-Smith, I., Williams, K.L., and Hochstrasser, D.F. 1996. From proteins to proteomes: large scale protein identification by two-dimensional electrophoresis and amino acid analysis. Biotechnology (NY) 14:61-65.

Wolfberg, T.G., McEntyre, J., and Schuler, G.D. 2001. Guide to the draft human genome. Nature 409:824-826.

World Health Organization. 1980. Declaration of global eradication of smallpox. Wkly. Epidemol. Rec. 55:148.

Wyatt, P.J. 2002. Early warning and remediation: minimizing the threat of bioterrorism. Journal of Homeland Security (April).

Xu, L., Sanchez, A., Yang, Z-Y., Zaki, S.R., Nabel, E.G., Nichol, S.T., and Nabel, G.J. 1998. Immunization for Ebola virus infection. Nat. Med. 4:37-42. 
Yao, T. 2002. Bioinformatics for the genomic sciences and towards systems biology. Japanese activities in the post-genome era. Prog. Biophys. Mol. Biol. 80:23-42.

Ye, J., Wang, S., Leonard, S.S., Sun, Y., Butterworth, L., Antonini, J., Ding, M., Rojanasakul, Y., Vallyathan, V., Castranova, V., and Shi., X. 1999. Role of reactive oxygen species and p53 in chromium (VI)-induced apoptosis. J. Biol. Chem. 274:3497434980.

Yu, D., Watanabe, H., Shibuya, H., and Miura, M. 2003. Redundancy of radioresistant signaling pathways originating from insulin-like growth factor I receptor. J. Biol. Chem. 278:6702-6709.

Zamore, P.D. 2001. RNA interference: listening to the sound of silence. Nat. Struct. Biol. 8:746-750.

Zilinskas, R.A., and Tucker, J.B. 2002. Limiting the contribution of the open scientific literature to the biological weapons threat. Journal of Homeland Security (December) 


\section{SECTION III}

\section{Molecular mechanisms}

\section{of metal toxicity and carcinogenesis}




\begin{abstract}
Chronic exposure to many heavy metals and metal-derivatives is associated with an increased risk of cancer, although the mechanisms of tumorigenesis are largely unknown. Approximately 125 scientists attended the $3^{\text {rd }}$ Conference on Molecular Mechanisms of Metal Toxicity and Carcinogenesis and presented the latest research concerning these mechanisms. Major areas of focus included exposure assessment and biomarker identification, roles of ROS and antioxidants in carcinogenesis, mechanisms of metalinduced DNA damage, metal signaling, and the development of animal models for use in metal toxicology studies. Here we highlight some of the research presented, and summarize the conference proceedings.
\end{abstract}




\section{$\underline{\text { Introduction }}$}

The 3rd Conference on Molecular Mechanisms of Metal Toxicity and Carcinogenesis was held at the National Institute for Occupational Safety and Health (NIOSH) in Morgantown, West Virginia. Over 125 participants from 13 different countries gathered at NIOSH to present their research on September 12-15, 2004. This conference was the third meeting of metal researchers in the past 5 years, with previous conferences convening in 2000 and 2002. Major areas of research emphasized at the conference included metal epidemiology, identification of biomarkers, reactive oxygen species (ROS) production, antioxidant effects, induction of DNA damage/lesions, metalinduced signaling pathways, and animal exposure studies. Here, we summarize the conference proceedings and examine the future directions of research concerning the molecular mechanisms that facilitate metal-induced carcinogenesis.

\section{Epidemiological implications of metal exposure and the search for reliable biomarkers}

Many metals are considered essential trace elements and must be present in low concentrations in the human body in order for normal cellular function. However, altered concentrations or transition states of metals in the body are thought to lead to a wide range of deleterious conditions, especially an increase in cancer incidence. Increased metal exposure in humans can occur via ingestion, inhalation, dermal contact, and occupational exposure [1-4]. Although correlations between metal exposure and cancer are well documented, more research is still needed in order to determine the exact mechanisms of metal-induced carcinogenesis. Much of the metal toxicology and carcinogenicity data available are acquired in animal model systems, with few studies 
representing the effects of metals in humans. Therefore, several groups at the conference focused their research on the link between the level of metals in the human body and carcinogenesis. Puneet and colleagues presented work examining the role of metals in gallbladder carcinoma. Using atomic absorption spectrometry, they showed that the bile of gallbladder carcinoma patients contained higher concentrations of cadmium (Cd), chromium $(\mathrm{Cr})$, and lead $(\mathrm{Pb})$ than patients with other non-cancerous gallbladder diseases, such as gallstones.

Additionally, Puneet's group observed an increase in the expression of the metalexposure protection protein metallothionein (MT) in $70 \%$ of the gallbladder carcinoma patients. These results suggest that the body may concentrate these metals in the hepatobiliary system and lead to gallbladder carcinoma. This group also examined the lipid peroxidation profiles of gallbladder carcinoma patients in order to determine if a free radical-induced mechanism might be involved. They found a significant increase in the amount of a major lipid peroxidation product, 4-hydroxynonenal (4-HNE), in gallbladder carcinoma patients compared to patients with other non-cancerous gallbladder diseases. These results suggest that the formation of lipid peroxidation products in the gallbladder, induced by metal exposure and free radical generation, may be an underlying cause of tumorigenesis.

Many metals must be controlled by a tightly regulated homeostasis. Two such examples are copper $(\mathrm{Cu})$ and iron $(\mathrm{Fe})$, the accumulation of which results in oxidative stress-induced cellular damage $[5,6]$. Wilson's disease (WD) and primary hemochromatosis $(\mathrm{PH})$ are metal storage diseases which are associated with DNA damage in the liver. In $\mathrm{WD}$, a defect in a Cu-transporting ATPase results in the 
intracellular accumulation of $\mathrm{Cu}$ [7]. In $\mathrm{PH}, \mathrm{Fe}$ accumulates in the liver because of a mutation in the hfe gene, which is responsible for mediating the effects of the transferrin receptor [8]. Patients with both WD and $\mathrm{PH}$ are shown to exhibit increased oxidative stress-induced etheno-DNA adducts [9]. Vinyl chloride, urethane, and 4-HNE produce etheno-DNA adducts as well [10-12]. These adducts can subsequently lead to the formation of strong miscoding lesions and cause mutations and/or genomic instability in patients suffering from WD and PH. Nair and Bartsch further examined the correlation between the formation of 4-HNE-induced DNA adducts and susceptibility to the development of liver cancer. They found that both WD and PH patients exhibiting high 4-HNE-induced DNA adducts were the most susceptible to the development of liver cancer, particularly those patients suffering from $\mathrm{PH}$.

Conversely, the dietary deficiency of many micronutrients, such as certain trace metals, has also been associated with an increased risk of cancer [13-16]. Ansari et al. presented data suggesting that significantly lower levels of selenium (Se) and zinc ( $\mathrm{Zn})$ were found in the serum, biliary fluid, and gallbladder tissue of gallbladder carcinoma patients when compared to healthy individuals. Serum manganese $(\mathrm{Mn})$ was also reduced in gallbladder carcinoma patients, leading Ansari's group to conclude that a deficiency in these trace elements is also associated with gallbladder carcinoma.

Since animal studies assessing the effects of metal exposure can often be difficult to interpret and inconclusive due to the role of some metals as co-carcinogens, reliable biomarkers are needed in order to assess metal exposure in humans. A good candidate for a human biomarker must be specific to the effects of the causal agent and easily quantitated and/or assayed for its presence in a noninvasive manner. Several studies 
presented at the conference examined the reliability of biomarkers for metal exposure. Using atomic absorption spectrometry, Rahnama et al. analysed the $\mathrm{Zn}, \mathrm{Cu}, \mathrm{Mn}$, and $\mathrm{Fe}$ content of saliva and serum from patients with squamous cell carcinoma (SCC) of the oral cavity. SCC patients exhibited increased concentrations of $\mathrm{Cu}, \mathrm{Mn}$, and $\mathrm{Fe}$ in their blood and increased concentrations of all four metals examined in saliva when compared to healthy individuals. These results suggest that analysis of saliva may be an easy and effective way to detect SCC of the oral cavity.

In order to identify specific biomarkers of mercury $(\mathrm{Hg})$ poisoning Song et al. examined cases of peripheral neuropathy in Hg-exposed patients. Levels of selected urinary proteins were measured in patients with acute or chronic $\mathrm{Hg}$ poisoning and healthy control individuals. Elevated levels of the $\alpha 1-\mathrm{m}, \beta 2-\mathrm{m}$, TRF, IgG, and NAG proteins were observed in both acute and chronic $\mathrm{Hg}$-exposed patients, suggesting that urine samples may be a simple and inexpensive way to test for $\mathrm{Hg}$ exposure.

In addition to studying the adverse effects of metal exposure, it is important to try to develop methods of exposure prevention. For example, Huang's group attempted to develop a correlation model between Fe exposure in coal mines and Coal Workers' Pneumoconiosis (CWP). Fe is an essential trace metal that is stored in Fe-containing proteins, such as ferritin and transferrin, where it is tightly bound and unavailable to cause oxidative damage [17-19]. Bio-available iron (BAI), such as Fe associated with citrate and ATP, has been shown to produce oxidants in a pH-dependent manner [20]. Some coal dusts contain BAI, and have been shown to activate the stress-inducible AP-1 and NFAT transcription factors, while coal dust lacking BAI had no effect on either 
transcription factor [21]. Previously, BAI content in Pennsylvanian coal was shown to be much higher than the BAI content in coal dust originating from Utah [22]. Huang posited that BAI content could be used as a predictor of coal toxicity. The BAI content of coal from Utah and Pennsylvania was calculated and compared to epidemiological studies reporting the incidence of CWP. A significant correlation was found between BAI levels and CWP incidence, suggesting that BAI levels may be used to predict the toxicity of coal before mining begins.

A second example of an in vitro predictive model for metal-induced disease was introduced by Hockertz et al. Primary mast cells from human lung tissue and foreskin specimens were exposed to wear particle antigens including chromium-cobaltmolybdenum alloy (CrCoMo), a titanium alloy (TiAL6V4), or ultra-high molecular weight polyethylene (UMHWPE), all of which can be released into the human body by the degradation of implanted osseoprostheses [23]. Histamine release, indicative of an allergic reaction, was observed when the antigens were added to serum-containing media and applied to primary mast cells. If a patient's IgE was present, histamine release increased, particularly for the CrCoMo antigen. This in vitro model could be useful in preventing potentially dangerous allergic reactions in patients with osseoprostheses and reduce the need for the administration of immunosuppressants.

In some cases, a single biomarker candidate may be difficult to obtain and a profiling-based approach may be useful in identifying a molecular fingerprint for toxicant exposure. Boyd et al. presented an example of a high throughput strategy utilizing an automated robotic workstation (COPAS BIOSORT) to dispense and measure the length of Caenorhabditis elegans worms. Toxicological endpoints were examined using a 
fluorescent dye that only penetrates deceased worms. An imaging workstation was used to track the motion of the live worms and acquire multidimensional image analysis data. This type of high throughput method can be used to examine the properties of potential neurological and developmental toxicants and detect subtle changes in gene or protein expression that may be undetectable by conventional methods.

\section{Balancing act: The role of reactive oxygen species (ROS) and antioxidants}

Many transition metals have been shown to produce elevated amounts of damaging ROS [24-28]. Disturbing the redox balance of a system leads to an increase in DNA damage, DNA-protein crosslink formation, lipid peroxidation, apoptosis, cellular toxicity, and/or the inappropriate activation of cellular signaling pathways [29-35]. Since the mechanisms of ROS action are not well understood, many conference participants focused their studies on the elucidation of these mechanisms. For example, $\mathrm{Cr}(\mathrm{VI})$ is a transition metal that is known for its ability to produce increased quantities of ROS in cellular systems, particularly ${ }^{\circ} \mathrm{OH}[36,37]$. Previous studies have focused on the effects of soluble $\mathrm{Cr}(\mathrm{VI})$, since solubility is thought to be an important factor in its ability to contribute to carcinogenesis [38]. However, water insoluble (or particulate) $\mathrm{Cr}(\mathrm{VI})$ has also been shown to be genotoxic and cytotoxic [24,39-41]. Leonard et al. examined the capability of insoluble $\mathrm{Cr}(\mathrm{VI})$ in the form of $\mathrm{PbCrO}_{4}$ to produce $\mathrm{ROS}$ using electron spin resonance (ESR) spectroscopy and the comet assay. Their results showed that insoluble $\mathrm{Cr}(\mathrm{VI})$ was capable of producing oxidative stress in a similar pattern to that of soluble $\operatorname{Cr}(\mathrm{VI})$. 
Additional studies examining the effects of $\mathrm{PbCrO}_{4}$ in the human lung cell line WHTBF-6, were presented by Wise et al. $\mathrm{PbCrO}_{4}$ was shown to enter the lung cells and exert clastogenic effects in a dose-dependent manner, although dicentric chromosome formation was not observed. In order to exclude $\mathrm{Pb}$ ions as the culprits of clastogenicity, HTBF-6 cells were also exposed to Pb-glutamate, which yielded no clastogenesis. However, $\mathrm{Na}_{2} \mathrm{CrO}_{4}$ treatment also proved to be clastogenic in the lung cells, suggesting that the $\mathrm{CrO}_{4}{ }^{2-}$ ions were the cause of clastogenicity. In addition, the antioxidant vitamin $\mathrm{C}$ prevented the uptake of $\mathrm{CrO}_{4}{ }^{2-}$ ions and exhibited only a slight effect on $\mathrm{Pb}$ levels. The cytotoxicity profiles of WHTBF-6 cells exposed to $\mathrm{CrO}_{4}{ }^{2-}$ ions and $\mathrm{PbCrO}_{4}$ were comparable. Both $\mathrm{PbCrO}_{4}$ and $\mathrm{Na}_{2} \mathrm{CrO}_{4}$ induced cell cycle arrest and inhibited growth, whereas $\mathrm{Pb}$ ions alone induced only mitotic arrest.

ROS production often leads to cell death through cytotoxicity and/or apoptosis, prompting several groups to examine the benefits of inducing ROS in a cellular system through metal treatment. Farmer et al. used synthetic melanins derived from dihydroxy indole (DHI) to study the speciation, metal-binding affinity, and redox reactivity of those synthetic melanins. Several metals bound the DHI-melanin, increasing redox cycling and the production of ${ }^{\circ} \mathrm{OH}$ and $\mathrm{O}_{2}{ }^{-}$surprisingly. Indium(III) ions alone and lipophillic metallodithiocarbamate exhibited an unusual amount of toxicity towards melanoma cells in culture. The dithiocarbamate disulfide disulfiram (DSF), which is traditionally prescribed as an alcohol-abuse deterrent, also showed strong $\mathrm{Cu}$-dependent activity towards melanoma cells. Cen's group confirmed that DSF exhibited a Cu-dependent toxicity towards melanoma cells, whereas nontransformed melanocytes were only slightly affected. Upon DSF treatment, melanoma cell survival decreased to less than 
$10 \%$ as the intracellular $\mathrm{Cu}$ concentrations increased. The addition of $\mathrm{Cu}$ chelators blocked the DSF-induced cell toxicity and $\mathrm{Cu}$ uptake by melanoma cells. Formation of a $\mathrm{Cu}(\mathrm{deDTC})_{2}$ complex was proposed to be the likely active agent. This response is unique to $\mathrm{Cu}(\mathrm{II})$ and was not observed with $\mathrm{Fe}(\mathrm{II}), \mathrm{Mn}(\mathrm{III})$, or $\mathrm{Zn}$ (II), suggesting that local administration of $\mathrm{Cu}$ and DSF or DHI may be useful in the treatment of melanoma.

Exposure to metal-containing particulates can also increase ROS production in cellular systems. For example, diesel exhaust particles (DEP) have been shown to induce DNA adducts and increase inflammation in the respiratory tract [42-46]. DEP contents include polycyclic-aromatic hydrocarbons (PAHs), redox active semi-quinones, and trace heavy metals $[47,48]$. Park et al. compared ROS production of the DEP standard reference material 2975 (SRM 2975) and DEP collected from the air in Korea as measured by thiobarbituric acid - reactive substances of deoxyribose (TBARS). Differences in transition metal composition were observed between samples; DEP from Korea contained more $\mathrm{Fe}$, less $\mathrm{Cu}$, and less $\mathrm{Zn}$ than SRM 2975. TBARS measurements of the water soluble fraction of SRM 2975 showed a broad absorption in the visible range, which was absent in the DEP from Korea. Although SRM 2975 increased the amount of TBARS fluorescence, $\mathrm{H}_{2} \mathrm{O}_{2}$ generated more TBARS in the DEP from Korea, probably due to the increase in Fe composition. These results support a role for Fe in DEP-induced $\mathrm{H}_{2} \mathrm{O}_{2}$ toxicity, which may be the underlying cause of the adverse health effects of DEP.

Some substances seem to exert both pro-oxidant and antioxidant effects. Recently, many epidemiological and experimental studies have suggested that drinking green or black tea may protect against cancer $[49,50]$. Sinha et al. presented evidence suggesting that tea extracts, in particular the polyphenolic components, exert their 
chemopreventative effects by acting as antioxidants. They proposed that tea extracts can prevent DNA damage caused by sodium arsenite in V-79 Chinese hamster lung fibroblasts. However, Azmi et al. presented evidence that the presence of at least one of those polyphenolic components, (-) epigallocatechin-3-gallate (EGCG), can induce ${ }^{\circ} \mathrm{OH} / \mathrm{O}_{2}{ }^{--}$formation and increase the rate of DNA oxidation in the presence of $\mathrm{Cu}$ ions. The results of Azmi's group suggest that EGCG's apoptosis-inducing pro-oxidant properties may be more important than its preventative antioxidant properties. These studies are also supported by the findings of Qanungo et al. and Zykova et al. which suggest that tea polyphenols may serve as either an antioxidant or an oxidant, depending on the physiological environment [51-53].

Ascorbate/ascorbic acid/vitamin $\mathrm{C}$ is another compound that has been shown to exhibit both pro-oxidant and antioxidant effects [54-58]. Huq and Hussain presented evidence suggesting that exposure to $\mathrm{Cd}$ acetates increases DNA damage in the presence of ascorbate. The mechanism occurs via the formation of a 1:1 covalent $\mathrm{Cd}(\mathrm{II}) /$ ascorbate adduct, causing a molecular activation of the transition metal. This group proposed that the deprotonated ascorbate ions bind to ${ }^{3} \mathrm{O}_{2}$ producing the volatile ROS species, singlet molecular oxygen $\left({ }^{1} \mathrm{O}_{2}\right)$.

Ironically, some transition metals may serve as antioxidants and prevent oxidative cellular damage. Aravind and Prasad presented evidence that $\mathrm{Zn}$ may be able to prevent $\mathrm{Cd}$ toxicity. Ceratophyllum demersum L. plants were treated with different concentrations of $\mathrm{CdCl}_{2}$ and/or $\mathrm{ZnCl}_{2}$. The production of ${ }^{\circ} \mathrm{OH}$, an oxidative shift in GSH levels, loss of carbonic anhydrase conformation, and DNA fragmentation were observed with $\mathrm{CdCl}_{2}$ treatment. Upon treatment with both $\mathrm{CdCl}_{2}$ and $\mathrm{ZnCl}_{2}$, the presence of $\mathrm{Zn}$ 
inhibited all of the aforementioned markers of oxidative damage, suggesting that $\mathrm{Zn}$ may be able to prevent the cytotoxic effects induced by $\mathrm{Cd}$.

Rhenium is a second transition metal that exhibits low ROS-induced toxicity. Thus, cluster rhenium compounds (CRCs) are thought to be a potential drug delivery agent. CRCs possess lower toxic effects than other metals currently used as anti-tumour agents, including palladium, platinum, and cisplatin [59]. Shtemenko and Shtemenko examined the mechanisms of lipid-CRC interactions in solution and during the formation of liposomes. They had previously shown that CRCs bind to carboxylic acids, amino acids, or adamantanic acids, and subsequently interact with the surface of red blood cells to stabilize the membrane in response to free radicals [60]. Administration of CRC1dichlorotetra- $\mu$-(i-butirato) dirhenium(III) or CRC2-tetrachlorodi- $\mu-(\gamma$-aminobutirato) dirhenium(III) chloride in models of hemolytic anemia led to an increase in hemoglobin and resistance of erythrocytes to oxidative stress, extending the life of hemolytic animals. In addition, $\mathrm{CRC} 1$ or $\mathrm{CRC} 2$ administration increased reduced glutathione pools, glutathione reductase expression, and glutathione peroxidase (GPx) expression in the tissues of animals with hemolytic anaemia. Thus, CRCs demonstrate antioxidant and antiradical properties in vivo and may be useful in the treatment of hemolytic anaemia.

Cellular systems have developed a wide range of antioxidant mechanimsms to combat the dangerous accumulation of ROS. Examples include the increased expression of ROS detoxification enzymes, such as catalase and superoxide dismutase (SOD), and the maintenance of pools of small molecular ROS scavengers, such as N-acetyl-cysteine (NAC) and reduced glutathione (GSH). These ROS scavenging molecules react with excess ROS, thus minimizing cellular damage. Glutathione (GSH), although widely 
known for its antioxidant activity, is also involved in Se metabolism and bioactivity [61]. Shen et al. presented evidence that Se caused a dose-dependent onset of mitochondrial permeability transition (MPT) in the presence of GSH, which could be inhibited by the MPT inhibitor cyclosporin A. An SOD mimic, Mn[III]tetrakis [4-benzoic acid] porphyrin, has been previously shown to prevent MPT caused by xanthine (X)-xanthine oxidase (XO) [62]. Surprisingly, SOD had no effect on MPT and was unable to prevent the reduction of cytochrome $c$ induced by selenite-GSH (Se-GSH) formation. Although others have observed an increase in $\mathrm{O}_{2}{ }^{--}$formation during Se-GSH generation, Shen's group measured $\mathrm{O}_{2}{ }^{--}$via the lucigenin assay and found no significant increase in $\mathrm{O}_{2}{ }^{--}$

when compared to $\mathrm{O}_{2}^{--}$production by the $\mathrm{X}-\mathrm{XO}$ pathway [63]. These results suggest that $\mathrm{O}_{2}{ }^{--}$is not responsible for Se-GSH-induced MPT in this system.

Resveratrol is a polyphenolic antioxidant that is synthesized by many plant species and has been shown to inhibit the growth of cultured cancer cells [64]. Xia et al. presented evidence that ROS-induced activation of the PI3K/Akt survival pathway can be inhibited by the presence of resveratrol in prostate cancer cells. Resveratrol also inhibited the expression of proteins involved in angiogenesis, such as HIF- $1 \alpha$ and VEGF, in a dose-dependent manner. Xia's results suggest that resveratrol may be able to inhibit prostate cancer progression and angiogenesis through the inhibition of these pathways.

\section{DNA damage/lesions and mitotic effects}

In addition to producing ROS, many metals have been shown to directly modify and/or damage DNA by forming DNA adducts, facilitating DNA protein crosslink formation, or inducing chromosomal breaks $[33,44,65,66]$. Many researchers at the 
conference presented work reflecting efforts to identify the mechanisms of metal-induced DNA damage. For example, O'Brien et al. examined the role of $\mathrm{O}_{2}$ in $\mathrm{Cr}(\mathrm{VI})$-induced DNA lesions and found that hypoxic conditions did not alter $\mathrm{Cr}(\mathrm{VI})$ reduction by ascorbic acid. However, both $\mathrm{Cr}(\mathrm{VI})$-DNA binding and the occurrence of polymerase arresting lesions (PALs) decreased under hypoxic conditions by $70 \%$ and $50-90 \%$, respectively. These results suggest that $\mathrm{O}_{2}$ can help facilitate the formation of $\mathrm{Cr}(\mathrm{VI})$ DNA complexes.

A common oxidative DNA modification, the 7,8-dihydro-8-oxo-2_deoxyguanosine (8-oxo-dG) lesion, can lead to the misincorporation of extraneous nucleotides during DNA replication $[67,68]$. The 8-oxo-dG lesions are prone to further oxidation by many transition metals, including $\mathrm{Cr}(\mathrm{V})$ and Iridium (IV). Further oxidation of 8-oxo-dG leads to the formation of guanidinohydantoin (Gh) and spiroiminodihydantoin ( $\mathrm{Sp}$ ) lesions, subsequently causing $\mathrm{G} \rightarrow \mathrm{T}$ and $\mathrm{G} \rightarrow \mathrm{C}$ transversions $[69,70]$. Gh and Sp lesions are thought to enhance base misincorporation and the polymerase blocking effects of the 8-oxo-dG lesion [71, 72]. Certain base excision repair (BER) enzymes recognize 8-oxo-dG lesions, but not Gh or Sp lesions [73, 74]. Hailer et al. showed that the mammalian BER glycosylases NEIL1 and NEIL2 both recognize and cleave Gh and Sp lesions in single-stranded DNA [75]. These results demonstrate that an alternative pathway is activated in response to the formation of Gh and Sp DNA lesions. The 8-oxo-dG lesion also affects transcription factor binding [76, 77]. Previous studies by Sugden's group reported that binding activity of the NF- $\kappa \mathrm{B}$ p50 subunit increases if the $\mathrm{G}_{1}$ nucleotide of the NF- $\kappa \mathrm{B}$ consensus binding sequence (5'-dAGTTGA $\mathrm{G}_{1} \mathrm{G}_{2} \mathrm{G}_{3} \mathrm{G}_{4}$ ACTTTCCCAGCC-3') is replaced with an 8-oxo-dG modified base [77]. In 
contrast, replacing the $\mathrm{G}_{3}$ nucleotide with an 8-oxo-dG decreases p50 binding activity. Sugden $e t a l$. found that $\mathrm{p} 50$ binding activity to the modified NF- $\kappa \mathrm{B}$ consensus sequences correlated with p50 in vitro transcription activity, providing a direct link between the regulation of gene transcription and ROS formation.

In addition to inducing DNA lesions, metals can interfere with cellular processes such as mitosis. Kligerman et al. presented evidence that arsenicals induced c-type anaphases consisting of small, condensed chromosomes - an effect usually seen with spindle poisons [78]. They proceeded to investigate the effects of several different modified arsenicals on mitosis and found that monomethylarsenous acid (MMA ${ }^{\text {III }}$ ) exhibited the most potent mitotic interference. When tubulin was directly exposed to $\mathrm{MMA}^{\mathrm{III}}$, an increase in the number of mitotic indices (MIs) was observed. None of the arsenicals with a valence state of $\mathrm{V}$ showed an obvious effect on tubulin polymerization, whereas all arsenicals with a valance state of III inhibited tubulin polymerization. Taken together, these results indicate that As(III) and its metabolites can interfere with cell division.

Activation of DNA repair enzymes is often observed in response to metal-induced DNA damage [79-81]. Lee et al. examined the effects of DNA repair gene polymorphisms on the number of $\mathrm{Cr}(\mathrm{VI})$-induced strand breaks in human white blood cells. Several DNA repair genes with known genetic polymorphisms were examined, including glutathione S transferase M1 (GSTM1), glutathione S transferase T1 (GSTT1), NADPH quinine oxidoreductase 1 (NQO1), X-ray repair cross complementation factor 1 (XRCC1), and the 8-oxo-7,8-dihydroguanine (8-oxo-G) DNA glycosylase (OGG1). White blood cells homozygous for the OGG1 $\mathrm{Cys}^{326}$ polymorphism exhibited an 
increased number of DNA strand breaks when compared to the OGG1 $\mathrm{Ser}^{326} / \mathrm{Ser}^{326}$ and OGG1 $\mathrm{Ser}^{326} / \mathrm{Cys}^{326}$ polymorphisms. White blood cells homozygous for the OGG1 $\mathrm{Cys}^{326}$ variation also exhibited an increase in the ratio of oxidative DNA damage to plasma antioxidant capacity. These results suggest that OGG1 $\mathrm{Cys}^{326}$ homozygous individuals may be defective in the repair of DNA adducts during oxidative stress conditions, possibly due to the oxidation of these residues.

\section{Metal-induced cellular signaling}

Although each metal activates its own unique set of signaling events, many metals also activate general ROS-mediated stress response pathways. DNA microarray technology has recently been used to examine the global effects of metals in several model systems. For example, Jin et al. examined the global transcriptional response of the yeast Sacchromyces cerevisiae to $\mathrm{Zn}, \mathrm{Cd}, \mathrm{Hg}, \mathrm{Cu}$, silver (Ag), $\mathrm{Cr}$, or arsenic (As) exposure. Approximately $25 \%$ of the yeast genes were affected by at least one metal (798 upregulated genes and 774 downregulated genes). Most of the metals upregulated genes involved in the oxidative damage process, sulfur assimilation, sulfur metabolism, and GSH biosynthesis. Genes encoding biomolecular transporters of sugar and lipid metabolism were downregulated. Approximately $10 \%$ of the total number of $S$. cerevisiae genes were affected by As treatment - a 2-5-fold increase in the number of genes affected by any other metal examined. Additional classes of genes induced by As treatment included double-stranded break (DSB) repair and DNA replication genes.

Other examples of the use of microarray analysis in toxicology studies included Song and Freedman's examination of the global transcriptional effects of $\mathrm{Cu}$ treatment on 
a human hepatoma cell line, Hep2G. After $4 \mathrm{~h}$ of $\mathrm{Cu}$ exposure, 42 genes were upregulated and 24 were downregulated. The upregulated genes included metallothionein IIA (MT2A), myosin heavy polypeptide (MYH8), CYP1A1, IL-1 receptor alpha (IL11RA), heat shock protein A1A (HSPA1A), and heme oxygenase 1 (HO-1). Downregulated genes included the HT017 protein, dynamin 1-like (DNM1L), DEAD box polypeptide 18 (DDX18), and GST theta 2 (GSTT2). RT-PCR confirmed the upregulation of HSPA1A, CYP1A1, and HO-1 with peak induction levels at 12, 24, and 8 hours respectively.

Many of the global effects of metals on transcription are thought to be controlled by the interactions between metal response elements (MREs) and MRE binding transcription factors such as MTF-1 [82]. Since PKC inhibitors can abrogate MT induction, it is thought that some metals induce signaling cascades through PKC activation, subsequent alteration of MTF-1 phosphorylation, and activation of MT transcription [83]. Craft and Freedman examined the role of p53 activation in MT induction by $\mathrm{Hg}$ and $\mathrm{Cd}$ and found MT transcription was reduced in $\mathrm{p} 53-/-$ cells when compared to wild-type p53 cells. These results suggest that p53 may be part of a general mechanism in the cellular response to both $\mathrm{Hg}$ and $\mathrm{Cd}$ exposure.

Arsenic signaling

After a metal ion is transported across the cytoplasmic membrane, its transition state is often altered by cellular reducing agents. Reduction of some metals to a lower transition state, such as $\mathrm{As}(\mathrm{V}) \rightarrow \mathrm{As}(\mathrm{III})$, often results in an increase in toxicity; thus it is 
beneficial to examine the metal's cellular point of entry. The ArsATPase is a catalytic subunit of the Escherichia coli ArsAB pump that translocates As(III) across the cellular membrane, conferring resistance to arsenicals and antimonials $[84,85]$. There are two halves of the Ars ATPase, A1 and A2, each consisting of a nucleotide binding domain (NBD) and a metal binding domain (MBD). The NBD and MBD are connected by two amino acid linkers which serve as a signal transduction domain $[85,86]$. Using sitedirected mutagenesis, Bhattacharjee and Rosen altered residues of the signal transduction domain and found that the D142A and P145A mutations caused a loss of As(III) resistance. These results indicate that this domain is important in the signaling events between the catalytic and allosteric sites of the Ars ATPase. The aquaglyceroporin (AQP) family is responsible for the uptake of $\mathrm{As}(\mathrm{III})$ and $\mathrm{Sb}(\mathrm{III})$ in humans [87, 88]. Mukhopadhyay et al. reported that overexpression of human AQP9 in the chronic myelogenous leukemia cell line K562 increased uptake of the As(III)-based drug Trisenox [89]. Since AQP9 overexpression in K562 cells exhibited hypersensitivity to Trisenox, it is possible that pharmacological alteration of AQP9 expression could boost Trisenox effectiveness in cancer patients.

As(III) induces oxidative stress and delays cell cycle reentry into the $\mathrm{G}_{1}$ phase by an unknown signaling mechanism $[90,91]$. Chen et al. presented evidence that $\mathrm{As}(\mathrm{III})$ induces ubiquitination and subsequent degradation of the $\mathrm{Cdc} 25 \mathrm{C}$ protein, a protein which is thought to cause the exit of cells from the G2/M phase [92]. These effects were not abrogated by treatment with antioxidants. Furthermore, immunoprecipitation showed that $\mathrm{Cdc} 25 \mathrm{C}$ associates with the $\mathrm{Fzr} / \mathrm{Cdh} 1$ recognition subunit of the mitotic APC ubiquitin ligase complex. siRNA silencing of Fzr/Cdh1 expression protected $\mathrm{Cdc} 25 \mathrm{C}$ 
from degradation and decreased ubiquitin conjugating activity. Chen's group concluded that As(III) induces the redox-independent ubiquitination and degradation of $\mathrm{Cdc} 25 \mathrm{C}$ through its association with Fzr/Cdh1.

As(III) exposure also induces remodelling of the cytoskeleton [93]. Qian et al. demonstrated that As(III) activated Cdc42 and NADPH oxidase. Activated NADPH oxidase produced $\mathrm{O}_{2}{ }^{--}$and induced actin filament reorganization in SVEC4-10 cells [94]. Overexpression of a dominant negative $\mathrm{Cdc} 42$ or treatment with the actin filament stabilization agent jasplakinolide inhibited actin filament reorganization and prevented NADPH oxidase activation. Qian's group concluded that As(III) activates NADPH oxidase through $\mathrm{Cdc} 42$ and leads to actin filament reorganization and the formation of lamellipodia and filopodia. These effects could possibly lead to increased cell migration and/or metastasis of As(III)-induced tumors.

Paradoxically, As also exhibits apoptotic-inducing effects. Ivanov and Hei presented evidence that human melanoma cells exposed to combinations of low concentrations of As $(2-10 \mu \mathrm{M})$ and EGFR, PI3K/Akt, or MEK/Erk inhibitors effectively induced apoptosis via the TRAIL and TNF $\alpha$ pathways in spite of low Fas levels [95]. The combination of As and synthetic small molecule inhibitors could potentially be used to sensitize melanoma cells to cytotoxic drugs, enabling the development of more effective chemotherapy regimens.

Lemarie et al. further examined the apoptotic pathway induced by As and found that $\mathrm{As}_{2} \mathrm{O}_{3}$ prevented monocyte adhesion and expression of the macrophage phenotypical markers transferrin receptor $\mathrm{CD} 71$ and integrin $\mathrm{CDIIc} . \mathrm{As}_{2} \mathrm{O}_{3}$ induced monocyte apoptosis, increased caspase 8 and caspase 3 expression, decreased cFLIP and XIAP 
expression, decreased $\mathrm{NF} \kappa \mathrm{B}$ binding activity, and exhibited a loss of mitochondrial membrane potential. Lemarie's group suggested that $\mathrm{As}_{2} \mathrm{O}_{3}$ may induce apoptosis by inhibiting $\mathrm{NF} \kappa \mathrm{B}$ activity and subsequently decreasing the expression of the cFLIP and XIAP pro-survival proteins, both of which are transcriptionally controlled by $\mathrm{NF} \kappa \mathrm{B}$. Taken together, these studies may provide insight into the signaling pathways responsible for As's ability to induce apoptotic effects as well as carcinogenic effects.

\section{Chromium signaling}

$\mathrm{Cr}(\mathrm{VI})$ has been known to produce ROS, induce DNA damage, and subsequently activate the ATM, p53, and Chk2 proteins $[96,97]$. It is known that ATM is activated specifically in response to DSBs, however no Cr-induced DSBs have been reported [98101]. Ceryak et al. exposed normal human dermal fibroblasts to $\mathrm{Cr}(\mathrm{VI})$ or the radiomimetic agent neocarzinostatin (NCS) and analysed the occurrence of DSBs, the phosphorylation status of histone $\mathrm{H} 2 \mathrm{~A} . \mathrm{X}(\gamma-\mathrm{H} 2 \mathrm{AX})$, and the formation of $\gamma-\mathrm{H} 2 \mathrm{AX}$ nuclear foci. Their evidence suggested that DSBs were formed in response to $\mathrm{Cr}(\mathrm{VI})$ exposure in an S phase-dependent manner, while NCS exposure exhibited an equal distribution of DSB formation throughout all phases of the cell cycle. Additionally, $\mathrm{Cr}(\mathrm{VI})$ exposure showed $\gamma-\mathrm{H} 2 \mathrm{AX}$ foci formation in PCNA positive cells; an effect that was absent in the NCS-exposed control cells and decreased in ATM-/- cells.

Xie et al. independently showed that $\mathrm{PbCrO}_{4}$ induced DSBs in a dose-dependent manner, resulting in the activation of ATM in human lung cells. $\gamma-\mathrm{H} 2 \mathrm{AX}$ is rapidly phosphorylated on $\operatorname{Ser}^{139}$ when DSBs are induced by ionizing radiation [102]. Xie's group also showed that $\mathrm{PbCrO}_{4}$ induced a concentration-dependent phosphorylation of $\gamma$ - 
$\mathrm{H} 2 \mathrm{AX}$ and subsequent foci formation. Taken together, these results demonstrate a general mechanism for $\mathrm{Cr}(\mathrm{VI})$-induced carcinogenesis involving the induction of $\mathrm{S}$ phase-dependent DSBs and marked by $\gamma-\mathrm{H} 2 \mathrm{AX}$ foci formation.

$\mathrm{Xu}$ presented additional evidence that $\mathrm{Cr}(\mathrm{VI})$ exposure activates $\mathrm{ATM} / \mathrm{ATR}$, phosphorylates the structural maintenance chromosome 1 (SMC1) protein, and activates caffeine sensitive S phase cell cycle arrest in a dose-dependent manner. Surprisingly, $\mathrm{Cr}(\mathrm{VI})$-induced S phase cell cycle arrest was shown to be independent of ATM at high concentrations. $\mathrm{Xu}$ proceeded to examine alternate pathways responsible for $\mathrm{Cr}(\mathrm{VI})$ induced S phase cell cycle arrest and found that Rad17, which is required for the release of active ATR, bound the site of $\mathrm{Cr}(\mathrm{VI})$-induced DNA damage. A non-functional Rad17 showed impaired $\mathrm{S}$ phase arrest in response to $\mathrm{Cr}(\mathrm{VI})$ exposure, suggesting that a low dose of $\mathrm{Cr}(\mathrm{VI})$ activates an ATM-dependent pathway, whereas a high dose of $\mathrm{Cr}(\mathrm{VI})$ activates an ATR-dependent pathway.

\section{Cadmium signaling}

The activation of transcription factors by metals is one of the most commonly studied effects of metal-induced cellular signaling. However, recent interest has been expressed in alternative targets of metal signaling, such as the translational machinery pathways. Aberrant regulation of the expression of the translational control proteins eIF3 and $\operatorname{eEF} 1 \delta$ has been shown to be responsible for $\mathrm{Cd}(\mathrm{II})$-induced transformation and tumorigenesis [103, 104]. Orthumpangat et al. presented evidence that a third translational control protein may also affect the cellular response to metals. Cell lines exposed to $\mathrm{Cd}(\mathrm{II})$ exhibited a decrease in eIF4E protein expression. siRNA silencing of 
eIF4E induced cell death, whereas eIF4E overexpression resulted in cell survival after exposure to an otherwise lethal dose of $\mathrm{Cd}(\mathrm{II})$. $\mathrm{Cd}(\mathrm{II})$ exposure also activated the ubiquitin pathway, resulting in the degradation of eIF4E and a subsequent decrease in cyclin D1 expression.

The expression of other members of the translational machinery family were altered upon exposure to $\mathrm{Cd}(\mathrm{II})$. One such protein, $\mathrm{eEF} 1 \mathrm{~A} 2$ is a cellular proto-oncogene which is overexpressed in many cancer cell lines and tumors. Orthumpangat's group reported that eEF1A2 expression was increased in response to $\mathrm{Cd}(\mathrm{II})$, while overexpression of eEF1A2 conferred resistance to $\mathrm{Cd}(\mathrm{II})$-induced apoptosis. These results confirm that the translational machinery is a potential mechanism for $\mathrm{Cd}(\mathrm{II})$ induced carcinogenesis.

Hep3B human hepatocarcinoma cells have been shown to undergo Cd-induced apoptosis in a caspase-independent manner [105]. The mechanism is thought to involve the nuclear translocation of endonuclease $\mathrm{G}$ (endoG) and the apoptosis-inducing factor (AIF), both of which are mitochondrial apoptogenic proteins. Lemarie et al. showed that the release of endoG and AIF in response to $\mathrm{Cd}$ exposure was preceded by an increase in cytoplasmic $\mathrm{Ca}^{2+}$ and a loss of mitochondrial membrane potential. Bapta-AM, a $\mathrm{Ca}^{2+}$ chelator, blocked these events and prevented apoptosis. Inhibition of ROS production by the mitochondrial inhibitors ruthenium red, rotenone, and diphenyleneiodonium prevented the loss of mitochondrial membrane potential. Bapta-AM and diphenyleneiodonium also blocked expression of the $\mathrm{NF} \kappa \mathrm{B}$-regulated anti-apoptotic protein bcl-x $(\mathrm{L})$ in $\mathrm{Cd}$ exposed cells. Lemarie's group concluded that $\mathrm{Cd}$ induces apoptosis in Hep3B cells through $\mathrm{Ca}^{2+}$ release and ROS-induced impairment of the 
mitochondria. These results are in agreement with the hypothesis that $\mathrm{Cd}$-induced apoptosis occurs through the release of endoG and AIF.

\section{Cobalt and copper signaling}

Exposure to the hard metal dust tungsten carbide-cobalt mixture (WC-Co) directly correlates with an increased risk of cancer in exposed workers [106]. Lombaert et al. demonstrated that both cobalt $(\mathrm{Co})$ and $\mathrm{WC}-\mathrm{Co}$ induced apoptosis of peripheral blood mononucleated cells (PBMCs). WC-Co apoptosis occurred at a higher rate than Co-induced apoptosis and was dependent on caspase 9 activation, whereas Co-induced apoptosis depended on the activation of both caspases 8 and 9. These results demonstrate that although $\mathrm{WC}-\mathrm{Co}$ and $\mathrm{Co}$ can produce similar cellular effects, the signaling mechanisms may be different.

Although $\mathrm{Cu}$ is a trace element necessary for the function of enzymes such as SOD, it can also produce ROS, DNA damage, and other carcinogenic effects when present in excess. Cherian and Ostrakhovitch examined the effects of $\mathrm{Cu}$ exposure on the p53 tumour suppressor signaling pathways in the breast cancer epithelial cell lines MDAMB-231 and MCF7. p53 mutant MDA-MB-231 cells are resistant to metal toxicity, while p53 wild-type MCF7 cells are sensitive to metal-induced apoptosis [107, 108]. ROS production was not observed in MDA-MB-231 cells exposed to $\mathrm{Cu}$; however, an increase in Akt phosphorylation, Akt nuclear translocation, Cyclin D1 expression, and cell cycle progression were still apparent. In contrast, ROS production in MCF7 cells increased in response to $\mathrm{Cu}$ exposure. Increases in p53 expression, p21 expression, $\mathrm{G}_{1}$ phase arrest, and apoptosis in MCF7 cells were also observed. Additionally, Cu-exposed MCF7 cells 
exhibited a loss of mitochondrial membrane potential and lacked Akt activation and translocation. Suppression of p53 in MCF7 cells with pifithrin or E6 protein decreased p53 phosphorylation and increased Akt phosphorylation, suggesting that p53 is involved in the response to $\mathrm{Cu}$-induced ROS formation [109].

\section{Nickel signaling}

Insoluble nickel (Ni) compounds, such as $\mathrm{Ni}_{3} \mathrm{~S}_{2}$, green $\mathrm{NiO}$, black $\mathrm{NiO}$, and $\mathrm{Ni}$ refinery dust, have been shown to exert carcinogenic effects in a variety of animal experiments [110]. Landolph et al. showed that $\mathrm{Ni}_{3} \mathrm{~S}_{2}$, green $\mathrm{NiO}$, and black $\mathrm{NiO}$ are phagocytosed by $\mathrm{C} 3 \mathrm{H} / 10 \mathrm{~T} 1 / 2$ mouse embryo cells. Cytotoxicity, chromosomal aberrations, and morphological transformation were observed upon $\mathrm{Ni}$ exposure. The extent of phagocytosis was shown to correlate with each Ni compound's ability to induce transformation. RAP-PCR differential display experiments showed 130 genes that were differentially expressed between the Ni-transformed and nontransformed cell lines. Increased expression of the ect-2, calnexin, and $w d r l$ genes in transformed cells were confirmed by Western blot. Respectively, these genes encode a Rho GDP/GTP exchange factor that modulates microtubule assembly, a molecular chaperone, and a stressinducible protein. Decreased expression of the vitamin D receptor interacting protein/thyroid hormone activating protein 80 (DRIP/TRAP-80) and two other novel genes was also observed in transformed cells. Landolph's group concluded that Ni ions generate ROS, mutate and activate proto-oncogenes and/or tumour suppressor genes, and also induce chromosomal aberrations. 
Paradoxically, Ni can upregulate the expression of some genes while downregulating others, possibly through the post-translational modification of histones. $\mathrm{Ni}$ suppresses the acetylation of core histones $\mathrm{H} 3$ and $\mathrm{H} 4$ and induces de novo DNA methylation, leading to gene silencing [34,111]. Costa's group found that water-soluble $\mathrm{Ni}$ salts could inhibit the acetylation of the core histones $\mathrm{H} 2 \mathrm{~A}, \mathrm{H} 2 \mathrm{~B}, \mathrm{H} 3$, and $\mathrm{H} 4$. Ni exposure also induced methylation of Lys 9 in histone $\mathrm{H} 3$ and increased the ubiquitination of histones $\mathrm{H} 2 \mathrm{~A}$ and $\mathrm{H} 2 \mathrm{~B}$. Golebiowski and Kasprzak also examined the acetylation status of the N-terminal tails of the core histones in Ni-exposed human and rodent cells exposed to $\mathrm{Ni}(\mathrm{II})$. Histone $\mathrm{H} 2 \mathrm{~B}$ exhibited the least acetylation, followed by histones $\mathrm{H} 4, \mathrm{H} 3$, and $\mathrm{H} 2 \mathrm{~A}$ in human airway epithelial cells and normal rat kidney cells. However, these effects were not seen in Chinese hamster ovary $(\mathrm{CHO})$ cells, suggesting that the decrease in acetylation may be cell-type dependent. $\mathrm{Ni}(\mathrm{II})$ has been shown to cleave the -SHHKAKGK motif of the C-terminal tail of histone H2A in vitro and in cell culture $[112,113]$. Karaczyn et al. examined the effects of $\mathrm{Ni}(\mathrm{II})$ on other histones and showed that histone $\mathrm{H} 2 \mathrm{~B}$ abundance increases with $\mathrm{Ni}(\mathrm{II})$ treatment over time. Mass spectrometry and amino acid sequencing analysis confirmed that the $\mathrm{H} 2 \mathrm{~B}$ immunoreactive bands were variants of histone H2B. The larger band represented a truncated histone H2B lacking 16 amino acids from the $\mathrm{N}$-terminal tail. The smaller band represented a histone $\mathrm{H} 2 \mathrm{~B}$ variant lacking both the $16 \mathrm{~N}$-terminal amino acids and an additional nine amino acids from the C-terminal tail. Post-translational modifications of the smaller band included two acetylated Lys residues. Similar, but weaker effects on histone $\mathrm{H} 2 \mathrm{~B}$ were seen with $\mathrm{Co}(\mathrm{II})$, but no effects were seen with $\mathrm{Cu}(\mathrm{II}), \mathrm{Cd}(\mathrm{II})$, or $\mathrm{Zn}(\mathrm{II})$. Since the terminal tails of histones are thought to play key roles in structuring 
chromatin and regulating gene expression, the loss of these regions may be involved in the mechanisms relating to $\mathrm{Ni}(\mathrm{II})$-induced carcinogenesis. Taken together, these results suggest that histone modification may play a major role in the mechanism of Ni-induced gene activation and/or silencing.

In addition to modifying core histones, Ni-exposure also activates the HIF- $1 \alpha$ transcription factor via the depletion of intracellular Fe and the subsequent inhibition of the Fe-dependent enzyme proline hydroxylase, which leads to the stabilization of HIF-1 $\alpha$ [114]. Huang et al. examined the effects of $\mathrm{Ni}_{3} \mathrm{~S}_{2}$ or $\mathrm{NiCl}_{2}$ exposure on other transcription factors and found that Ni ions increased ROS production and activated NFAT. NFAT activation was inhibited by catalase, NAC, and desferoxamine (DFO), but not by SOD or sodium formate. Ni activation of the HIF-1 $\alpha$, PI3K, Akt, and p70S6K

was abrogated by PI3K inhibitors. Overexpression of Akt and PI3K dominant negative (DN) mutants also inhibited HIF-1 $\alpha$ activation and Cap43 expression, while exposure to rapamycin, a p70S6K inhibitor, had no effect. In conclusion, Huang's group suggested that $\mathrm{Ni}$ generates $\mathrm{H}_{2} \mathrm{O}_{2}$ which in turn activates NFAT. HIF-1 $\alpha$ and Cap43 are also activated by Ni via a PI3K/Akt-dependent pathway, independently of p70S6K activity.

\section{Animal studies}

Although animal studies provide valuable information concerning the toxic effects and signaling pathways of environmental contaminants, adequate animal models do not exist for some metals due in part to their roles as co-carcinogens. Thus, it is difficult to assess the effects of the metal itself because a known carcinogenic compound must be administered simultaneously in order for a tumour to develop. For example, 
Burns et al. presented evidence that hairless mice (Skh1strain) exposed to ultra-violet radiation (UVR) and Cr- or As-contaminated drinking water elevated the number of tumors produced by UVR to 8.3 - and 4.6-fold, respectively. These data confirm that metals can act as hazardous co-carcinogens even at low levels of exposure.

Most metal toxicity studies have been conducted on adult animals, yet few have focused on the effects of metal exposure during the pubescent period. Chatterjee et al. examined Sprague-Dawley rats exposed to intravenous-infused $\mathrm{CdCl}_{2} 40-100$ days after birth. Histopathological examination of the mammary tissue showed that $\mathrm{Cd}(\mathrm{II})$ exposure slightly suppressed apoptosis while DNA strand breaks increased by $61 \%$. At low doses, no change in histopathology of the mammary tissue was observed. However, at high doses, exposed rats exhibited intraductal proliferations. In addition, MT expression was elevated $60-86 \%$ in $\mathrm{Cd}(\mathrm{II})$-treated animals in a dose-dependent manner. These results indicate that $\mathrm{Cd}(\mathrm{II})$ exposure may lead to an increased incidence of cancer in pubescent animals.

Additionally, Chatterjee et al. examined the chemopreventive effects of vanadium (V) supplementation. Rats were exposed to diethlnitrosamine (DEN) and phenobarbitol to induce hepatocarcinogenesis, and subsequently fed V-supplemented chow for 20 weeks. V supplementation reduced the nodular incidence, total number of tumors, and multiplicity of tumors, and decreased metallothionein expression, BrdU labelling index (a marker of cell proliferation), and iNOS expression. In addition, V supplementation increased p53 immunoreactivity and the apoptotic labeling index. These results suggest that $\mathrm{V}$ may play a significant role in controlling cellular activities during chemicalinduced hepatocarcinogenesis. 
Depleted uranium (DU) is a radioactive heavy metal used to manufacture military munitions. United States military personnel wounded by DU shrapnel may have a higher risk of cancer incidence, due to DU's genotoxic and mutagenic effects $[115,116]$. DU can also cause radiation-specific cellular damage and transformation of human osteoblast cells $[117,118]$. In order to simulate the effects of a DU-containing shrapnel wound, Miller et al. implanted non-tumourigenic immortalized cells into syngenic DBA/2 mice with or without DU implantation pellets. Mice implanted with DU pellets showed an $80 \%$ incidence of tumorigenesis, whereas control mice exhibited a $10 \%$ incidence of leukemia, suggesting that DU can significantly enhance tumour incidence.

Chromium(III) Picolinate $\left(\mathrm{Cr}(\mathrm{Pic})_{3}\right)$ is a dietary supplement associated with oxidative damage, DNA damage, antioxidant enzyme depletion, and renal/liver dysfunction in rats $[119,120]$. In cell culture, $\mathrm{Cr}(\mathrm{Pic})_{3}$ has been shown to cause mutations and DNA fragmentation [121]. Rasco et al. examined the prenatal effects of dietary supplementation of $\mathrm{Cr}(\mathrm{Pic})_{3}, \mathrm{CrCl}_{3}$, or picolinic acid in pregnant female mice. The fetuses birthed from the $\mathrm{Cr}(\mathrm{Pic})_{3}$-fed females showed an increase in bifurcated cervical arches, delays in righting reflex, delays in hind limb grasp, and deficiencies in motor skills. These results demonstrate that dietary supplementation of $\mathrm{Cr}(\mathrm{Pic})_{3}$ exerts negative effects on the developing nervous system of mammalian fetuses.

Barchowsky et al. developed an animal model to examine the effects of As(III) on angiogenesis and the expression of tissue remodelling genes in cardiac tissue. Male mice were exposed to $\operatorname{As}(\mathrm{III})$-contaminated drinking water at low to moderately high concentrations for up to 20 weeks. Enhanced vascularization of Matrigel implants was observed after 5 weeks of As(III) exposure. RT-PCR showed a dose and time-dependent 
induction of VEGF, VEGF receptors, plasminogen activator inhibitor-1, endothelin-1, and matrix metalloproteinase-9 in cardiac tissue. Barchowsky's group concluded that the effects of chronic As(III) exposure on the cardiovascular tissue varies with dose and length of exposure.

\section{$\underline{\text { Summary }}$}

The research presented at the $3^{\text {rd }}$ Conference on Molecular Mechanisms of Metal Toxicity and Carcinogenesis provided new insights into the mechanisms of ROS production, the mechanisms of metal signaling, and the development of animal exposure models. However, the following areas of metal research still need further exploration. First, there is a need for the development of new human biomarkers for metal exposure. Without definitive and specific biomarkers, it is very difficult to assess the extent of metal exposure in humans, and thus, difficult to treat the resulting ailments. Second, since most metals cause some form of ROS-induced cellular stress, the elucidation of the mechanisms of ROS production may provide information concerning the general mechanisms of metal-induced carcinogenesis. Third, defining the mechanisms of metalinduced DNA damage may provide new insights into the signaling events involved in DNA damage repair pathways. Fourth, a better understanding of the complex signaling networks that lead to the adverse effects of metals could lead to the identification of superior and more specific novel therapeutic agents. Finally, better animal models for metal exposure are necessary in order to thoroughly evaluate the toxic and carcinogenic effects of metals in a model system. Through the use of current technology and the 
implementation of new experimental strategies, metal researchers can address these concerns. 


\section{References}

1. Churg A, Brauer M, Carmen Avila-Casado M, Fortoul TI, Wright JL: Chronic exposure to high levels of particulate air pollution and small airway remodeling. Environ Health Perspect 111: 714-718, 2003

2. Gambelunghe A, Piccinini R, Ambrogi M, Villarini M, Moretti M, Marchetti C, Abbritti G, Muzi G: Primary DNA damage in chromeplating workers. Toxicology 188: $187-195,2003$

3. Hunder G, Javdani J, Elsenhans B, Schumann K: 109Cd accumulation in the calcified parts of rat bones. Toxicology 159: 1-10, 2001

4. Tsai SM, Wang TN, Ko YC: Mortality for certain diseases in areas with high levels of arsenic in drinking water. Arch Environ Health 54:186-193, 1999

5. Gaetke LM, Chow CK: Copper toxicity, oxidative stress, and antioxidant nutrients. Toxicology 189: 147-163, 2003

6. Papanikolaou G, Pantopoulos K: Iron metabolism and toxicity. Toxicol Appl Pharmacol 202: 199-211, 2005

7. Tanzi RE, Petrukhin K, Chernov I, Pellequer JL, Wasco W, Ross B, Romano DM, Parano E, Pavone L, Brzustowicz LM: The Wilson disease gene is a copper transporting ATPase with homology to the Menkes disease gene. Nat Genet 5: 344-350, 1993

8. Parkkila S, Waheed A, Britton RS, Bacon BR, Zhou XY, Tomatsu S, Fleming RE, Sly WS: Association of the transferrin receptor in human placenta with HFE, the protein 
defective in hereditary hemochromatosis. Proc Natl Acad Sci USA 94: 13198-13202, 1997

9. Nair J, Carmichael PL, Fernando RC, Phillips DH, Strain AJ, Bartsch H: Lipid peroxidation-induced etheno-DNA adducts in the liver of patients with the genetic metal storage disorders Wilson's disease and primary hemochromatosis. Cancer Epidemiol Biomarkers Prev 7: 435-440, 1998

10. Feng Z, Hu W, Amin S, Tang MS: Mutational spectrum and genotoxicity of the major lipid peroxidation product, trans-4-hydroxy-2-nonenal, inducedDNAadducts in nucleotide excision repair-proficient and -deficient human cells. Biochemistry 42: 78487854,2003

11. Benedetti A, Pompella A, Fulceri R, Romani A, Comporti M: 4- Hydroxynonenal and other aldehydes produced in the liver in vivo after bromobenzene intoxication. Toxicol Pathol 14: 457-461, 1986

12. Bartsch H, Nair J, Velic I: Etheno-DNA base adducts as tools in human cancer aetiology and chemoprevention. Eur J Cancer Prev 6: 529-534, 1997

13. McCullough ML, Giovannucci EL: Diet and cancer prevention. Oncogene 23: 63496364,2004

14. Rohrmann S, Smit E, Giovannucci E, Platz EA: Association between serum concentrations of micronutrients and lower urinary tract symptoms in older men in the Third National Health and Nutrition Examination Survey. Urology 64: 504-509, 2004 15. Karunasinghe N, Ryan J, Tuckey J, Masters J, Jamieson M, Clarke LC, Marshall JR, Ferguson LR: DNA stability and serum selenium levels in a high-risk group for prostate cancer. Cancer Epidemiol Biomarkers Prev 13: 391-397, 2004 
16. Ames BN: DNA damage from micronutrient deficiencies is likely to be a major cause of cancer. Mutat Res 475: 7-20, 2001

17. Goddard JG, Gower JD, Green CJ: A chelator is required for microsomal lipid peroxidation following reductive ferritin-iron mobilisation. Free Radic Res Commun 17: $177-185,1992$

18. Reif DW, Simmons RD: Nitric oxide mediates iron release from ferritin. Arch Biochem Biophys 283: 537-541, 1990

19. Winston GW, Feierman DE, Cederbaum AI: The role of iron chelates in hydroxyl radical production by rat liver microsomes, NADPHcytochrome P-450 reductase and xanthine oxidase. Arch Biochem Biophys 232: 378-390, 1984

20. Morgan EH: Studies on the mechanism of iron release from transferrin. Biochim Biophys Acta 580: 312-326, 1979

21. Huang C, Li J, Zhang Q, Huang X: Role of bioavailable iron in coal dust-induced activation of activator protein-1 and nuclear factor of activated $\mathrm{T}$ cells: difference between Pennsylvania and Utah coal dusts. Am J Respir Cell Mol Biol 27: 568-574, 2002

22. Zhang Q, Dai J, Ali A, Chen L, Huang X: Roles of bioavailable iron and calcium in coal dust-induced oxidative stress: Possible implications in coal workers' lung disease. Free Radic Res 36: 285-294, 2002

23. Katzer A, Hockertz S, Buchhorn GH, Loehr JF: In vitro toxicity and mutagenicity of CoCrMo and Ti6Al wear particles. Toxicology 190: 145-154, 2003

24. Leonard SS, Roberts JR, Antonini JM, Castranova V, Shi X: PbCrO4 mediates cellular responses via reactive oxygen species. Mol Cell Biochem 255: 171-179, 2004 
25. Shi X, Flynn DC, Porter DW, Leonard SS, Vallyathan V, Castranova V: Efficacy of taurine based compounds as hydroxyl radical scavengers in silica induced peroxidation. Ann Clin Lab Sci 27: 365-374, 1997

26. Wang Y, Fang J, Leonard SS, Rao KM: Cadmium inhibits the electron transfer chain and induces reactive oxygen species. Free Radic Biol Med 36: 1434-1443, 2004

27. Leonard S, Gannett PM, Rojanasakul Y, Schwegler-Berry D, Castranova V, Vallyathan V, Shi X: Cobalt-mediated generation of reactive oxygen species and its possible mechanism. J Inorg Biochem 70: 239-244, 1998

28. Hei TK, Filipic M: Role of oxidative damage in the genotoxicity of arsenic. Free Radic Biol Med 37: 574-581, 2004

29. Lefebvre Y, Pezerat H: Reactive oxygen species produced from chromate pigments and ascorbate. Environ Health Perspect 102(Suppl 3): 243-245, 1994

30. Wang S, Leonard SS,Ye J, Ding M, Shi X: The role of hydroxyl radical as a messenger in Cr(VI)-induced p53 activation. Am J Physiol Cell Physiol 279: C868C875, 2000

31. Balamurugan K, Rajaram R, Ramasami T, Narayanan S: Chromium(III)-induced apoptosis of lymphocytes: Death decision by ROS and Src-family tyrosine kinases. Free Radic Biol Med 33: 1622-1640, 2002

32. Petit A,Mwale F, Tkaczyk C, Antoniou J, Zukor DJ,HukOL: Induction of protein oxidation by cobalt and chromium ions in human U937 macrophages. Biomaterials 26 : 4416-4422, 2005 
33. Chakrabarti SK, Bai C, Subramanian KS: DNA-protein crosslinks induced by nickel compounds in isolated rat lymphocytes: role of reactive oxygen species and specific amino acids. Toxicol Appl Pharmacol 170: 153-165, 2001

34. Kang J, Zhang Y, Chen J, Chen H, Lin C, Wang Q, Ou Y: Nickelinduced histone hypoacetylation: the role of reactive oxygen species. Toxicol Sci 74: 279-286, 2003

35. Lin C, Kang J, Zheng R: Oxidative stress is involved in inhibition of copper on histone acetylation in cells. Chem Biol Interact 151: 167-176, 2005

36. Bagchi D, Bagchi M, Stohs SJ: Chromium (VI)-induced oxidative stress, apoptotic cell death and modulation of p53 tumor suppressor gene. Mol Cell Biochem 222: 149158,2001

37. Wang S, Leonard SS, Ye J, Gao N, Wang L, Shi X: Role of reactive oxygen species and $\mathrm{Cr}(\mathrm{VI})$ in Ras-mediated signal transduction. Mol Cell Biochem 255: 119-127, 2004

38. Newbold RF, Amos J, Connell JR: The cytotoxic, mutagenic and clastogenic effects of chromium-containing compounds on mammalian cells in culture. Mutat Res 67: 5563, 1979

39. Wise JP, Leonard JC, Patierno SR: Clastogenicity of lead chromate particles in hamster and human cells. Mutat Res 278: 69-79, 1992

40. Wise JP, Sr., Wise SS, Little JE: The cytotoxicity and genotoxicity of particulate and soluble hexavalent chromium in human lung cells. Mutat Res 517: 221-229, 2002

41. Leonard SS, Vallyathan V, Castranova V, Shi X: Generation of reactive oxygen species in the enzymatic reduction of $\mathrm{PbCrO} 4$ and relatedDNA damage. Mol Cell Biochem 234-235: 309-315, 2002 
42. Han JY, Takeshita K, Utsumi H: Noninvasive detection of hydroxyl radical generation in lung by diesel exhaust particles. Free Radic Biol Med 30: 516-525, 2001 43. Casillas AM, Hiura T, Li N, Nel AE: Enhancement of allergic inflammation by diesel exhaust particles: Permissive role of reactive oxygen species. Ann Allergy Asthma Immunol 83: 624-629, 1999

44. Tsurudome Y, Hirano T, Yamato H, Tanaka I, Sagai M, Hirano H, Nagata N, Itoh H, Kasai H: Changes in levels of 8-hydroxyguanine in DNA, its repair and OGG1 mRNA in rat lungs after intratracheal administration of diesel exhaust particles. Carcinogenesis 20: $1573-1576,1999$

45. Baulig A, Garlatti M, Bonvallot V, Marchand A, Barouki R, Marano F, BaezaSquiban A: Involvement of reactive oxygen species in the metabolic pathways triggered by diesel exhaust particles in human airway epithelial cells. Am J Physiol Lung Cell Mol Physiol 285:L671-L679, 2003

46. Siegel PD, Saxena RK, Saxena QB, Ma JK, Ma JY, Yin XJ, Castranova V, Al Humadi N, Lewis DM: Effect of diesel exhaust particulate (DEP) on immune responses: Contributions of particulate versus organic soluble components. J Toxicol Environ Health A $67: 221-231,2004$

47. Schuetzle D: Sampling of vehicle emissions for chemical analysis and biological testing. Environ Health Perspect 47: 65-80, 1983

48. Ichinose T, Furuyama A, Sagai M: Biological effects of diesel exhaust particles (DEP). II. Acute toxicity of DEP introduced into lung by intratracheal instillation. Toxicology 99: 153-167, 1995 
49. Rah DK, Han DW, Baek HS, Hyon SH, Park JC: Prevention of reactive oxygen species-induced oxidative stress in human microvascular endothelial cells by green tea polyphenol. Toxicol Lett 155: 269-275, 2005

50. Erba D, Riso P, Bordoni A, Foti P, Biagi PL, Testolin G: Effectiveness of moderate green tea consumption on antioxidative status and plasma lipid profile in humans. J Nutr Biochem 16: 144-149, 2005

51. Qanungo S, Das M, Haldar S, Basu A: Epigallocatechin-3-gallate induces mitochondrial membrane depolarization and caspase-dependent apoptosis in pancreatic cancer cells. Carcinogenesis, 2005

52. Zykova TA, Zhang Y, Zhu F, Bode AM, Dong Z: The signal transduction networks required for phosphorylation of STAT1 at Ser727 in mouse epidermal JB6 cells in the UVB response and inhibitory mechanisms of tea polyphenols. Carcinogenesis 26: 331342,2005

53. Elbling L,Weiss RM, Teufelhofer O, Uhl M, Knasmueller S, Schulte-Hermann R, Berger W, Micksche M: Green tea extract and (-)-epigallocatechin-3-gallate, the major tea catechin, exert oxidant but lack antioxidant activities. FASEB J 2005

54. McCord JM: The evolution of free radicals and oxidative stress. Am J Med 108: 652659,2000

55. Stahl W, Sies H: Antioxidant defense: Vitamins E and C and carotenoids. Diabetes 46(Suppl 2): S14-S18, 1997

56. Podmore ID, Griffiths HR, Herbert KE, Mistry N, Mistry P, Lunec J: Vitamin C exhibits pro-oxidant properties. Nature 392: 559, 1998 
57. Herbert V, Shaw S, Jayatilleke E: Vitamin C-driven free radical generation from iron. J Nutr 126: 1213S-1220S, 1996

58. Leonard SS, Cutler D, Ding M, Vallyathan V, Castranova V, Shi X: Antioxidant properties of fruit and vegetable juices: More to the story than ascorbic acid. Ann Clin Lab Sci 32: 193-200, 2002

59. Pirozhkova-Patalah IV, Shtemenko NI: Influence of cis-[Re2GABA2Cl4]Cl2 on the antioxidant defense system parameters of normal human blood. Biochemistry (Mosc) 66: $721-724,2001$

60. Hrynevych I, Oliinyk SA, Shtemenko NI, Shtemenko OV: Antioxidant properties of rhenium cluster complexes with butyric acid derivatives in blood plasma and erythrocytes. Ukr Biokhim Zh 75: 65-71, 2003

61. Turner RJ,Weiner JH, Taylor DE: Selenium metabolism in Escherichia coli. Biometals 11: 223-227, 1998

62. Madesh M, Hajnoczky G: VDAC-dependent permeabilization of the outer mitochondrial membrane by superoxide induces rapid and massive cytochrome c release. J Cell Biol 155: 1003-1015, 2001

63. Yan L, Spallholz JE: Generation of reactive oxygen species from the reaction of selenium compounds with thiols and mammary tumor cells. Biochem Pharmacol 45: 429-437, 1993

64. ElAttar TM, Virji AS: Modulating effect of resveratrol and quercetin on oral cancer cell growth and proliferation. Anticancer Drugs 10:187-193, 1999 
65. Bau DT, Wang TS, Chung CH,Wang AS, Wang AS, JanKY: Oxidative DNA adducts and DNA-protein cross-links are the major DNA lesions induced by arsenite. Environ Health Perspect 110(Suppl 5): 753-756, 2002

66. Matsui M, Nishigori C, Toyokuni S, Takada J, Akaboshi M, Ishikawa M, Imamura S, Miyachi Y: The role of oxidative DNA damage in human arsenic carcinogenesis: detection of 8-hydroxy-2_-deoxyguanosine in arsenic-related Bowen's disease. J Invest Dermatol 113: 26-31, 1999

67. Shibutani S, Takeshita M, Grollman AP: Insertion of specific bases during DNA synthesis past the oxidation-damaged base 8-oxodG. Nature 349: 431-434, 1991

68. Grollman AP, Moriya M: Mutagenesis by 8-oxoguanine: An enemy within. Trends Genet 9: 246-249, 1993

69. Henderson PT, Delaney JC, Muller JG, Neeley WL, Tannenbaum SR, Burrows CJ, Essigmann JM: The hydantoin lesions formed from oxidation of 7,8-dihydro-8oxoguanine are potent sources of replication errors in vivo. Biochemistry 42: 9257-9262, 2003

70. Leipold MD, Muller JG, Burrows CJ, David SS: Removal of hydantoin products of 8oxoguanine oxidation by the Escherichia coli DNA repair enzyme, FPG. Biochemistry 9: 14984-14992, 2000

71. Henderson PT, Delaney JC, Gu F, Tannenbaum SR, Essigmann JM: Oxidation of 7,8dihydro-8-oxoguanine affords lesions that are potent sources of replication errors in vivo. Biochemistry 41: 914-921, 2002 
72. Muller JG, Duarte V, Hickerson RP, Burrows CJ: Gel electrophoretic detection of 7,8-dihydro-8-oxoguanine and 7,8-dihydro-8-oxoadenine via oxidation by $\operatorname{Ir}$ (IV). Nucleic Acids Res 26: 2247-2249, 1998

73. Michaels ML, Tchou J, Grollman AP, Miller JH: A repair system for 8-oxo-7,8dihydrodeoxyguanine. Biochemistry 31: 10964-10968, 1992

74. Michaels ML, Cruz C, Grollman AP, Miller JH: Evidence that MutY and MutM combine to prevent mutations by an oxidatively damaged form of guanine in DNA. Proc Natl Acad Sci USA 89: 7022-7025, 1992

75. Hailer MK, Slade PG, Martin BD, Rosenquist TA, Sugden KD: Recognition of the oxidized lesions spiroiminodihydantoin and guanidinohydantoin in DNA by the mammalian base excision repair glycosylases NEIL1 and NEIL2. DNA Repair (Amst) 4: $41-50,2005$

76. Ramon O, Sauvaigo S, Gasparutto D, Faure P, Favier A, Cadet J: Effects of 8-oxo7,8-dihydro-2_-deoxyguanosine on the binding of the transcription factor Sp1 to its cognate target DNA sequence (GC box). Free Radic Res 31: 217-229, 1999

77. Hailer-Morrison MK, Kotler JM, Martin BD, Sugden KD: Oxidized guanine lesions as modulators of gene transcription. Altered p50 binding affinity and repair shielding by 7,8-dihydro-8-oxo-2_-deoxyguanosine lesions in the NF-kappaB promoter element. Biochemistry 42: 9761-9770, 2003

78. Miller BM, Adler ID: Suspect spindle poisons: Analysis of cmitotic effects in mouse bone marrow cells. Mutagenesis 4: 208-215, 1989 
79. Mateuca R, Aka PV, De Boeck M, Hauspie R, Kirsch-Volders M, Lison D: Influence of hOGG1, XRCC1 and XRCC3 genotypes on biomarkers of genotoxicity in workers exposed to cobalt or hard metal dusts. Toxicol Lett 156: 277-288, 2005

80. Kim YD, An SC, Oyama T, Kawamoto T, Kim H: Oxidative stress, hogg1 expression and NF-kappaB activity in cells exposed to low level chromium. J Occup Health 45: 271-277, 2003

81. Zharkov DO, Rosenquist TA: Inactivation of mammalian 8-oxoguanine-DNA glycosylase by cadmium(II): Implications for cadmium genotoxicity. DNA Repair (Amst) 1: 661-670, 2002

82. Palmiter RD: Regulation of metallothionein genes by heavy metals appears to be mediated by a zinc-sensitive inhibitor that interacts with a constitutively active transcription factor, MTF-1. Proc Natl Acad Sci USA 91: 1219-1223, 1994

83. Saydam N, Adams TK, Steiner F, SchaffnerW, Freedman JH: Regulation of metallothionein transcription by the metal-responsive transcription factor MTF-1: Identification of signal transduction cascades that control metal-inducible transcription. J Biol Chem 277: 20438-20445, 2002

84. Rosen BP: Transport and detoxification systems for transition metals, heavy metals and metalloids in eukaryotic and prokaryotic microbes. Comp Biochem Physiol A Mol Integr Physiol 133: 689-693, 2002

85. Rosen BP: Biochemistry of arsenic detoxification. FEBS Lett 529: 86-92, 2002

86. Rosen BP, Hsu CM, Karkaria CE, Owolabi JB, Tisa LS: Molecular analysis of an ATP-dependent anion pump. Philos Trans R Soc Lond B Biol Sci 326: 455-463, 1990 
87. Liu Z, Boles E, Rosen BP: Arsenic trioxide uptake by hexose permeases in Saccharomyces cerevisiae. J Biol Chem 279: 17312-17318, 2004

88. Liu Z, Carbrey JM, Agre P, Rosen BP: Arsenic trioxide uptake by human and rat aquaglyceroporins. Biochem Biophys Res Commun 316: 1178-1185, 2004

89. Bhattacharjee H, Carbrey J, Rosen BP, Mukhopadhyay R: Drug uptake and pharmacological modulation of drug sensitivity in leukemia by AQP9. Biochem Biophys Res Commun 322: 836-841, 2004

90. Lee TC, Ho IC: Modulation of cellular antioxidant defense activities by sodium arsenite in human fibroblasts. Arch Toxicol 69: 498-504, 1995

91. Seol JG, Park WH, Kim ES, Jung CW, Hyun JM, Kim BK, Lee YY: Effect of arsenic trioxide on cell cycle arrest in head and neck cancer cell line PCI-1. Biochem Biophys Res Commun 265: 400-404, 1999

92. Millar JB, Russell P: The cdc25 M-phase inducer: An unconventional protein phosphatase. Cell 68: 407-410, 1992

93. Chou IN: Distinct cytoskeletal injuries induced by $\mathrm{As}, \mathrm{Cd}, \mathrm{Co}, \mathrm{Cr}$, and $\mathrm{Ni}$ compounds. Biomed Environ Sci 2: 358-365, 1989

94. Qian Y, Liu KJ, Chen Y, Flynn DC, Castranova V, Shi X: Cdc42 regulates arsenicinduced NADPH oxidase activation and cell migration through actin filament reorganization. J Biol Chem 280: 3875-3884, 2005

95. Ivanov VN, Hei TK: Arsenite sensitizes human melanomas to apoptosis via tumor necrosis factor alpha-mediated pathway. J Biol Chem 279: 22747-22758, 2004

96. Wang S, Shi X: Mechanisms of $\mathrm{Cr}(\mathrm{VI})$-induced p53 activation: The role of phosphorylation,mdm2and ERK. Carcinogenesis 22: 757-762, 2001 
97. Ha L, Ceryak S, Patierno SR: Chromium (VI) activates ataxia telangiectasia mutated (ATM) protein. Requirement ofATMfor both apoptosis and recovery from terminal growth arrest. J Biol Chem 278: 17885-17894, 2003

98. Buscemi G, Perego P, Carenini N, Nakanishi M, Chessa L, Chen J, Khanna K, Delia D: Activation of ATM and Chk2 kinases in relation to the amount of DNA strand breaks. Oncogene 23: 7691-7700, 2004

99. McKinnon PJ:ATMand ataxia telangiectasia.EMBORep 5: 772-776, 2004

100. Falck J, Coates J, Jackson SP: Conserved modes of recruitment of ATM, ATR and DNA-PKcs to sites of DNA damage. Nature 434: 605-611, 2005

101. Lee JH, Paull TT: ATM activation by DNA double-strand breaks through the Mre11-Rad50-Nbs1 complex. Science 308: 551-554, 2005

102. Rogakou EP, Pilch DR, Orr AH, Ivanova VS, Bonner WM: DNA double-stranded breaks induce histone H2AX phosphorylation on serine 139. J Biol Chem 273: 58585868,1998

103. Joseph P, Lei YX, Whong WZ, Ong TM: Molecular cloning and functional analysis of a novel cadmium-responsive proto-oncogene. Cancer Res 62: 703-707, 2002

104. Joseph P, Lei YX, Whong WZ, Ong TM: Oncogenic potential of mouse translation elongation factor-1 delta, a novel cadmium-responsive proto-oncogene. J Biol Chem 277: $6131-6136,2002$

105. Lemarie A, Lagadic-Gossmann D, Morzadec C, Allain N, Fardel O, Vernhet L: Cadmium induces caspase-independent apoptosis in liver Hep3B cells: role for calcium in signaling oxidative stress-related impairment of mitochondria and relocation of 
endonuclease G and apoptosis-inducing factor. Free Radic Biol Med 36: 1517-1531, 2004

106. Moulin JJ, Wild P, Romazini S, Lasfargues G, Peltier A, Bozec C, Deguerry P, Pellet F, Perdrix A: Lung cancer risk in hard-metalworkers. Am J Epidemiol 148: 241248,1998

107. Fan LZ, Cherian MG: Potential role of p53 on metallothionein induction in human epithelial breast cancer cells. Br J Cancer 87: 1019-1026, 2002

108. Ostrakhovitch EA, Cherian MG: Differential regulation of signal transduction pathways in wild type and mutated p53 breast cancer epithelial cells by copper and zinc. Arch Biochem Biophys 423: 351-361, 2004

109. Ostrakhovitch EA, Cherian MG: Role of p53 and reactive oxygen species in apoptotic response to copper and zinc in epithelial breast cancer cells. Apoptosis 10: 111121,2005

110. Nickel and Nickel Compounds. IARC Monographs 49: 257-445, 1990

111. Zhao J, Yan Y, Salnikow K, Kluz T, Costa M: Nickel-induced downregulation of serpin by hypoxic signaling. Toxicol Appl Pharmacol 194: 60-68, 2004

112. Bal W, Karantza V, Moudrianakis EN, Kasprzak KS: Interaction of Nickel(II) with histones: In vitro binding of nickel(II) to the core histone tetramer. Arch Biochem Biophys 364: 161-166, 1999

113. Bal W, Liang R, Lukszo J, Lee SH, Dizdaroglu M, Kasprzak KS: Ni(II) specifically cleaves the $\mathrm{C}$-terminal tail of the major variant of histone $\mathrm{H} 2 \mathrm{~A}$ and forms an oxidative damage-mediating complex with the cleaved-off octapeptide. Chem Res Toxicol 13: $616-624,2000$ 
114. Davidson T, Salnikow K, Costa M: Hypoxia inducible factor-1 alphaindependent suppression of aryl hydrocarbon receptor-regulated genes by nickel. Mol Pharmacol 64: $1485-1493,2003$

115. Miller AC, Blakely WF, Livengood D, Whittaker T, Xu J, Ejnik JW, Hamilton MM, Parlette E, John TS, Gerstenberg HM, Hsu H: Transformation of human osteoblast cells to the tumorigenic phenotype by depleted uranium-uranyl chloride. Environ Health Perspect 106: 465-471, 1998

116. Miller AC, Fuciarelli AF, Jackson WE, Ejnik EJ, Emond C, Strocko S, Hogan J, Page N, Pellmar T: Urinary and serum mutagenicity studies with rats implanted with depleted uranium or tantalum pellets. Mutagenesis 13: 643-648, 1998

117. Yazzie M, Gamble SL, Civitello ER, Stearns DM: Uranyl acetate causes DNA single strand breaks in vitro in the presence of ascorbate (vitamin C). Chem Res Toxicol 16: $524-530,2003$

118. Miller AC, Brooks K, Stewart M, Anderson B, Shi L, McClain D, Page N: Genomic instability in human osteoblast cells after exposure to depleted uranium: Delayed lethality and micronuclei formation. J Environ Radioact 64: 247-259, 2003

119. Stearns DM,Wise JP, Sr., Patierno SR,Wetterhahn KE: Chromium(III) picolinate produces chromosome damage in Chinese hamster ovary cells. FASEB J 9: 1643-1648, 1995

120. Bagchi D, Bagchi M, Balmoori J, Ye X, Stohs SJ: Comparative induction of oxidative stress in cultured J774A.1 macrophage cells by chromium picolinate and chromium nicotinate. Res Commun Mol Pathol Pharmacol 97: 335-346, 1997 
121. Stearns DM, Silveira SM, Wolf KK, Luke AM: Chromium(III) tris(picolinate) is mutagenic at the hypoxanthine (guanine) phosphoribosyltransferase locus in Chinese hamster ovary cells. Mutat Res 513: 135-142, 2002 


\section{SECTION IV}

As(III) transcriptionally activates the gadd45a gene via the formation of $\mathrm{H}_{2} \mathrm{O}_{2}$ 


\begin{abstract}
:
Arsenic is a ubiquitous environmental contaminant associated with an increased risk of human cancers of the skin, lung, bladder, and prostate. Intriguingly, it is also used to treat certain types of leukemia. It has recently been suggested that these paradoxic effects may be mediated by arsenic's ability to simultaneously activate DNA damage, apoptotic, and transformation pathways. Here, we investigate the effects of arsenic exposure on the induction of the growth arrest and DNA damage protein $45 \alpha$ (GADD45 $\alpha$ ), which is thought to play roles in apoptosis, DNA damage response, and cell cycle arrest. We found that arsenic transcriptionally activates the gadd $45 \alpha$ promoter located in a 153 base pair region between -234 and -81 , relative to the transcriptional start site. In addition, this transcriptional induction was abrogated in the presence of $\mathrm{H}_{2} \mathrm{O}_{2}$ scavengers, suggesting a role for $\mathrm{H}_{2} \mathrm{O}_{2}$ in the transcriptional control of the gadd45a gene through a Fenton-like free radical mechanism.
\end{abstract}




\section{$\underline{\text { Introduction }}$}

Inorganic arsenic is a ubiquitous environmental contaminant associated with a multitude of adverse health effects, including hyperkeratosis, hyperpigementation, diabetes mellitus, cardiovascular disease, reproductive defects, and cancers of several tissues including liver, bladder, skin, lung, kidney, and prostate [1-17]. The most common route of arsenic exposure is the ingestion of contaminated drinking water, which has been documented in many countries at concentrations as high as $3.4 \mathrm{mg} / \mathrm{L}$; more than 3000 times the World Health Organization recommended limits of $10 \mu \mathrm{g} / \mathrm{L}$ [18-23]. In the United States, more than 56 million Americans are estimated to have been exposed to drinking water containing arsenic concentrations that elevate the fatal cancer risk [24].

Although arsenic is poorly mutagenic in rodent and bacterial models, it has been shown to cause DNA adduct formation, DNA-protein crosslinking, and the formation of reactive oxygen species (ROS) in vitro [25-27]. In addition, arsenic has been shown to induce an assortment of signaling events including NF- $\mathrm{BB}$ activation, AP-1 activation, cmyc overexpression, involucrin repression, and extracellular signal-regulated kinase (ERK) activation, which are involved in such diverse processes as DNA repair, cellular differentiation, cell cycle arrest, and malignant transformation [28-32]. Together, these findings suggest that arsenic may be exerting its carcinogenic effects through an epigenetic mechanism.

Cell cycle dysregulation and/or perturbation is a major mechanism of carcinogenesis. While the signaling pathways involved in the $\mathrm{G}_{1} / \mathrm{S}$ phase checkpoint have been well examined, much less is known about the signaling events that occur at the $\mathrm{G}_{2} / \mathrm{M}$ phase checkpoint. Previous data from our lab and others have suggested that 
arsenic treatment can induce $\mathrm{G}_{2} / \mathrm{M}$ phase growth arrest in several different cell lines [3336]. A major player in $\mathrm{G}_{2} / \mathrm{M}$ arrest is the growth arrest and DNA damage-inducible protein $45 \alpha(G A D D 45 \alpha)$, which is induced by a variety of stress-induced signals including methyl methanesulfonate (MMS), ultraviolet (UV) irradiation, ionizing radiation (IR), sodium arsenite exposure, and serum starvation [37-42]. In addition, GADD $45 \alpha$ is proposed to play roles in chromatin remodeling and apoptosis $[43,44]$.

Transcription of the gadd45a gene is thought to be controlled by both the promoter region and the third intron region and seems to be differentially activated depending on the stimulus [45]. For example, in response to IR, the p53 transcription factor binds to its consensus sequence site in the third intron of the gadd45a gene and subsequently interacts with the WT1 transcription factor to enhance gene expression [46]. However, several groups have also suggested that after MMS and UV exposure, the ubiquitous Oct-1 transcription factor binds the promoter region between -101 and -82 base pairs (bp) relative to the transcriptional start site (tss) of the gadd45a gene with the help of an unidentified cofactor to activate gadd45a transcription in a p53-independent manner [47-50]. Recently, the forkhead transcription factor family member FOXO3a, has also been shown to bind to the forkhead response elements (FHREs) located in the gadd45a gene promoter region at $-505,-377$, and -803 in response to $\mathrm{UV}$, resulting in transcriptional activation [51]. Thus, gadd45a gene regulation is complex and may involve many different signaling pathways.

Since GADD $45 \alpha$ is a general stress response protein, we examined the effects of ROS produced in response to As(III) exposure on gadd45a gene regulation. We used a human bronchial epithelial airway cell line, BEAS-2B, to examine these effects because 
the lung is a target of arsenic induced carcinogenesis, particularly in occupational settings [7]. Our results show that As(III) transcriptionally induces gadd45a gene expression from its promoter region via a free radical mechanism involving the formation of $\mathrm{H}_{2} \mathrm{O}_{2}$.

\section{Materials and Methods}

Cell Culture and Media.

The BEAS-2B human lung epithelial cell line was obtained from the American Type Culture Collection (Manasses, VA) and maintained in Dulbecco's Modified Eagle Medium (Sigma, St. Louis, MO) containing 5\% fetal bovine serum (Invitrogen/Gibco BRL, Carlsbad, CA), 1 unit/mL penicillin, $1 \mu \mathrm{g} / \mathrm{mL}$ streptomycin, and $300 \mu \mathrm{g} / \mathrm{mL} \mathrm{L-}$ glutamine (Sigma, St. Louis, MO). BEAS-2B cells were passaged when confluency was reached, usually every 4-5 days.

\section{Western Blotting.}

Six well tissue culture plates were grown to a density of approximately $1 \times 10^{6}$ cells per well and treated with concentrations of $\mathrm{AsCl}_{3}$ (Sigma, St. Louis, MO) ranging from 0-50 $\mu \mathrm{M}$ over a time period of 0-24 hours. Phosphate buffered saline (PBS) washed cells were incubated five minutes with $100 \mu \mathrm{L}$ of MPER mammalian lysis reagent (Pierce Biotechnology, Inc., Rockford, IL) with shaking at room temperature. A portion of each sample's cell lysate $(25 \mu \mathrm{L})$ was subsequently analyzed for total protein concentration using a BCA Protein Assay kit (Pierce Biotechnology, Inc., Rockford, IL). Pre-cast 4$20 \%$ gradient polyacrylamide gels (Invitrogen, Carlsbad, CA) were loaded with $20 \mu \mathrm{g}$ of total protein for each sample and electrophoresis was perfomed for approximately 105 
minutes at 125 volts using a $1 \mathrm{X}$ dilution of $10 \mathrm{X}$ Tris-Glycine Running Buffer (Invitrogen, Carlsbad, CA), the XCell SureLock Mini-Cell system (Invitrogen, Carlsbad, CA), and a PowerPac 300 power supply (Bio-Rad Laboratories, Hercules, CA). Gels were rinsed with a $1 \mathrm{X}$ dilution of 25X Tris-Glycine Transfer Buffer (Invitrogen, Carlsbad, CA) and transferred to a PVDF membrane (Invitrogen, Carlsbad, CA) at 35 volts for two hours using the XCell II Blot Module (Invitrogen, Carlsbad, CA). PVDF membranes were blocked for 1 hour at room temperature with 5\% milk buffer in TBSTween (Sigma, St. Louis, MO). Membranes were incubated with a 1:200 dilution of GADD45 $\alpha$ (H-165) primary antibody (Santa Cruz Biotechnology, Inc., Santa Cruz, CA) in $5 \%$ milk buffer overnight at $4^{\circ} \mathrm{C}$ on a rocking platform. For $\beta$-actin primary antibody (Sigma, St. Louis, MO) and GAPDH primary antibody (Santa Cruz Biotechnology, Inc., Santa Cruz, CA), dilutions of 1:2000 and 1:200 were used, respectively. Membranes were subjected to three ten minute washes with TBS-Tween (Sigma, St. Louis, MO) and immediately placed in a 1:1000 dilution of an anti-rabbit or anti-mouse IgG AP-linked secondary antibody (Cell Signaling Technology, Beverly, MA) in 5\% milk buffer for 2-4 hours at room temperature with shaking. After three ten minute washes with TBS-Tween (Sigma, St. Louis, MO), membranes were immediately incubated with CDP-Star Reagent (New England BioLabs, Inc., Beverly, MA) for five minutes with shaking in the dark at room temperature. Membranes were rinsed with TBS-Tween and exposed to X-ray film (Daigger, Vernon Hills, IL).

\section{Oxygen Consumption.}


A Gilson 5/6 Oxygraph (Gilson Medical Electronics, Inc., Middleton, WI) was used to perform oxygen consumption studies. BEAS-2B cells were trypsinized and washed with 1X PBS (Invivtrogen/Gibco BRL, Carlsbad, CA) and $4 \times 10^{6}$ cells were re-suspended in a final volume of $1 \mathrm{~mL}$ of PBS. $1 \mathrm{mM} \mathrm{AsCl}_{3}$ (Sigma, St. Louis, MO) was added to each aliquot and allowed to incubate for 20 minutes at room temperature. Oxygen consumption rates were calculated using the following equation:

nmoles $\mathrm{O}_{2}$ consumed $/$ minute $/ 10^{6}$ cells $=\underline{(\mathrm{BP}-47) \Delta \mathrm{B}(1.835)}$,

$$
(\mathrm{m})(\mathrm{t})(\mathrm{n})
$$

where $\mathrm{BP}=$ atmospheric pressure in $\mathrm{mmHg}, \Delta \mathrm{B}=$ number of vertical blocks traversed on the oxygraph chart paper (rise of experimental slope), $\mathrm{m}=$ slope of $\mathrm{O}_{2}$ standards (409 in this case), $\mathrm{t}=$ time in minutes used to determine $\Delta \mathrm{B}$ (run of experimental slope), and $\mathrm{n}$ $=\mathrm{n} \times 10^{6}$ cells used in the assay. Three replicates of three different samples were averaged together to determine mean $\mathrm{O}_{2}$ consumption and error bars equal \pm standard error of the mean (SEM).

\section{Electron Spin Resonance (ESR).}

$1 \times 10^{6}$ BEAS-2B cells were suspended in $500 \mu \mathrm{L}$ of $1 \mathrm{X}$ PBS (Invitrogen/Gibco BRL, Carlsbad, CA) and treated with $1 \mathrm{mM} \mathrm{AsCl}_{3}$ (Sigma, St. Louis, MO) and/or $2000 \mathrm{U} / \mathrm{mL}$ catalase isolated from bovine liver (Sigma, St. Louis, MO). All ESR measurements were conducted using a Bruker EMX spectrometer (Bruker Instruments Inc. Billerica, MA) and a flat cell assembly. Hyperfine couplings were measured (to $0.1 \mathrm{G}$ ) directly from 
magnetic field separation using potassium tetraperoxochromate $\left(\mathrm{K}_{3} \mathrm{CrO}_{8}\right)$ and 1,1diphenyl-2-picrylhydrazyl (DPPH) as reference standards. The relative radical concentration was estimated by multiplying half of the peak height by $\left(\Delta \mathrm{H}_{\mathrm{pp}}\right)^{2}$, where $\Delta \mathrm{H}_{\mathrm{pp}}$ represents peak-to peak width. The Acquisit program was used for data acquisitions and analyses. Reactants were mixed in test tubes in a final volume of $1.0 \mathrm{~mL}$. The reaction mixture was then transferred to a flat cell for ESR measurement. The concentrations given in the figure legends are final concentrations. Experiments were performed at room temperature and under ambient air. Statistical analysis was performed using Student's t-test and error bars equal \pm SEM.

Construction of GPX1-EGFP and SOD1-EGFP fusion constructs. pcDNA3.1(+)/GPx1 and pcDNA3/SOD1 constructs were graciously provided to our laboratory by Dr. Larry Oberley's lab at the University of Iowa [52,53]. The GPx1 cDNA was removed from the pcDNA3.1 construct using a BamHI (Promega Life Sciences, Madison, WI) and HindIII (Promega Life Sciences, Madison, WI) double enzymatic digest. The SOD1 cDNA was removed from the pcDNA3 constuct using a KpnI (Promega Life Sciences, Madison, WI) and ApaI (Promega Life Sciences, Madison, WI) double enzymatic digest. Both GPx1 and SOD1 cDNA fragments were isolated from an agarose gel and ligated into a pEGFP-C3 (BD Biosciences - Clontech, Palo Alto, CA) vector in frame with the EGFP protein. Contents of both vectors were verified by DNA sequencing (Biotech Core, Inc., Mountain View, CA).

\section{Transient transfections.}


Transient transfections were performed using SuperFect Transfection Reagent (Qiagen, Inc., Valencia, CA) according to the manufacturer's instructions. Briefly, cells were plated at 50\% confluency, and DNA/SuperFect complexes were allowed to enter BEAS2B cells for three hours. DNA complexes were removed and fresh growth medium was added. Transfection efficiencies of the pEGFP-C3, pEGFP-C3/GPx1, and pEGFPC3/SOD1 were calculated by counting EGFP $(+)$ cells with a confocal microscope and determined to be roughly $8-10 \%$ for all three plasmids.

Quantitative real- time polymerase chain reaction ( $q R T-P C R$ ).

Total RNA was isolated from approximately $1 \times 10^{6}$ BEAS-2B cells using an RNeasy Mini Kit (Qiagen, Inc., Valencia, CA). Total RNA was quantified using a NanoDrop ND-1000 UV-Vis Spectrophotometer (NanoDrop Technologies, Wilmington, DE). Quantitect SYBR Green one-step qRT-PCR kits (Qiagen, Inc., Valencia, CA) were used to set up qRT-PCR reactions using $10 \mathrm{ng}$ of total RNA as a template. qRT-PCR experiments were performed on an ABI 7700 qRT-PCR machine (Applied Biosystems, Foster City, CA). Validated GADD45 $\alpha$ primer sets were obtained from Qiagen, Inc. (Valencia, CA) and 18S rRNA primer set controls were obtained from Ambion, Inc. (Austin, TX). Each sample was replicated three times per plate and an average $\Delta \mathrm{C}_{\mathrm{t}}$ value was calculated. Relative quantitation of GADD $45 \alpha$ mRNA was calculated using the $\Delta \Delta \mathrm{C}_{\mathrm{t}}$ method. Error bars represent $\pm \mathrm{SEM}$.

Dual-Luciferase Reporter Assay. 
BEAS-2B cells were applied to 12 -well tissue culture plates at approximately $50 \%$ confluency and transiently transfected with either a full length or deleted GADD45 $\alpha$ promoter-firefly luciferase construct (kind gifts from Dr. Dennis Bruemmer at the University of California - Los Angeles, CA) or a GADD45 $\alpha$ intron 3- firefly luciferase construct (a kind gift from Dr. Albert J. Fornace, Jr. at Harvard University, Cambridge, MA) [54,55]. In addition, each sample was co-transfected with a pRL-TK Renilla luciferase vector (Promega Life Sciences, Madison, WI) underneath the constitutive control of the herpes simplex virus thymidine kinase promoter to provide a measure of transfection efficiency for normalization. Constructs were allowed to express for at least

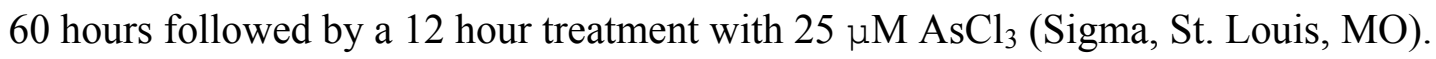
$100 \mu \mathrm{L}$ of firefly luciferase substrate was injected into each well of a Lumitrac $20096-$ well plate (USA Scientific, Inc., Ocala, FL) containing $20 \mu \mathrm{L}$ of cell lysate. Firefly luciferase units were measured by an EG\&G Berthold Microplate Luminometer MicroLumat Plus with an automatic injector (EG\&G Berthold, Germany). WinGlow software (EG\&G Berthold, Germany) was used to obtain readings with a 2.0 second delay and a 10.0 second measurement of luciferase activity and expressed in luciferase units. Luciferase substrates were obtained from the Dual-Luciferase Reporter Assay kit (Promega Life Sciences, Madison, WI). Three replicates were assayed per experiment and the ratio of inducible firefly luciferase activity to basal Renilla luciferase activity was averaged for each group. Fold induction was calculated by dividing the average ratios of As(III)-treated samples by the average ratios of samples left untreated. Error bars represent \pm SEM and statistical significance was calculated using Student's t-test. Data shown is representative of three independent experiments. 
$\underline{\text { Results }}$

As(III) exposure induces expression of the GADD45 $\alpha$ protein in a time-and dosedependent manner. Because GADD45 $\alpha$ expression has been observed in response to many stress conditions including UV irradiation, serum starvation, and alkylating agents, we investigated the effects of As(III) exposure on its induction $[32,37,38]$. In order to simulate airway exposure to arsenic, an immortalized non-tumorigenic BEAS-2B human lung airway epithelial cell line was used for these experiments. Western blot analysis of GADD45 $\alpha$ in response to increasing concentrations of $\mathrm{AsCl}_{3}$ revealed a time- and dosedependent increase in protein abundance (Fig. 1), whereas equal concentrations of $\mathrm{NaCl}$ had no effect (data not shown). $\beta$-actin abundance remained unaffected throughout the dose and time course of As(III) exposure. Densitometry readings, normalized to $\beta$-actin expression, confirmed that GADD $45 \alpha$ protein abundance increased more than 100 -fold over untreated BEAS-2B cells 12 hours after $25 \mu \mathrm{M}$ As(III ) treatment (data not shown). This result demonstrates that GADD45 $\alpha$ protein is induced in BEAS-2B cells in response to As(III) exposure in a dose-dependent manner.

\section{As(III) exposure increases oxygen consumption and $\mathrm{OH}$ production in BEAS-2B}

cells. Since As(III) has been shown to exert mutagenic effects via reactive oxygen species (ROS) production in several cellular systems, it is possible that the signaling events induced by As(III), specifically GADD $45 \alpha$ induction, are also mediated by a ROS mechanism [56]. In order to address this possibility, BEAS-2B cells were exposed to 1 $\mathrm{mM}$ As(III) for 20 minutes and the rate of oxygen consumption was measured by a 
Gilson 5/6 Oxygraph. As(III)-exposed BEAS-2B cells showed approximately a threefold increase in the amount of oxygen consumed in vitro (Fig. 2A), suggesting that a free radical mechanism may be occurring in BEAS-2B cells upon As(III) stimulation.

To determine the identity of the radicals produced, we employed electron spin resonance (ESR) spectroscopy. Representative ESR spectra are displayed in Figure 2B. A basal level of ${ }^{\circ} \mathrm{OH}$, signified by its 1-2-2-1 relative peak height fingerprint, is produced by normal BEAS-2B cells, and was expected as a consequence of normal respiration; however, after a 20 minute exposure to $1 \mathrm{mM} \mathrm{As}(\mathrm{III})$, the ${ }^{\circ} \mathrm{OH}$ signal significantly increased (Fig. 2B). Spectral results were quantified by peak height measurements in Figure $2 \mathrm{C}$, where a 2.5 - fold increase in ${ }^{\circ} \mathrm{OH}$ production was observed after $\mathrm{As}(\mathrm{III})$ exposure when compared to normal respiring cells. The ${ }^{\circ} \mathrm{OH}$ signal was attenuated by the addition of 2000 units $/ \mathrm{mL}$ of catalase, showing that $\mathrm{H}_{2} \mathrm{O}_{2}$ is a precursor of ${ }^{\circ} \mathrm{OH}$. These data indicate that ${ }^{\circ} \mathrm{OH}$ is a major free radical formed in the BEAS-2B cell line in response to As(III) exposure.

\section{GADD45a protein abundance decreases in response to As(III) in the presence of the} $\mathrm{H}_{2} \mathrm{O}_{2}$ scavenger, GPx1. Because As(III) produced ${ }^{\circ} \mathrm{OH}$ in the BEAS-2B cell line and GADD45 $\alpha$ is induced in response to many stressors, we hypothesized that its induction may occur through an oxidative stress mechanism. To assess the role of ROS in GADD45 $\alpha$ induction, we constructed glutathione peroxidase 1 (GPx1)-EGFP and superoxide dismutase 1 (SOD1)-EGFP overexpression/fusion vectors and examined their effects on GADD45 $\alpha$ protein abundance. The GPx1 enzyme is a $\mathrm{H}_{2} \mathrm{O}_{2}$ scavenger, whereas the SOD1 enzyme is a $\mathrm{O}_{2}{ }^{-\cdots}$ scavenger. GPx1-EGFP, SOD1-EGFP, and empty 
vector $\mathrm{pEGFP}-\mathrm{C} 3$ constructs were transiently transfected into BEAS-2B cells. 48 hours after transfection, cells were treated with $25 \mu \mathrm{M}$ As(III) for 12 hours, and subjected to Western blot analysis. Overexpression of the GPx1-EGFP fusion construct reduced GADD $45 \alpha$ protein abundance by at least 50\% (Fig. 3) as measured by densitometry and normalized to GAPDH expression (data not shown). Empty vector and SOD1 construct overexpression did not affect GADD45 $\alpha$ expression (Fig. 3), implying that the formation of $\mathrm{H}_{2} \mathrm{O}_{2}$ is partially responsible for the induction of the GADD $45 \alpha$ protein in response to As(III).

As(III) exposure increases GADD45 $\alpha$ mRNA abundance. To determine how As(III) exposure induces the GADD45 $\alpha$ protein, we examined GADD45 $\alpha$ transcript abundance at several time points using qRT-PCR. A concentration of $25 \mu \mathrm{M}$ As(III) was chosen to obtain a maximal effect. Relative quantification of GADD45 $\alpha$ mRNA was performed using the 0 hour time point as a calibration value. As shown in Figure 4, GADD45 $\alpha$ mRNA increases almost 30-fold after three hours of treatment. Although GADD45 $\alpha$ mRNA slightly decreased during the following three time points, it began to increase again at the 24 hour time point, mimicking the GADD $45 \alpha$ protein expression pattern (see

Fig.1). Therefore, we reasoned that the gadd $45 \alpha$ gene could be transcriptionally induced by As(III) exposure.

\section{As(III) activates transcription of gadd45 $\alpha$ through both the promoter region and the}

third intron region. To establish whether the increase in mRNA abundance resulted from transcriptional activation or as a consequence of increased mRNA stability, we 
examined the effects of As(III) on induction of the gadd $45 \alpha$ promoter and intron 3 regions. GADD45 $\alpha$ promoter-luciferase and intron 3-luciferase transcriptional fusion constructs were transiently transfected into BEAS-2B cells, subjected to As(III) treatment for 12 hours, and assayed for luciferase activity. The GADD45 $\alpha$ promoter construct showed a five-fold increase in luciferase activity in response to $25 \mu \mathrm{M} \mathrm{As}$ (III) (Fig. 5). Similarly, the GADD $45 \alpha$ intron 3 construct exhibited a four-fold increase in activity (Fig. 5). Neither of the control constructs containing the luciferase gene alone (GVB2 or GL3) showed any discernible difference between the untreated samples and the As(III)-exposed samples, illustrating that both the promoter and intron 3 regions of the gadd $45 a$ gene are activated by As(III) exposure.

Since $\mathrm{H}_{2} \mathrm{O}_{2}$ was involved in As(III)-induced GADD45a protein levels, we examined the effects of $\mathrm{H}_{2} \mathrm{O}_{2}$ on the transcriptional activation of gadd45a. GPx1 or a control vector was co-transfected with the aforementioned GADD45 $\alpha$ promoter and intron 3 constructs. GPx 1 overexpression decreased promoter-luciferase activity by $50 \%$ when compared to transfection with the empty vector (Fig. 6). Surprisingly, the control vector itself slightly increased luciferase activity in the gadd $45 a$ promoter construct. The reason for this phenomenon is unclear. In contrast, the activity of the intron 3 construct after As(III) exposure remained largely unaffected (Fig. 6). These results suggest a role for $\mathrm{H}_{2} \mathrm{O}_{2}$ in the transcriptional activation of the gadd45a promoter region.

\section{As(III) activation of the GADD45 $\alpha$ promoter region occurs between -81 and -234}

relative to the tss. Given that the GADD45 $\alpha$ promoter-luciferase transcriptional fusion construct was activated by the presence of $\mathrm{H}_{2} \mathrm{O}_{2}$, we wanted to pinpoint which portion of 
the promoter region was responsible for the activation. Six GADD45 $\alpha$ promoterluciferase deletion constructs, named for the length of the promoter region with regards to the transcriptional start site $(+1)$, were transfected into BEAS-2B cells and exposed to 25 $\mu \mathrm{M}$ As(III) for 12 hours (Fig. 7A). A five- to six- fold increase in luciferase activity was observed in all constructs containing at least 234 base pairs upstream of the +1 site (Fig. 7B). A further deletion of approximately $150 \mathrm{bp}$ (to -81) eliminated most of the luciferase activity. Putative transcription factor binding sites located in this region include consensus sequences for AP-1, MBF-1, Egr-1, Egr-2, Egr-3, and WT1 (-KTS) [57].

We subsequently examined the effects of $\mathrm{As}(\mathrm{III})$-induced $\mathrm{H}_{2} \mathrm{O}_{2}$ formation on the induction of the promoter deletion constructs. Again, GPx1 overexpression and the removal of $\mathrm{H}_{2} \mathrm{O}_{2}$ decreased luciferase induction by approximately $50 \%$ in all constructs showing more than five-fold induction (Fig. 7C). No change was seen in the smaller constructs. These results suggest that the 153 bp region located between -234 and -81 contains an $\mathrm{As}(\mathrm{III})$-responsive region that is sensitive to the production of $\mathrm{H}_{2} \mathrm{O}_{2}$.

\section{$\underline{\text { Discussion }}$}

The findings presented here suggest that As(III) exposure induces the transcriptional activation of the gadd45a gene through a Fenton-like free radical mechanism (Fig. 8). The Fenton reaction, which is usually associated with an excess of $\mathrm{Fe}(\mathrm{II})$, occurs when a transition metal is oxidized during its interaction with $\mathrm{H}_{2} \mathrm{O}_{2}$, producing an oxidized metal and two molecules of ${ }^{\circ} \mathrm{OH}$. Our data show that As(III) treatment increases the amount of molecular oxygen consumed by BEAS-2B cells, 
indicating that more oxygen is available for conversion to $\mathrm{O}_{2}{ }^{\cdot-}$ and subsequent formation of $\mathrm{H}_{2} \mathrm{O}_{2}$. In addition, ESR data shows that the relative amount of ' $\mathrm{OH}$ increases in response to As(III) exposure, which is alleviated by treatment with the $\mathrm{H}_{2} \mathrm{O}_{2}$ scavenger enzyme catalase. The removal of $\mathrm{H}_{2} \mathrm{O}_{2}$ from the intracellular environment by GPx1 overexpression decreases gadd45a promoter-luciferase activity and GADD45 $\alpha$ protein expression, further supporting a role for $\mathrm{H}_{2} \mathrm{O}_{2}$ in GADD45 $\alpha$ induction. Surprisingly, treatment with $\mathrm{H}_{2} \mathrm{O}_{2}$ alone only weakly induced GADD45 $\alpha$ protein expression when compared to equal concentrations of As(III) treatment, whereas co-treatment with $\mathrm{H}_{2} \mathrm{O}_{2}$ and As(III) enhanced GADD45 $\alpha$ protein induction (data not shown). Collectively, these results suggest that the formation of ${ }^{\circ} \mathrm{OH}$ through a Fenton-like reaction is at least partially responsible for the induction of gadd $45 a$ transcription and protein expression in response to As(III) exposure.

The induction of gadd45a transcription by the production of $\mathrm{H}_{2} \mathrm{O}_{2}$ and/or ${ }^{\circ} \mathrm{OH}$ and each molecule's subsequent intracellular activities may partially account for the wide variety of chemical and physical inducers of GADD $45 \alpha$ protein expression. IR and UV irradiation, both potent inducers of GADD45 $\alpha$ expression, also induce ${ }^{\circ} \mathrm{OH}$ formation [37,58]. Additionally, generation of $\mathrm{H}_{2} \mathrm{O}_{2}$ and ${ }^{\circ} \mathrm{OH}$ via the Fenton reaction can induce the formation of apurinic sites, the same type of DNA lesion induced by another potent GADD45 $\alpha$ inducer, methyl methanesulfonate (MMS) [37,59]. These data suggest that $\mathrm{H}_{2} \mathrm{O}_{2}$ and/or ' $\mathrm{OH}$ production may be a key regulator of GADD45 $\alpha$ transcriptional induction.

Because, BEAS-2B cells contain a p53 protein that has been inactivated by expression of the E6 viral protein, gadd45a transcriptional activation by As(III) occurs 
through a p53-independent mechanism in these cells [60]. Based on the experimental data presented in this manuscript, we have identified several other candidate transcription factors that may be involved in gadd45a transcription. One major candidate is the AP-1 transcription factor, since it has previously been identified as an As(III)-activated protein $[61,62]$. In addition, the yeast homolog of the human AP-1 protein, Yap1, contains a redox regulated domain consisting of disulfide bonds that can mask or expose its nuclear localization sequence, depending on the redox status of the cell [63]. These findings make AP-1 an ideal candidate for ROS-mediated transcriptional activation. Moreover, the $153 \mathrm{bp}$ region of the gadd45a promoter-luciferase deletion constructs affected by antioxidant overexpression boasts four possible AP-1 consensus binding sequences [57]. Finally, AP-1 has also been identified as the transcription factor responsible for increasing expression of the DNA damage response gene gadd153 after As(III) exposure, suggesting that $\mathrm{H}_{2} \mathrm{O}_{2}$ production and redox status may be a general mechanism for the transcriptional activation of DNA damage response genes [64].

Alternatively, the early growth response 1 (Egr-1) transcription factor may also be involved in $\mathrm{H}_{2} \mathrm{O}_{2}$-mediated transcriptional activation of gadd45a. Egr-1 has recently been shown to induce gadd45a transcription in response to UV irradiation [65]. Furthermore, Egr-1 induction occurs three hours after $25 \mu \mathrm{M}$ As(III) treatment coincidental with the increase in gadd45a mRNA abundance shown in Fig. 4 (D. Bhatia and F. Chen, unpublished data). Testing is underway in our laboratory to determine the effects of Egr-1 on gadd45a transcriptional activation in response to As(III) exposure.

In conclusion, we have shown that the gadd45a gene is transcriptionally induced by $\mathrm{As}(\mathrm{III})$ exposure through the formation of $\mathrm{H}_{2} \mathrm{O}_{2}$. This induction occurs in the 
promoter region of the gadd45a gene and the redox responsive element is located in the 234 to -81 base pair region. Future work will focus on the identification of the transcription factor(s) responsible for the oxidative stress-dependent transcriptional induction of gadd45a. 
List of Abbreviations:

GADD45 $\alpha$

$\mathrm{H}_{2} \mathrm{O}_{2}$

As(III)

bp

tss

mg

$\mu \mathrm{g}$

L

DNA

ROS

$\mathrm{NF}-\kappa \mathrm{B}$

AP-1

ERK

G1/S

G2/M

MMS

UV

IR

FHRE

$\mathrm{mL}$

$\mathrm{AsCl}_{3}$

$\mu \mathrm{M}$ growth arrest and DNA damage-inducible protein 45 alpha

hydrogen peroxide

arsenite

base pairs

transcriptional start site

milligram

microgram

liter

deoxyribonucleic acid

reactive oxygen species

nuclear factor $\kappa \mathrm{B}$

activator protein 1

extracellular signal-regulated kinase

gap $1 /$ synthesis phase checkpoint

gap2/mitosis phase checkpoint

methylmethane sulfonate

ultraviolet irradiation

ionizing radiation

forkhead response elements

milliliter

arsenic trichloride

micromolar 


\begin{tabular}{|c|c|}
\hline$\mu \mathrm{L}$ & microliter \\
\hline PBS & phosphate buffered saline \\
\hline$\mu \mathrm{g}$ & microgram \\
\hline PVDF & Polyvinylidene fluoride \\
\hline TBS-Tween & Tris-buffered saline \\
\hline $\mathrm{O}_{2}$ & oxygen \\
\hline SEM & standard error of the mean \\
\hline $\mathrm{mM}$ & millimolar \\
\hline ESR & electron spin resonance \\
\hline G & Gauss \\
\hline DPPH & diphenyl-2-picrylhydrazyl \\
\hline $\mathrm{K}_{3} \mathrm{CrO}_{8}$ & potassium tetraperoxochromate \\
\hline GPx1 & glutathione peroxidase 1 \\
\hline SOD1 & superoxide dismutase 1 \\
\hline cDNA & complementary DNA \\
\hline EGFP & enhanced green fluorescence protein \\
\hline qRT-PCR & quantitative real-time polymerase chain reaction \\
\hline RNA & ribonucleic acid \\
\hline rRNA & ribosomal ribonucleic acid \\
\hline $\mathrm{C}_{\mathrm{t}}$ & threshold cycle \\
\hline$\cdot \mathrm{OH}$ & hydroxyl radical \\
\hline $\mathrm{O}_{2}{ }^{\cdot-}$ & superoxide radical \\
\hline GAPDH & Glyceraldehyde-3-phosphate dehydrogenase \\
\hline
\end{tabular}


mRNA

MBF-1

Egr-1

Egr-2

Egr-3

Yap1

gadd 153 messenger ribonucleic acid

metal binding factor 1

early growth response gene 1

early growth response gene 2

early growth response gene 3

yeast activator protein 1

growth arrest and DNA damage-inducible protein 153 


\section{Figure Legends:}

Fig. 1. $25 \mu M$ As(III) induces maximal GADD45 $\alpha$ expression at 12 hours.

A dose/time course Western blot of As(III)-exposed BEAS-2B cells show

maximal GADD45 $\alpha$ induction after 12 hours of treatment. BEAS-2B cells were exposed to As(III) concentrations of $0,3.25,6.25,12.5,25$, and $50 \mu \mathrm{M} .20 \mu \mathrm{g}$ of total protein were loaded into each lane and GADD45 $\alpha$ expression was detected with a polyclonal antibody.
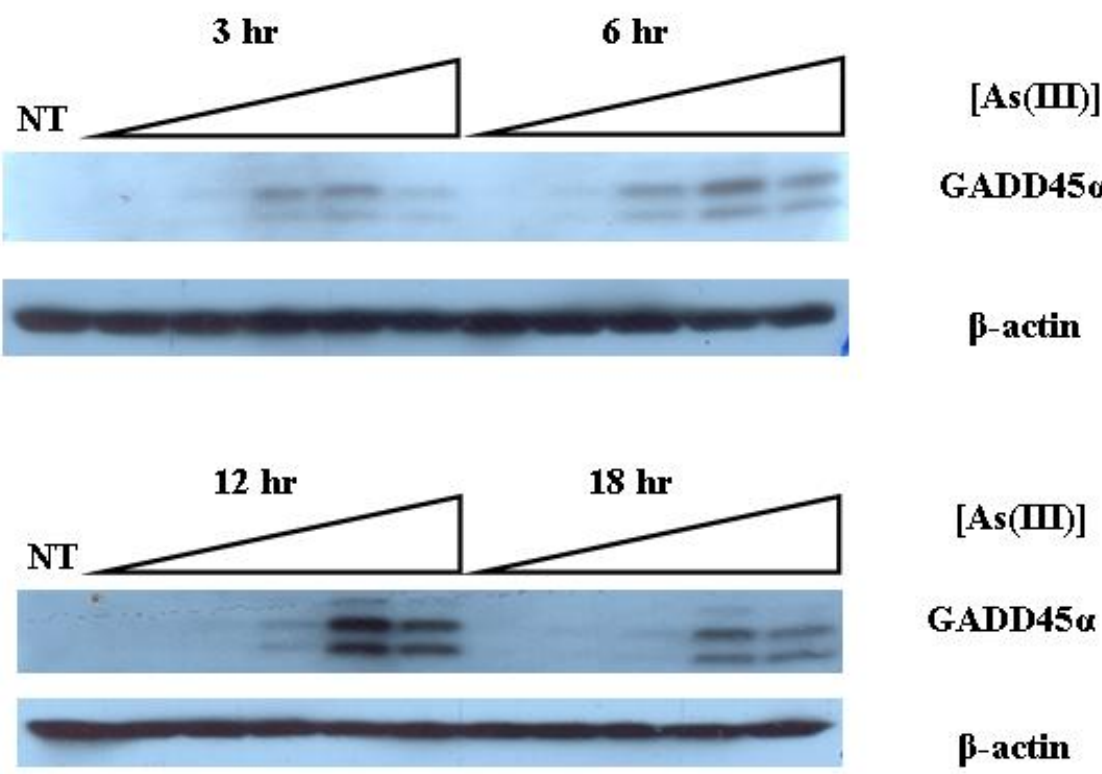
Fig. 2. A. As(III) exposure increases $\mathrm{O}_{2}$ consumption in BEAS-2B cells.

Aliquots of $4 \times 10^{6}$ BEAS-2B cells were injected into a Gilson 5/6 Oxygraph and the rate of oxygen consumption was measured with or without a 20 minute exposure to $1 \mathrm{mM} \mathrm{As}(\mathrm{III}) . \mathrm{O}_{2}$ consumption in the presence of $\mathrm{As}(\mathrm{III})$ was increased approximately three fold.

A.

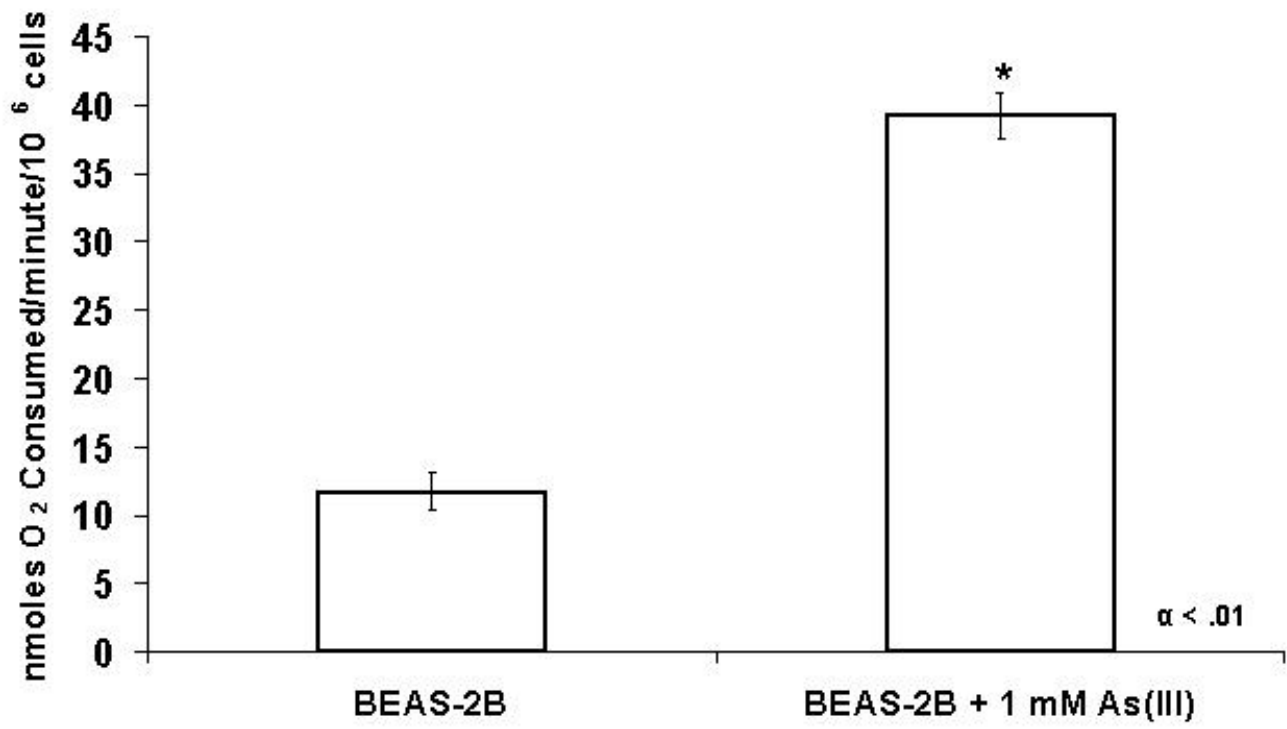


Figure $2 B$. As(III) induces the formation of ${ }^{\circ} \mathrm{OH}$ in BEAS-2B cells. Formation of ${ }^{\circ} \mathrm{OH}$ was measured by ESR spectroscopy in aliquots of $1 \times 10^{6}$ BEAS-2B cells with or without exposure to $1 \mathrm{mM}$ As(III). Figures shown are examples of spectra of control BEAS-2B cells (left) and As(III)-exposed BEAS-2B cells (right) exhibiting the characteristic ${ }^{\circ} \mathrm{OH}$ ESR fingerprint.

B.

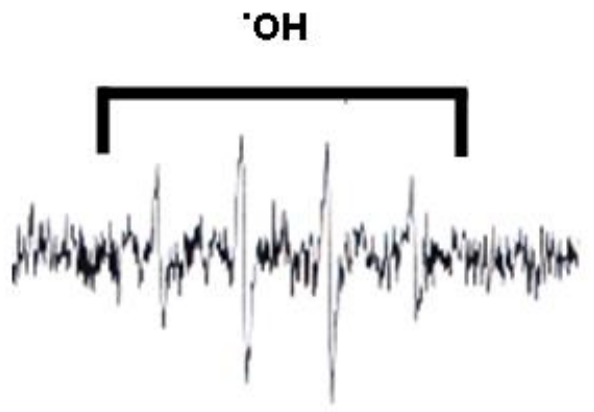

BEAS-2B

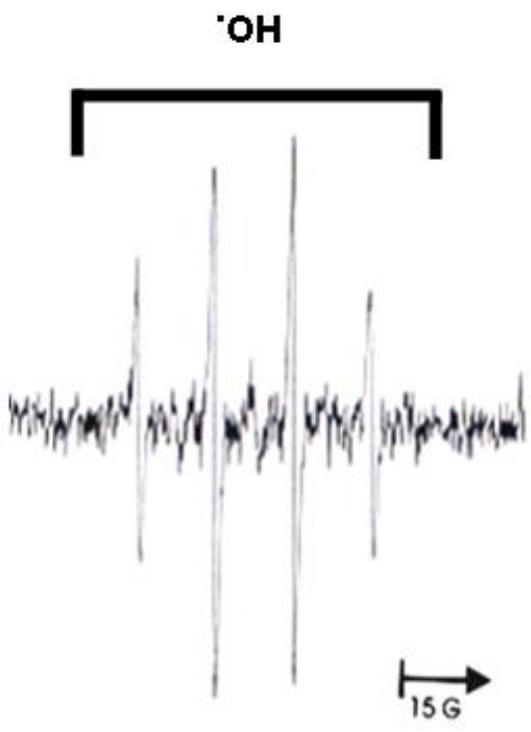

BEAS-2B + 1 mM As(III) 
Figure 2C. Graphical representation of ESR peak height. ESR peak heights were measured and quantified as described in Materials and Methods. As(III)-exposed BEAS2B cells showed a 2.5 fold increase in the amount of ${ }^{\circ} \mathrm{OH}$ formation which was abrogated by the addition of 2000 units $/ \mathrm{mL}$ of catalase, confirming the identity of ${ }^{\circ} \mathrm{OH}$.

c.

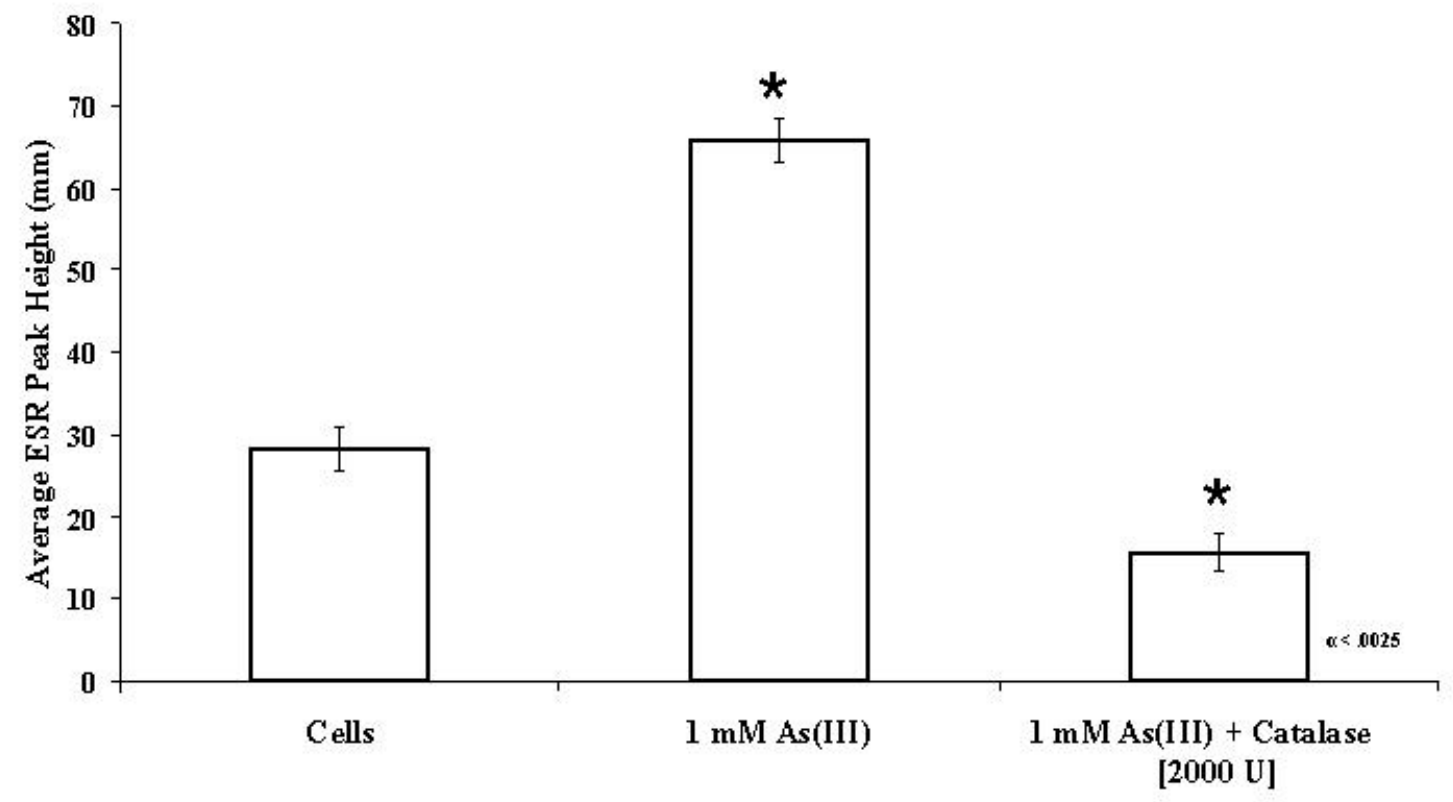


Fig. 3. Overexpression of the $\mathrm{H}_{2} \mathrm{O}_{2}$ scavenging enzyme GPx1 reduces GADD45 $\alpha$ protein expression. BEAS-2B cells were transiently transfected with a GPx1, SOD1, or $\mathrm{C} 3$ empty vector and assayed for changes in GADD45 $\alpha$ expression via western blot. Removal of $\mathrm{H}_{2} \mathrm{O}_{2}$ by GPx1 overexpression decreased GADD $45 \alpha$ expression by approximately $50 \%$.

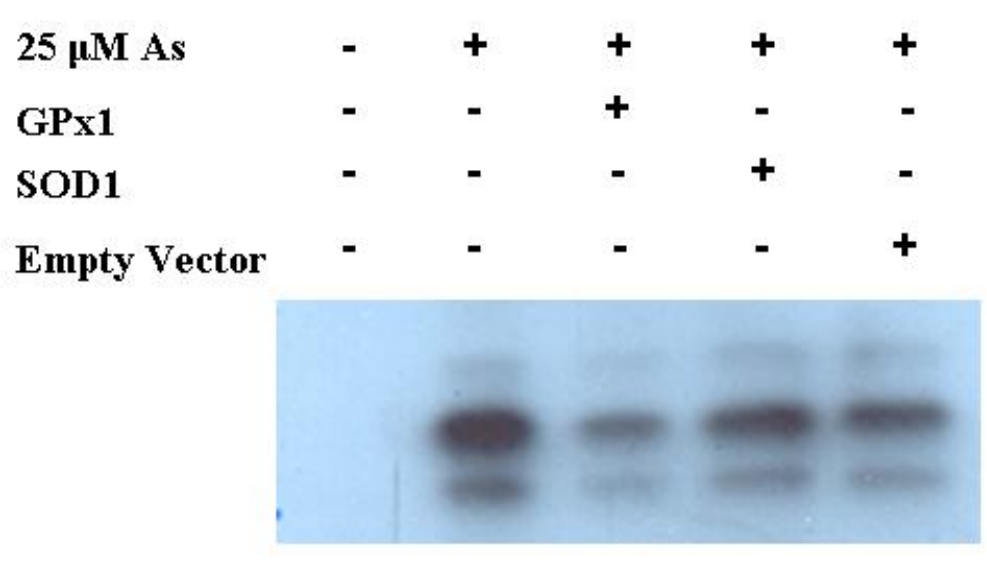

\title{
GADD45 $\alpha$
}

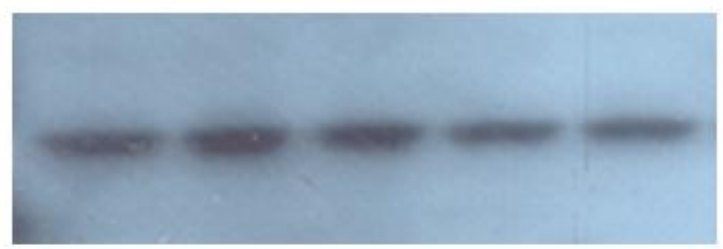

\author{
GAPDH
}


Fig. 4. As(III) exposure increases GADD45 $\alpha$ transcript abundance. Relative qRT-PCR was employed to measure the abundance of the GADD45 $\alpha$ transcript using the $0 \mathrm{hr}$ time point as a calibrator. Transcript abundance increased approximately 30 fold after a three hour As(III) treatment.

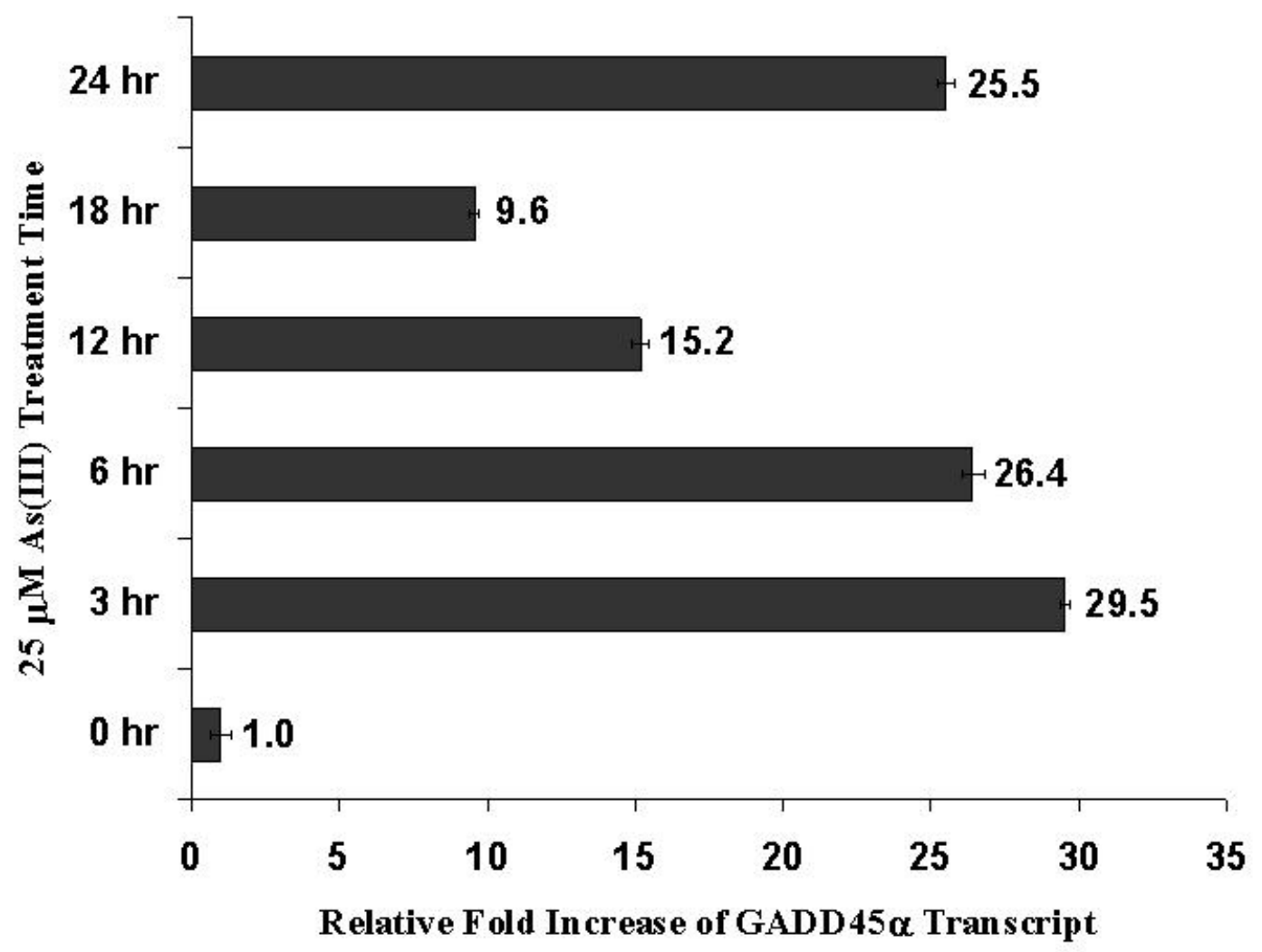


Fig. 5. As(III) activates both the GADD45 $\alpha$ promoter region and the intron 3 region. A dual luciferase reporter system was used to determine the activation of the GADD45 $\alpha$ promoter-luciferase (G45) and the intron 3-luciferase (Int3) constructs. Constructs were transiently transfected into BEAS-2B cells and luciferase activity was normalized to an internal transfection control. 5.2 and 4 fold increases in the G45 and Int3 luciferase activity, respectively, were observed in As(III)-exposed samples when compared to the untreated control samples.

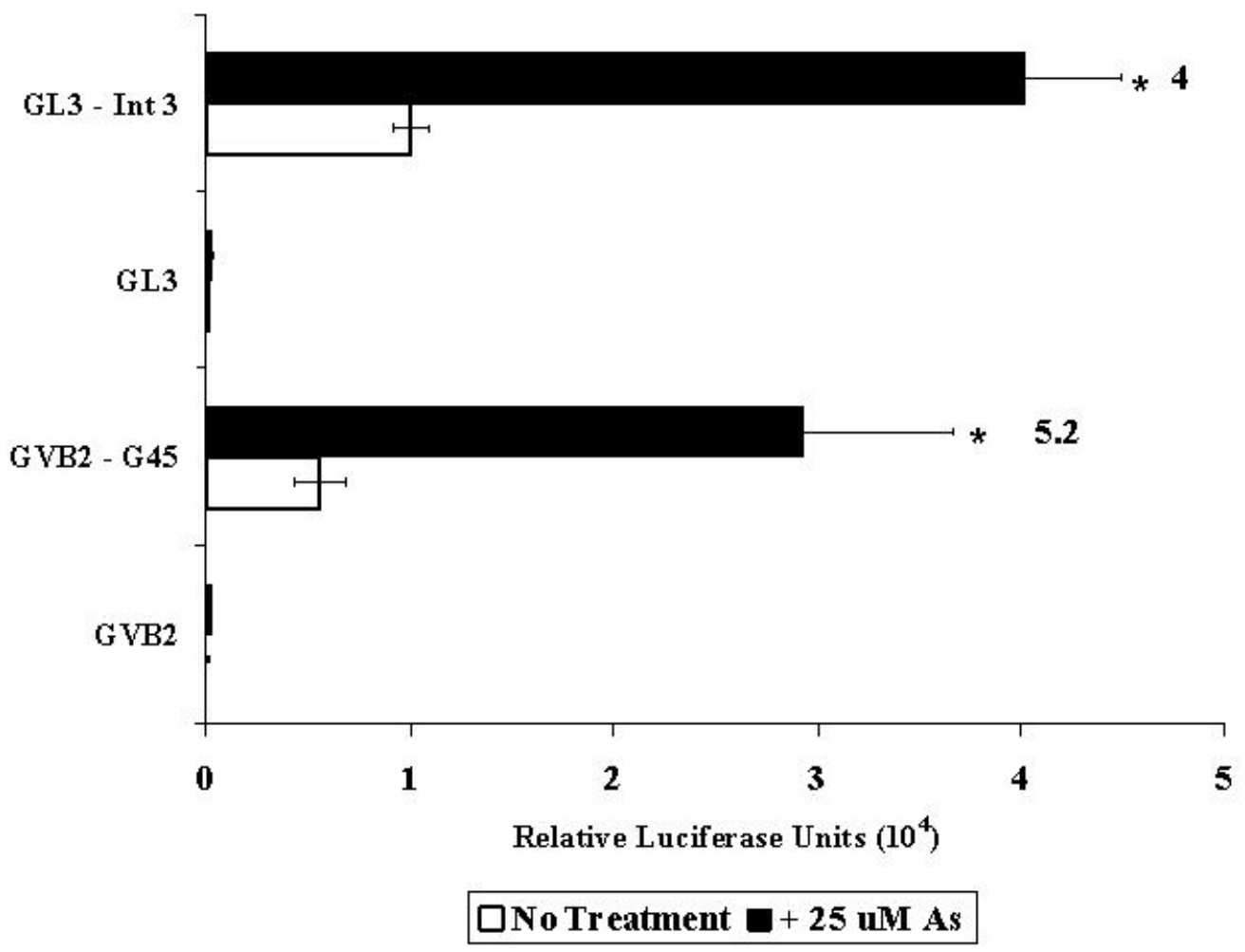


Fig. 6. Overexpression of GPX1 reduces GADD45 $\alpha$ promoter activation, but not intron 3 activation. G45 and Int3 luciferase constructs were transiently co-transfected with either an empty vector or the vector overexpressing the GPx1 protein and exposed to $25 \mu \mathrm{M}$ As(III) or left untreated. GPx1 overexpression decreased the G45 promoter luciferase activity by $50 \%$, but seemed to have no effect on Int3 activity.

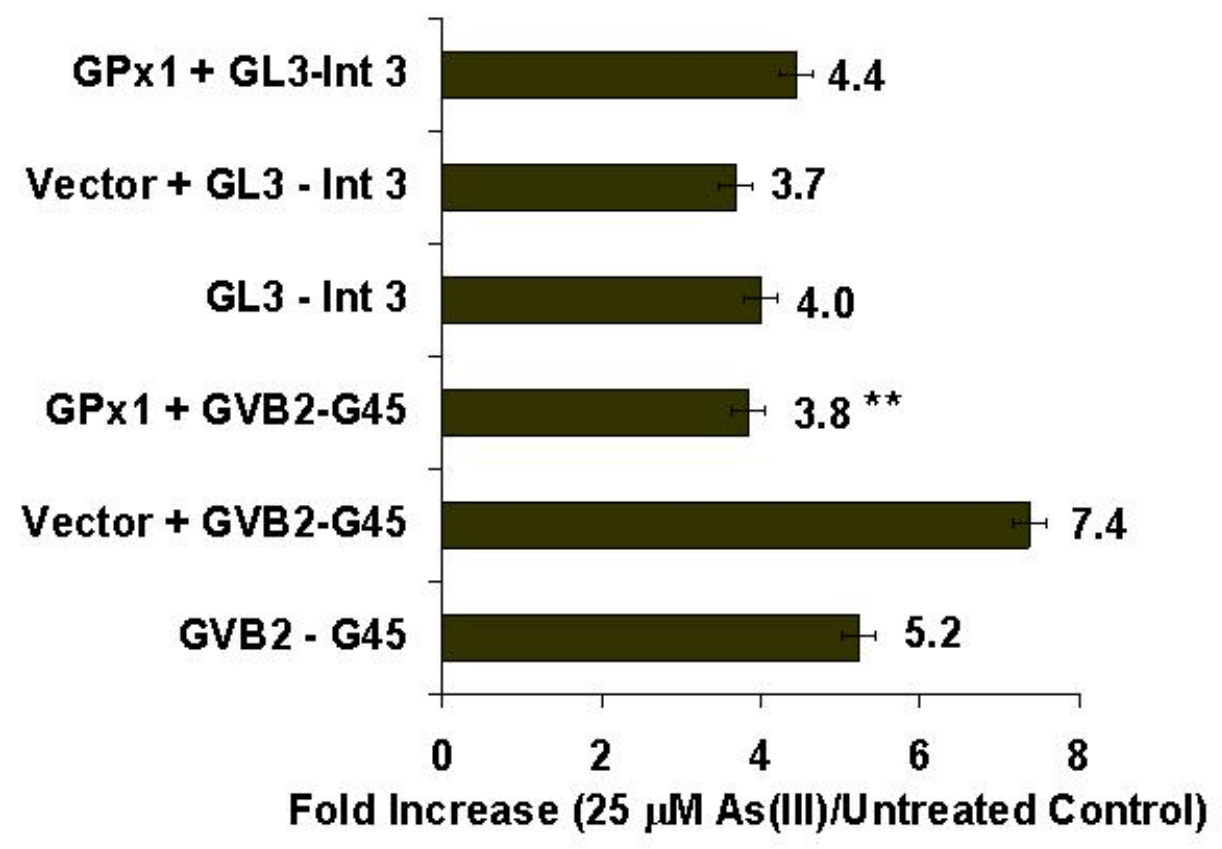


Fig. 7A. Schematic diagram of GADD45 $\alpha$ promoter-luciferase deletion constructs.

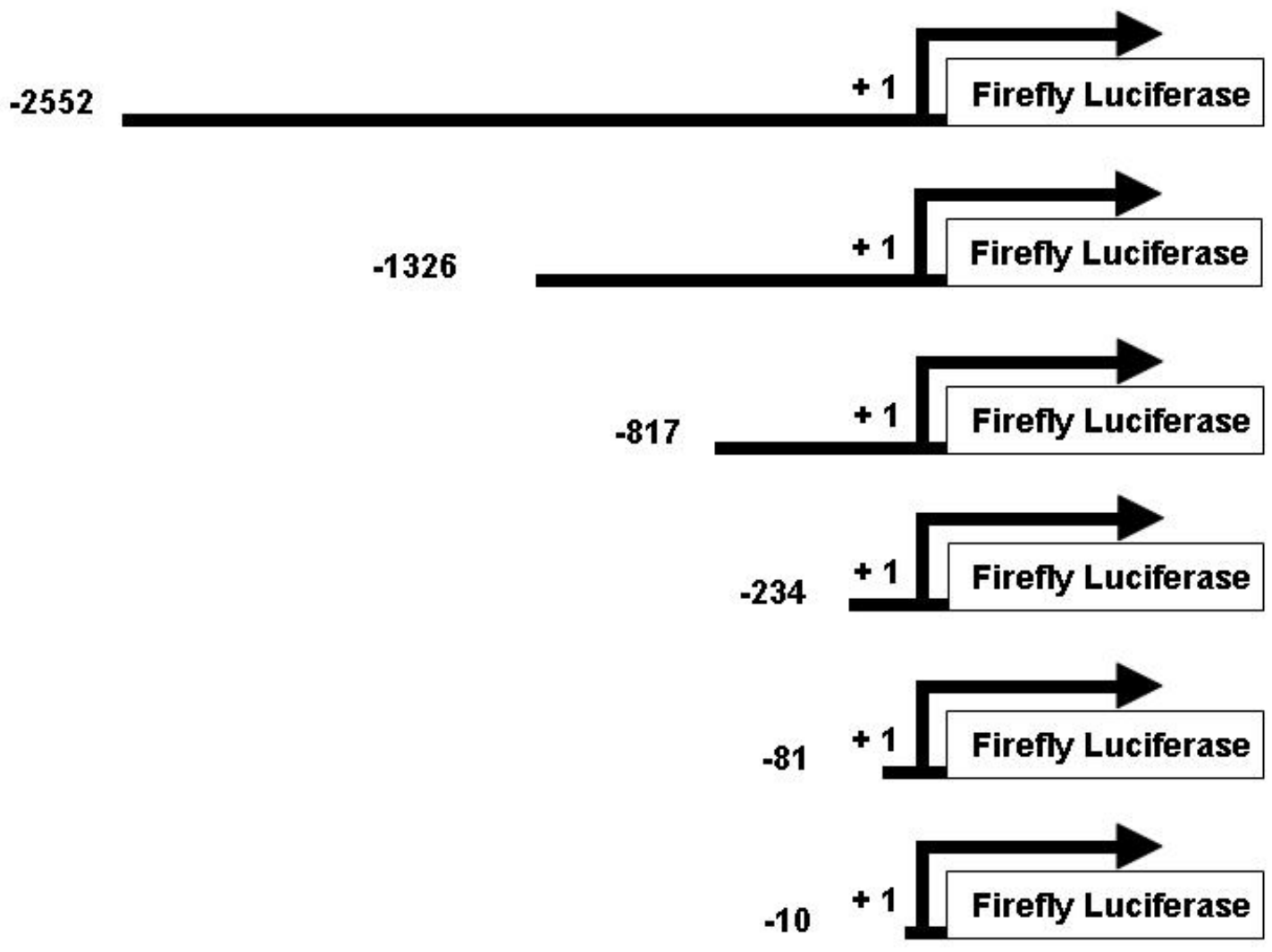


Fig. 7B. GADD45 $\alpha$ promoter activation occurs between the -234 and -81 region. The effects of $\mathrm{As}(\mathrm{III})$ on the activation of GADD $45 \alpha$ promoter luciferase deletion constructs were examined after a 12 hour treatment period with $25 \mu \mathrm{M} \mathrm{As}(\mathrm{III})$. The full length (2552), $-1326,-817$, and -234 constructs all retained an induction of approximately 5-6 fold when exposed to arsenic, whereas the -81 construct showed a loss of activation by As(III).

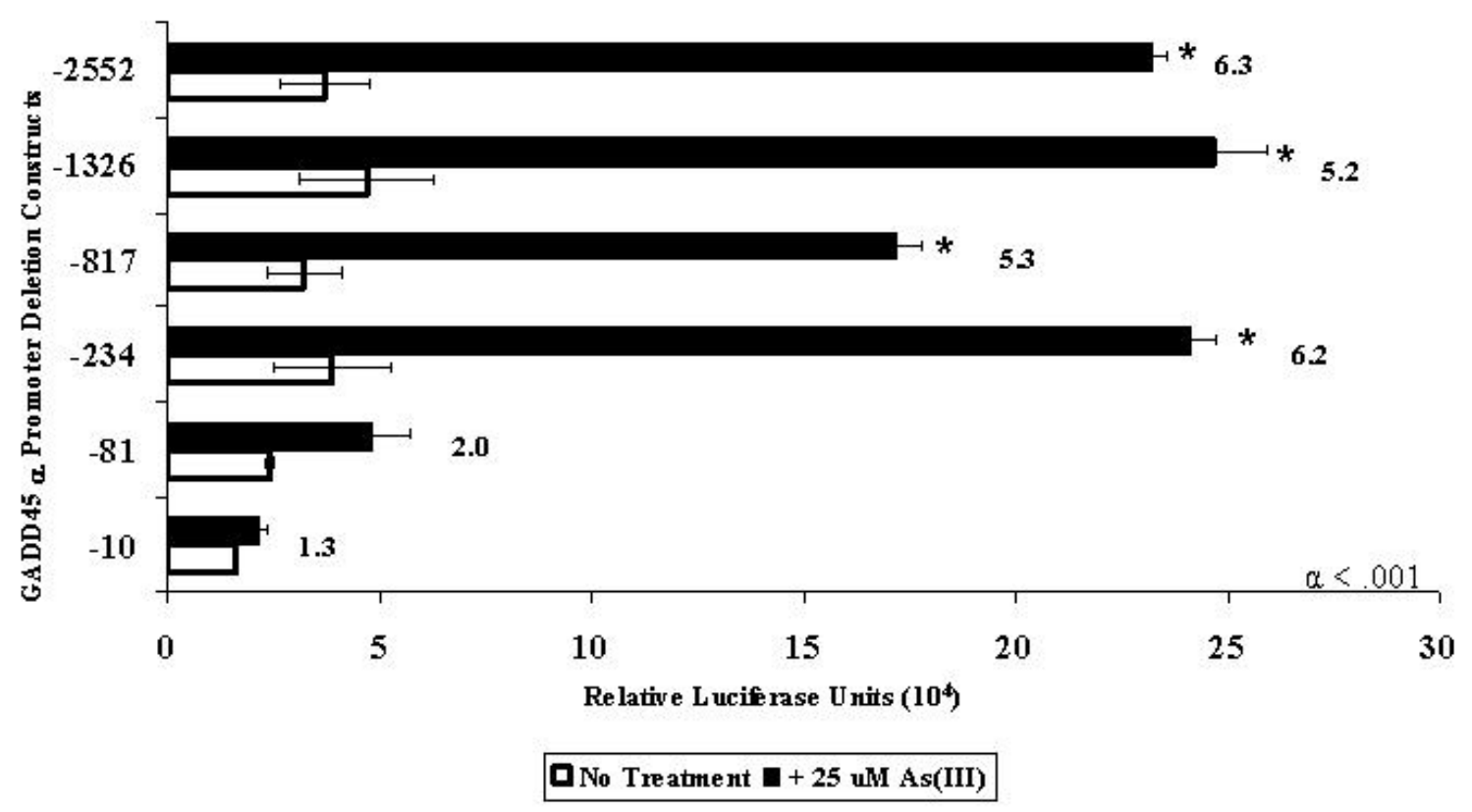


Fig. 7C. Activation of the full length, $-1326,-817$, and -234 constructs was reduced by $50 \%$ in GPx1-overexpressing cell lysates.

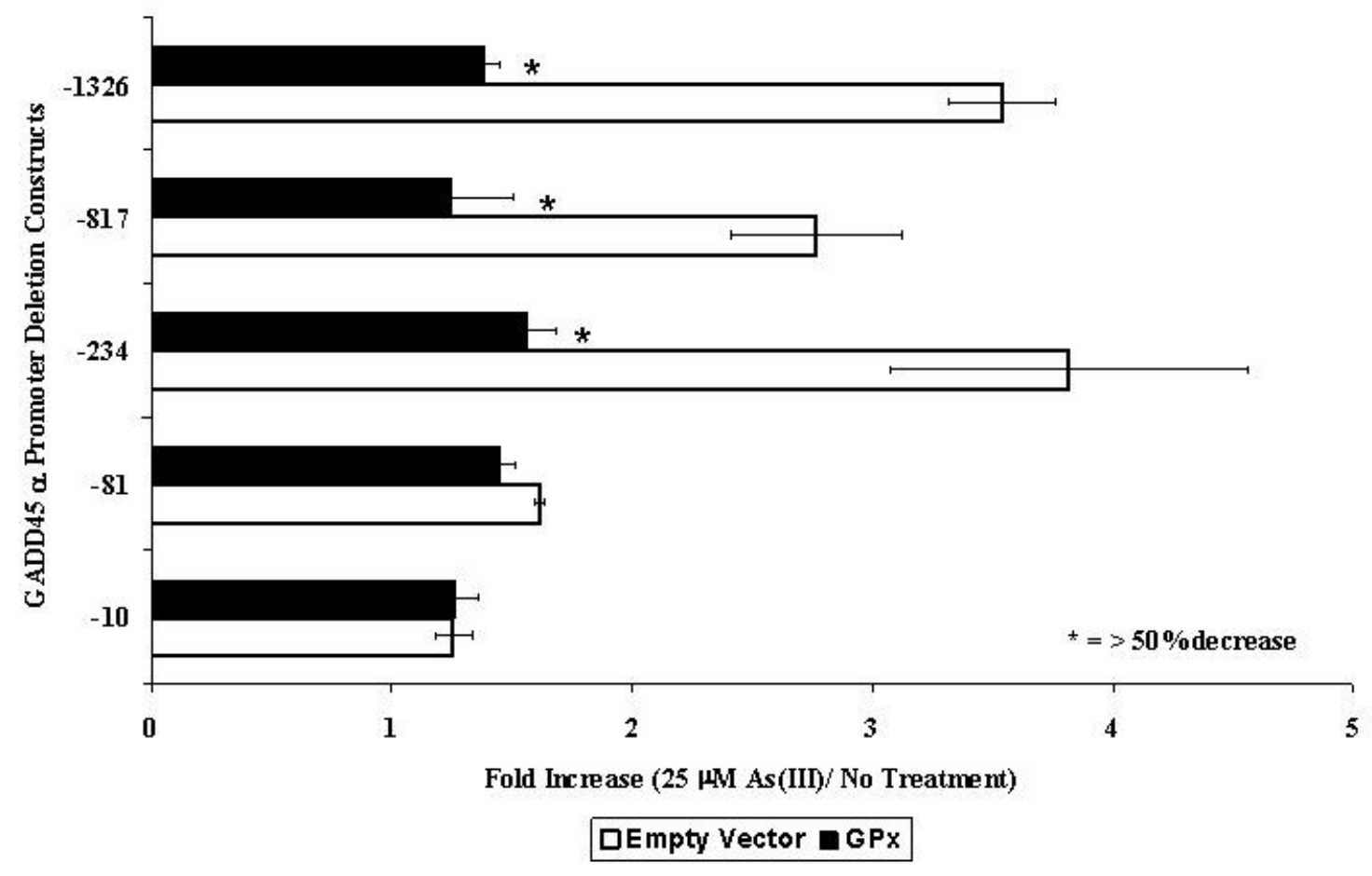


Fig. 8. Proposed ROS pathway involving arsenic. The proposed ROS pathway responsible for the activation of the gadd45a promoter region is a Fenton-like reaction in which molecular oxygen accepts an electron, forming $\mathrm{O}_{2}{ }^{\cdot-}$, and is then converted to $\mathrm{H}_{2} \mathrm{O}_{2}$ by superoxide dismutase. $\mathrm{H}_{2} \mathrm{O}_{2}$ is then further broken down into water and molecular oxygen, unless the presence of a transition metal, such as As(III), is present. Excess As(III) can then react with $\mathrm{H}_{2} \mathrm{O}_{2}$ and produce ${ }^{\circ} \mathrm{OH}$, which leads to DNA damage, lipid peroxidation, and the activation of cellular signaling pathways, including the induction of gadd45a transcription.

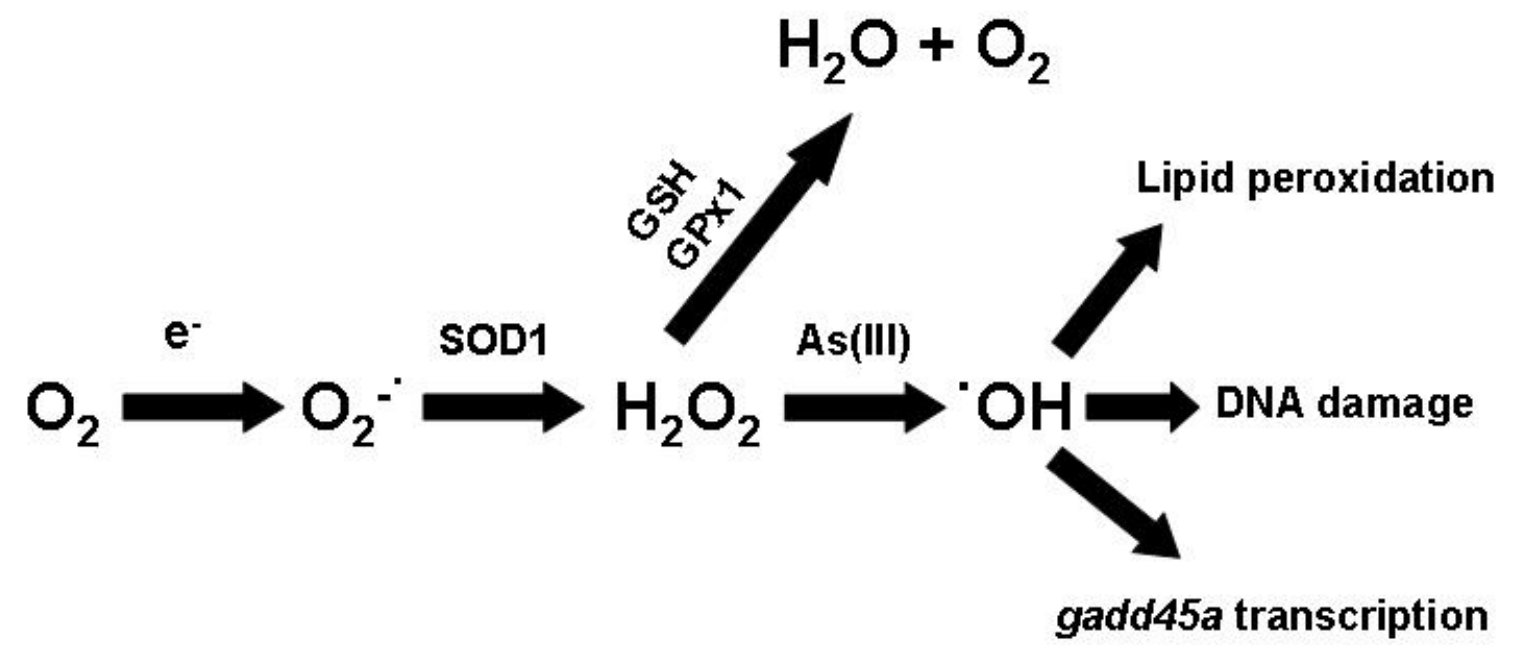




\section{References}

[1] Balasoiu, C. F.; Zagury, G. J.; Deschenes, L. Partitioning and speciation of chromium, copper, and arsenic in CCA-contaminated soils: influence of soil composition. Sci. Total Environ. 280:239-255; 2001.

[2] Stephanopoulos, D. E.; Willman, D. A.; Shevlin, D.; Pinter, L.; Gummin, D. D. Treatment and toxicokinetics of acute pediatric arsenic ingestion: danger of arsenic insecticides in children. Pediatr. Crit. Care Med. 3:74-80; 2002.

[3] Bailey, E. J.; Kennaway, E. L.; Urquhart, M. E. Arsenic content of cigarettes. Br. J. Cancer 11:49-53; 1957.

[4] Das, H. K.; Mitra, A. K.; Sengupta, P. K.; Hossain, A.; Islam, F.; Rabbani, G. H. Arsenic concentrations in rice, vegetables, and fish in Bangladesh: a preliminary study. Environ. Int. 30: 383-387; 2004.

[5] Haque, R.; Mazumder, D. N.; Samanata, S.; Ghosh, N.; Kalman, D.; Smith, M. M.; Mitra, S.; Santra, A.; Lahiri, S.; Das, S.; De, B. K.; Smith, A. H. Arsenic in drinking water and skin lesions: dose-response data from West Bengal, India. Epidemiology 14:174-182; 2003.

[6] Roychowdhury, T.; Uchino, T.; Tokunaga, H.; Ando, M. Arsenic and other heavy metals in soils from an arsenic-affected area of West Bengal, India. Chemosphere 49:605-618; 2002.

[7] Axelson, O.; Dahlgren, E.; Jansson, C. D.; Rehnlund, S. O. Arsenic exposure and mortality: a case-referent study from a Swedish copper smelter. Br. J. Ind. Med 35:8-15; 1978. 
[8] Smith, A. H.; Lingas, E. O.; Rahman, M. Contamination of drinking-water by arsenic in Bangladesh: a public health emergency. Bull. World Health Organ. 78:1093$1103 ; 2000$.

[9] Centeno, J. A.; Mullick, F. G.; Martinez, L.; Page, N. P.; Gibb, H.; Longfellow, D.; Thompson, C.; Ladich, E. R. Pathology related to chronic arsenic exposure. Environ. Health Perspect. 110 Supp 5: 883-886; 2002.

[10] Chen, C. J.; Chuang, Y. C.; Lin, T. M.; Wu, H. Y. Malignant neoplasms among residents of a blackfoot disease-endemic area in Taiwan: high-arsenic artesian well water and cancers. Cancer Res. 45:5895-5899; 1985.

[11] Chen, C. J.; Hsueh, Y. M.; Lai, M. S.; Shyu, M. P.; Chen, S. Y.; Wu, M. M.; Kuo, T. L.; Tai, T. Y. Increased prevalence of hypertension and long-term arsenic exposure. Hypertension 25:53-60; 1995.

[12] International Agency for Research on Cancer (IARC). Carcinogenesis of arsenic compounds. IARC Monograph on Evaluation of Carcinogenic Risks 23:37-141; 1980. [13] Leonard, A.; Lauwerys, R. R. Carcinogenicity, teratogenicity, and mutagenicity of arsenic. Mutat. Res. 75:49-62; 1980.

[14] Mabuchi, K.; Lilienfeld, A. M.; Snell, L. M. Lung cancer among pesticide workers exposed to inorganic arsenicals. Arch. Environ. Health 34:312-320; 1979.

[15] Pinto, S. S.; Nelson, K. W. Arsenic toxicology and industrial exposure. Annu. Rev. Pharmacol. Toxicol. 16:95-100; 1976.

[16] Pinto, S. S.; Enterline, P. E.; Henderson, V.; Varner, M. O. Mortality experience in relation to a measured arsenic trioxide exposure. Environ. Health Perspect. 19:127-130; 1977. 
[17] Steinmaus, C.; Moore, L.; Hopenhayn-Rich, C.; Biggs, M. L.; Smith, A. H. Arsenic in drinking water and bladder cancer. Cancer Invest. 18:174-182; 2000.

[18] World Health Organization (WHO). Arsenic in Drinking Water. Fact Sheet No. 210 Geneva: WHO Press; 2001.

[19] National Research Council (NRC). Arsenic in Drinking Water. Washington, D.C.: National Academy Press; 1999.

[20] Klaassen, C. D.; Amdur, M. O.; Doull, J. Cassarett and Doull's Toxicology: The Basic Sciences of Poisons. New York: McGraw-Hill; 1996.

[21] Bagla, P.; Kaiser, J. India's spreading health crisis draws global arsenic experts. Science 274: 174-175; 1996.

[22] Lewis, D. R.; Southwick, J. W.; Ouellet-Hellstrom, R.; Rench, J.; Calderon, R. L. Drinking water arsenic in Utah: A cohort mortality study. Environ. Health Perspect. 107: 359-365; 1999.

[23] Nordstrom, D. K. Public health. Worldwide occurrences of arsenic in ground water. Science 296: 2143-2145; 2002.

[24] Natural Resources Defense Council (NRDC). Arsenic and old laws: a scientific and public health analysis of arsenic occurrence in drinking water, its health effects, and EPA's outdated arsenic tap water standard. http://www.nrdc.org/water/drinking/arsenic/chap1.asp

[25] Rossman, T. G.; Stone, D.; Molina, M.; Troll, W. Absence of arsenite mutagenicity in E. coli and Chinese hamster cells. Environ. Mutagen. 2: 371-379; 1980.

[26] Germolec, D. R.; Spalding, J.; Boorman, G. A.; Wilmer, J. L.; Yoshida, T.; Simeonova, P. P.; Bruccoleri, A.; Kayama, F.; Gaido, K.; Tennant, R.; Burleson, F.; 
Dong, W.; Lang, R. W.; Luster, M. I. Arsenic can mediate skin neoplasia by chronic stimulation of keratinocyte-derived growth factors. Mutat. Res. 386: 209-218; 1997. [27] Germolec, D. R.; Spalding, J.; Yu, H.S.; Chen, G. S.; Simeonova, P. P.; Humble, M. C.; Bruccoleri, A.; Boorman, G. A.; Foley, J. F.; Yoshida, T.; Luster, M. I. Arsenic enhancement of skin neoplasia by chronic stimulation of growth factors. Am. J. Pathol. 153: $1775-1785 ; 1998$.

[28] Kachinskas, D. J.; Philips, M. A.; Qin, Q.; Stokes, J. D.; Rice, R. H. Arsenate perturbation of human keratinocyte differentiation.. Cell Growth Diff. 5: 1235-1241; 1994.

[29] Huang, C.; Ma, W. Y.; Li, J.; Goranson, A.; Dong, Z. Requirement of Erk, but not JNK, for arsenite-induced cell transformation. J. Biol. Chem. 274: 14595-14601; 1999. [30] Chen, F.; Zhang, Z.; Leonard, S. S.; Shi, X. Contrasting roles of NF-kappaB and JNK in arsenite-induced p53-independent expression of GADD45alpha. Oncogene 20: $3585-3589 ; 2001$.

[31] Wijeweera, J. B.; Gandolfi, A. J.; Parrish, A.; Lantz, R. C. Sodium arsenite enhances AP-1 and NFkappaB DNA binding and induces stress protein expression in precision-cut rat lung slices. Toxicol. Sci. 61: 283-294; 2001.

[32] Chen, F.; Lu, Y.; Zhang, Z.; Vallyathan, V.; Ding, M.; Castranova, V.; Shi, X. Opposite effect of NF-kappaB and c-Jun N-terminal kinase on p53-independent GADD45 induction by arsenite. J. Biol. Chem. 276: 11414-11419; 2001.

[33] Yih, L.H., Hsueh, S.W., Luu, W.S., Chiu, T.H., Lee, T.C. Arsenite induces prominent mitotic arrest via inhibition of G2 checkpoint activation in CGL-2 cells. Carcinogenesis 26: 53-63; 2005. 
[34] Chen, F., Zhang, Z., Bower, J., Lu, Y., Leonard, S.S., Ding, M., Castranova, V., Piwinica-Worms, H., Shi, X. Arsenite-induced Cdc25C degradation is through the KENbox and ubiquitin-proteosome pathway. Proc. Natl. Acad. Sci. U.S.A. 99: 1990-1995; 2002.

[35] Park, W.H., Seol, J.G., Kim, E.S., Hyun, J.M., Jung, C.W., Lee, C.C., Kim, B.K., Lee, Y.Y. Arsenic trioxide-mediated growth inhibition in MC/CAR myeloma cells via cell cycle arrest in association with induction of cyclin-dependent kinase inhibitor, p21, and apoptosis. Cancer Res. 60: 3065-3071; 2000.

[36] Seol, J.G., Park, W.H., Kim, E.S., Jung, C.W., Hyun, J.M., Kim, B.K., Lee, Y.Y. Effect of arsenic trioxide on cell cycle arrest in head and neck cancer cell line PCI-1. Biochm. Biophys. Res. Commun. 265; 400-404.

[37] Fornace, A. J. Jr.; Nebert, D. W.; Hollander, M. C.; Luethy, J. D.; Papathanasiou, M.; Fargnoli, J.; Holbrook, N. J. Mammalian genes coordinately regulated by growth arrest signals and DNA-damaging agents. Mol. Cell. Biol. 9: 4196-4203; 1989.

[38] Yih, L. H.; Peck, K.; Lee, T. C. Changes in gene expression profiles of human fibroblasts in response to sodium arsenite treatment. Carcinogenesis 23: 867-876; 2002. [39] Andrew, A. S.; Warren, A. J.; Barchowsky, A.; Temple, K. A.; Klei, L.; Soucy, N. V.; O’Hara, K. A.; Hamilton, J. W. Genomic and proteomic profiling of responses to toxic metals in human lung cells. Environ. Health Perspect. 111: 825-835; 2003. [40] Zhan, Q.; Antinore, M. J.; Wang, X. W.; Carrier, F.; Smith, M. L.; Harris, C. C.; Fornace, A. J. Jr. Association with Cdc2 and inhibition of Cdc2/Cyclin B1 kinase activity by the p53-regulated protein Gadd45. Oncogene 18: 2892-2900; 1999. 
[41] Wang, X. W.; Zhan, Q.; Coursen, J. D.; Khan, M. A.; Kontny, H. U.; Yu, L.;

Hollander, M. C.; O’Conner, P. M.; Fornace, A. J. Jr.; Harris, C. C. GADD45 induction of a G2/M cell cycle checkpoint. Proc. Natl. Acad. Sci. U. S. A. 96: 3706-3711; 1999. [42] Mak, S. K.; Kultz, D. Gadd45 proteins induce G2/M arrest and modulate apoptosis in kidney cells exposed to hyperosmotic stress. J. Biol. Chem. 279: 39075-39084; 2004. [43] Carrier, F.; Georgel, P. T.; Pourquier, P.; Blake, M.; Kontny, H. U.; Antinore, M. J.; Gariboldi, M.; Myers, T. G.; Weinstein, J. N.; Pommier, Y.; Fornace, A. J. Jr. Gadd45, a p53-responsive stress protein, modifies DNA accessibility on damaged chromatin. Mol. Cell. Biol. 19: 1673-1685; 1999.

[44] Kastan, M. B.; Zhan, Q.; el-Deiry, W. S.; Carrier, F.; Jacks, T.; Walsh, W. V.;

Plunkett, B. S.; Vogelstein, B.; Fornace, A. J. Jr. A mammalian cell cycle checkpoint pathway utilizing p53 and GADD45 is defective in ataxia-telangiectasia. Cell 71: 587$597 ; 1992$.

[45] Graunke, D. M.; Fornace, A. J. Jr.; Pieper, R. O. Presetting of chromatin structure and transcription factor binding poise the human GADD45 gene for rapid transcriptional up-regulation. Nucleic Acids Res. 27: 3881-3890; 1999.

[46] Zhan, Q.; Chen, I. T.; Antinore, M. J.; Fornace, A. J. Jr. Tumor suppressor p53 can participate in transcriptional induction of the GADD45 promoter in the absence of direct DNA binding. Mol. Cell. Biol. 18: 2768-2778; 1998.

[47] Takahashi, S.; Satio, S.; Ohtani, N.; Sakai, T. Involvement of the Oct-1 regulatory element of the gadd45 promoter in the p53-independent response to ultraviolet irradiation. Cancer Res. 61: 1187-1195; 2001. 
[48] Jin, S.; Fan, F.; Fan, W.; Zhao, H.; Tong, T.; Blanck, P.; Alomo, I.; Rajasekaran, B.;

Zhan, Q. Transcription factors Oct-1 and NF-YA regulate the $\mathrm{p} 53$-independent induction of the GADD45 following DNA damage. Oncogene 20: 2683-2690; 2001.

[49] Zhao, H.; Jin, S.; Fan, F.; Fan, W.; Tong, T.; Zhan, Q. Activation of the transcription factor Oct-1 in response to DNA damage. Cancer Res 60: 6276-6280; 2000.

[50] Daino, K.; Ichimura, S.; Nenoi, M. Comprehensive search for x-ray-responsive elements and binding factors in the regulatory region of the GADD45a gene. J. Radiat. Res. (Tokyo). 44: 311-318; 2003.

[51] Tran, H.; Brunet, A.; Grenier, J. M.; Datta, S. R.; Fornace, A. J. Jr.; DiStefano, P. S.; Chiang, L. W.; Greenberg, M. E. DNA repair pathway stimulated by the forkhead transcription factor FOXO3a through the GADD45 protein. Science 296: 530-534; 2002.

[52] Li, S.; Yan, T.; Yang, J. Q.; Oberley, T. D.; Oberley, L. W. The role of cellular glutathione peroxidase redox regulation in the suppression of tumor cell growth by manganese superoxide dismutase. Cancer Res. 60: 3927-3939; 2000.

[53] Zhang, Y.; Zhao, W.; Zhang, H. J.; Domann, F. E.; Oberley, L. W. Overexpression of copper zinc superoxide dismutase suppresses human glioma cell growth. Cancer Res. 62: 1205-1212; 2002.

[54] Bruemmer, D., Yin, F., Liu, J., Berger, J.P., Sakai, T., Blaschke, F., Fleck, E., Van Herle, A.J., Forman, B.M., Law, R.E. Regulation of the growth arrest and DNA damageinducible gene 45 (GADD45) by peroxisome proliferators-activated receptor gamma in vascular smooth muscle cells. Circ. Res. 93: e38-47; 2003. 
[55] Zhan, Q., Chen, I.T., Antinore, M.J., Fornace, A.J. Jr. Tumor suppressor p53 can participate in transcriptional induction of the GADD45 promoter in the absence of direct DNA binding. Mol. Cell. Biol. 18; 2768-2778; 1998.

[56] Hei, T. K.; Liu, S. X.; Waldren, C. Mutagenicity of arsenic in mammalian cells: role of reactive oxygen species. Proc. Natl. Acad. Sci. U. S. A. 95: 8103-8107; 1998. [57] Schug, J.; Overton, G. C. TESS: Transcription Element Search Software on the WWW'. Technical Report CBIL-TR-1997-1001-v0.0. Computational Biology and Informatics Laboratory, School of Medicine, University of Pennsylvania; 1997. http://www.cbil.upenn.edu/tess

[58] Halliwell, B.; Gutteridge, J. M. C. Free Radicals in Biology and Medicine. New York: Oxford University Press, Inc.; 1999.

[59] Nakamura, J., La, D.K., Swenberg, J.A. 5'-nicked apurinic/apyrimidinic sites are resistant to $\beta$-elimination by $\beta$-polymerase and are persistent in human cultured cells after oxidative stress. J. Biol. Chem. 275: 5323-5328; 2000.

[60] Reddel, R.R., Ke, Y., Gerwin, B.I., McMenamin, M.G., Lechner, J.F., Su, R.T., Brash, D.E., Park, J.B., Rhim, J.S., Harris, C.C. Transformation of human bronchial epithelial cells by infection with SV40 or adenovirus-12 SV40 hybrid virus, or transfection via strontium phosphate coprecipitation with a plasmid containing SV40 early region genes. Cancer Res. 48: 1904-1909; 1988.

[61] Cavigelli, M.; Li, W. W.; Lin, A.; Su, B.; Yoshioka, K.; Karin, M. The tumor promoter arsenite stimulates AP-1 activity by inhibiting a JNK phosphatase. EMBO J. 15: 6269-6279; 1996.

[62] Simeonova, P. P.; Wang, S.; Toriuma, W.; Kommineni, V.; Matheson, J.; Unimye, N.; Kayama, F.; Harki, D.; Ding, M.; Vallyathan, V.; Luster, M. I. Arsenic mediates cell 
proliferation and gene expression in the bladder epithelium: association with activating protein-1 transactivation. Cancer Res. 60: 3445-3453; 2000.

[63] Wood, M. J.; Storz, G.; Tjandra, N. Structural basis for redox regulation of Yap1 transcription factor localization. Nature 430: 917-921 ; 2004.

[64] Guyton, K. Z.; Xu, Q.; Holbrook, N. J. Induction of the mammalian stress response gene GADD153 by oxidative stress: role of AP-1 element. Biochem. J. 314: 547-554; 1996.

[65] Thyss, R., Virolle, V., Imbert, V., Peyron, J.F., Aberdam, D., Virolle, T. NFผB/Egr-1/Gadd45 are sequentially activated upon UVB irradiation to mediate epidermal cell death. EMBO J. 24: 128-137; 2005. 


\section{OVERALL CONCLUSIONS}

1. Gene-environment interactions are an integral part of environmental-induced carcinogenesis. The elucidation of the human genome sequence and new techniques that have emerged will play a major role in understanding the molecular mechanisms underlying the carcinogenic action of environmental contaminants.

2. Metal exposure is a major contributor to environmental induced carcinogenesis. Each metal produces its own effects, and these effects are different for each cell type. Identification of each individual mechanism of metal-induced carcinogenesis is necessary in order to obtain effective treatments.

3. Arsenite produces hydroxyl radical in the BEAS-2B cell line.

4. Arsenite induces GADD45 $\alpha$ in a dose- and time-dependent manner.

5. Arsenite can eleveate hydrogen peroxide and/or hydroxyl radical production and subsequently GADD $45 \alpha$ protein levels in the BEAS-2B cell line.

6. Arsenite induces hydrogen peroxide-mediated GADD45 $\alpha$ transcription.

7. A 153 base pair region of the GADD45 promoter is regulated by As(III)induced hydrogen peroxide formation.

8. Arsenite induces GADD45 $\alpha$ expression in a p53-independent manner in the BEAS-2B cell line.

9. The transcriptional induction of the gadd45a gene by arsenite seems to occur through a Fenton-like reaction mechanism. 


\title{
Jacquelyn Bower
}

Home Address

742 Ridgeway Avenue

Morgantown, WV 26505

(304) 685-9514
Business Address

1095 Willowdale Rd, MS2015

Morgantown, WV 26505

(304) 285-6372

Education West Virginia University, Morgantown, WV

Department of Basic Pharmaceutical Sciences

$\mathrm{PhD}$ Candidate

University of Notre Dame, Notre Dame, IN

Bachelor of Science, May 2001

Major: Biological Sciences

\author{
Honors Sigma Xi Graduate Research Competition Winner (2005) \\ And Awards Basic Pharmaceutical Sciences Departmental Teaching Award (2005) \\ West Virginia University Van Liere Convocation Research Award (2004) \\ Basic Pharmaceutical Sciences Departmental Graduate Research Award (2003) \\ Oak Ridge Institute for Science \& Education Fellowship (2002) \\ Centers for Disease Control and Prevention Regular Fellowship (2001 - present) \\ University of Notre Dame Dean's Honor List (2001) \\ National Science Foundation Fellowship (2000) \\ University of Notre Dame Scholar (1997) \\ Robert C. Byrd Honors Scholarship (1997)
}

Presentations Invited Speaker - Chinese Academy of Sciences, Institute for Nutritional Sciences, 2005, Shanghai, China A Graduate Education at West Virginia University

Invited Speaker $-3^{\text {rd }}$ International Conference on the Molecular Mechanisms of Metal Toxicity and Carcinogenesis, 2004, Morgantown, WV As(III)-

Induction of the Growth Arrest and DNA Damage-inducible protein $45 \alpha$

Invited Speaker - West Virginia University Van Liere Convocation, 2004, Morgantown, WV The Role of GADD $45 \alpha$ in G2/M Phase Arrest

Graduate Research Association of Students in Pharmacy, 2004, Atlanta, GA The Role of GADD45 $\alpha$ in G2/M Phase Arrest

Allegheny Erie Society of Toxicology Spring Meeting, 2003, Pittsburgh, PA GADD45a is an Oxidative Stress Response Protein

Experimental Biology, 2003, San Diego, CA GADD45a is an Oxidative Stress Response Protein

Professional Activities
Invited Reviewer for Neurotoxicology and Teratology (2004)

American Association for the Advancement of Science (AAAS) - Member 2004-present

Association for Women in Science - West Virginia University Chapter (AWIS) Treasurer 2004 - 2005

American Physiological Society (APS) - Member 2003-present

Served as an experimental consultant for researchers at the Chinese Academy of Sciences Institute for Nutritional Sciences, West Virginia University, and the National Institute for Occupational Safety and Health

Student Representative - Graduate Research Advisory Council (2003 - 2004) 
Research Experience

Teaching Experience
CENTERS FOR DISEASE CONTROL AND PREVENTION-NIOSH, Morgantown, WV PhD Candidate, Xianglin Shi, PhD, September 2001-Present

- Currently conducting independent research involving reactive oxygen species and the effects of arsenic on the induction of the GADD45 $\alpha$ pathway and its role in cell cycle arrest.

THE JACKSON LABORATORY, Bar Harbor, ME Participant, November 7-13, 2003

- Participated in the "Short Course on Gene Microarray Development and Analysis: Approaches to Heart, Lung, Blood, and Sleep Disorders."

- $\quad$ Designed, prepared, and analyzed microarray experimental data.

CENTERS FOR DISEASE CONTROL AND PREVENTION-NIOSH, Morgantown, WV

Biological Research Technician, Xianglin Shi, PhD, May 2001 - September 2001

- Conducted independent research regarding the regulatory role of nuclear transcription factor NF- $\mathrm{KB}$ and the $\mathrm{G} 2 / \mathrm{M}$ phase cell-cycle checkpoint protein, GADD $45 \alpha$.

UNIVERSITY OF NOTRE DAME, Notre Dame, IN

Lab Assistant, Jeffrey Schorey, PhD, October 1998 - May 2001

- Conducted undergraduate research in microbiology, immunology, and molecular biology including isolation and purification of a complement activating mycobacterial surface glycolipid.

- Cloned retroviral constructs for subsequent transduction of primary murine bone marrow macrophages.

UNIVERSITY OF NOTRE DAME, Notre Dame, IN NSF Fellowship, Crislyn D'Souza-Schorey, PhD, Summer 2000

- Conducted undergraduate research in cell biology, including the effects of ARF6 on mycobacterial pathogenesis by retroviral expression of ARF6 in primary murine bone marrow macrophages.

WASHINGTON UNIVERSITY, St. Louis, MO

Lab Assistant, Frederik Lindberg, MD/PhD, Summer 1999

- Conducted undergraduate research in immunology, including production of antigens to make monoclonal antibodies to hSIRP $\alpha 1$, an NK surface receptor molecule responsible for recognition of CD47 on red blood cells.

KAPLAN TEST PREP, INC., Pittsburgh, PA

Teacher, Steven Danyluk, Center Manager, March 2002 - November 2005

- Presented lectures to prepare Kaplan students for standardized testing including the MCAT, GRE, DAT, SAT, and ACT.

- $\quad$ Privately tutored students for the MCAT, GRE, and SAT.

WEST VIRGINIA UNIVERSITY, Morgantown, WV

Teaching Assistant Coordinator, Joseph Ma, PhD, September 2004 - December 2004

Teaching Assistant, Joseph Ma, PhD, September 2003-May 2004

- $\quad$ Organized and managed a group of ten teaching assistants

- Delegated general laboratory duties to ensure that laboratory exercises were executed in an efficient manner.

- $\quad$ Provided laboratory assistance to first year pharmacy students learning basic research techniques.

- $\quad$ Prepared lectures to guide students in the concepts behind laboratory exercises. 
UNIVERSITY OF NOTRE DAME, Notre Dame, IN

Teaching Assistant, Michelle Whaley, PhD, January 2001-May 2001

- Guided and assisted second year students conducting independent research projects.

Lab Skills Biological Research Techniques:

- Molecular: western blotting, protein purification, standard cloning, 2DE, quantitative RT-PCR, immunoprecipitation, flow cytometry, ELISA, luciferase reporter gene assays, and site-directed mutagenesis.

- General \& Technical: Tissue culture, mouse manipulations, HPLC, TLC, oxygen consumption, ESR, and confocal microscopy.

Publications Bower, J.J., Leonard, S.S., Chen, F., and Shi, X. As(III) transcriptionally activates the gadd45a gene via the formation of $\mathrm{H}_{2} \mathrm{O}_{2}$. (submitted)

Bower, J.J., Leonard, S.S., and Shi, X. (2005) Conference overview: Molecular mechanisms of metal toxicity and carcinogenesis. Mol Cell Biochem 279:3-15

Bower, J.J. and Shi, X. (2005) Environmental health research in the post-genomic sequencing era: New fields, new challenges, and new opportunities. J Toxicol Environ Health B Crit Rev 8:71-94

Leonard, S.S., Bower, J.J., and Shi, X. (2004) Conference overview: Metal-induced toxicity, carcinogenesis, mechanisms and cellular responses. Mol Cell Biochem 255:3-10

Chen, F., Zhang, Z., Bower, J., Lu, Y., Leonard, S.S., Ding, M., Castranova, V., Piwnica-Worms, H., and Shi, X. (2002) Arsenite-Induced Cdc25C Degradation is through the KEN-box and Ubiquitin-Proteasome Pathway. Proc Natl Acad Sci USA 99:1990-5

Chen, F., Bower, J., Leonard, S.S., Ding, M., Lu, Y., Rojanasakul, Y., Kung, H.H., Vallyathan, V., Castranova, V., and Shi, X. (2002) Protective Roles of NF-kappa B for Chromium(VI)-induced Cytotoxicity Is Revealed by Expression of Ikappa B Kinase-beta Mutant. J Biol Chem 277:33423349.

Chen, F., Bower, J., Demers, L.M., Shi, X. (2001) Upstream Signal Transduction of NF-kB Activation. Atlas Genet Cytogenet Oncol Haematol December.

URL : http://www.infobiogen.fr/services/chromcancer/Deep/NFKBID20033.html

Bohlson, S. S., Strasser, J.A., Bower, J.J., and Schorey, J.S. (2001) Role of Complement in Mycobacterium avium Pathogenesis: In Vivo and In Vitro Analyses of the Host Response to Infection in the Absence of Complement Component C3. Infect Immun 69:7729-7735. 